\title{
Genetics and biology of pancreatic ductal adenocarcinoma
}

\author{
Haoqiang Ying, ${ }_{1}^{1}$ Prasenjit Dey, ${ }^{2}$ Wantong Yao, ${ }^{3}$ Alec C. Kimmelman, ${ }^{4}$ Giulio F. Draetta,,${ }^{1,3,5}$ \\ Anirban Maitra, ${ }^{6,7}$ and Ronald A. DePinho ${ }^{2}$ \\ ${ }^{1}$ Department of Molecular and Cellular Oncology, ${ }^{2}$ Department of Cancer Biology, ${ }^{3}$ Department of Genomic Medicine, University \\ of Texas MD Anderson Cancer Center, Houston, Texas 77030, USA; ${ }^{4}$ Division of Genomic Stability and DNA Repair, Department \\ of Radiation Oncology, Dana-Farber Cancer Institute, Boston, Massachusetts 02115, USA; ${ }^{5}$ Institute for Applied Cancer Science, \\ ${ }^{6}$ Department of Pathology and Translational Molecular Pathology, ${ }^{7}$ Sheikh Ahmed Pancreatic Cancer Research Center, University \\ of Texas MD Anderson Cancer Center, Houston, Texas 77030, USA
}

With 5-year survival rates remaining constant at $6 \%$ and rising incidences associated with an epidemic in obesity and metabolic syndrome, pancreatic ductal adenocarcinoma (PDAC) is on track to become the second most common cause of cancer-related deaths by 2030 . The high mortality rate of PDAC stems primarily from the lack of early diagnosis and ineffective treatment for advanced tumors. During the past decade, the comprehensive atlas of genomic alterations, the prominence of specific pathways, the preclinical validation of such emerging targets, sophisticated preclinical model systems, and the molecular classification of PDAC into specific disease subtypes have all converged to illuminate drug discovery programs with clearer clinical path hypotheses. A deeper understanding of cancer cell biology, particularly altered cancer cell metabolism and impaired DNA repair processes, is providing novel therapeutic strategies that show strong preclinical activity. Elucidation of tumor biology principles, most notably a deeper understanding of the complexity of immune regulation in the tumor microenvironment, has provided an exciting framework to reawaken the immune system to attack PDAC cancer cells. While the long road of translation lies ahead, the path to meaningful clinical progress has never been clearer to improve PDAC patient survival.

Pancreatic ductal adenocarcinoma (PDAC) pathogenesis

On gross inspection, PDAC presents as a poorly demarcated, firm white-yellow mass, with the surrounding nonmalignant pancreas typically showing atrophy, fibrosis, and dilated ducts due to the obstructive effects of expanding carcinoma. Microscopically, these neoplasms vary from

[Keywords: KRAS; cancer metabolism; pancreatic cancer; tumor immune modulation]

Corresponding authors: rdepinho@mdanderson.org, hying@mdanderson. org
Artic

Article is online at http://www.genesdev.org/cgi/doi/10.1101/gad.275776. 115. well-differentiated gland-forming carcinomas to poorly differentiated "sarcomatoid" carcinomas diagnosed only upon immunolabeling due to predominant mesenchymal features (Hruban et al. 2007). PDAC evolves from well-defined precursor lesions that, in the context of their genetic features, define the genetic progression model of pancreatic carcinogenesis (Yachida et al. 2010). Early disease histology manifests as several distinct types of precursor lesions-the most common are microscopic pancreatic intraepithelial neoplasia (PanIN), followed by the macroscopic cysts; namely, the intraductal papillary mucinous neoplasm (IPMN) and mucinous cystic neoplasm (MCN) (Matthaei et al. 2011). Since most PDAC cases become clinically apparent at advanced stages, major opportunities to reduce mortality rest with diagnostics and treatments that would enable the reliable identification and elimination of high-risk precursor lesions. Thus, the identification of these precursor lesions has provided an essential framework to define the genomic features that drive progression to advanced disease and develop effective screening and targeted therapeutics for earlier stage disease (Eser et al. 2011).

The noninvasive PanIN lesions were formerly classified into three grades according to the extent of cytological and architectural atypia: PanIN1A (flat lesion) and PanIN1B (micropapillary type) show low-grade dysplasia; PanIN2 exhibits additional loss of polarity, nuclear crowding, cell enlargement, and hyperchromasia with frequent papillary formation; and PanIN3 is advanced lesions with severe nuclear atypia, luminal necrosis, and manifest epithelial cell budding into the ductal lumen (Kloppel 2000; Hruban et al. 2004; Sipos et al. 2009). Most recently, this three-tier classification has been supplanted by a twotier low-grade (PanIN-1 and PanIN-2) and high-grade (PanIN-3) classification, which recognizes that the

(C) 2016 Ying et al. This article is distributed exclusively by Cold Spring Harbor Laboratory Press for the first six months after the full-issue publication date (see http://genesdev.cshlp.org/site/misc/terms.xhtml). After six months, it is available under a Creative Commons License (Attribution-NonCommercial 4.0 International), as described at http:// creativecommons.org/licenses/by-nc/4.0/. 
greatest biological potential for progression lies in the latter lesions and that these should be the object for early detection efforts (Basturk et al. 2015). The evidence that PanIN lesions possess malignant potential stems from confluent observations of an increased prevalence of PanIN with age and increased cancer incidence, their physical proximity to invasive cancer in resected specimens, their pervasiveness in the pancreata of individuals with a strong family history of pancreatic cancer, and a full spectrum of PanINs observed prior to tumorigenesis in genetically engineered mouse models (GEMMs) of PDAC (Cubilla and Fitzgerald 1976; Andea et al. 2003; Hingorani et al. 2003; Brune et al. 2006). While low-grade lesions are frequently observed in normal adult pancreas or patients with chronic pancreatitis and are associated with a low risk of developing PDAC, high-grade PanIN3 lesions are almost exclusively found in patients with invasive PDAC (Sipos et al. 2009).

The targeting of oncogenic Kras expression to all pancreatic epithelial cells during development using Pdx1or Ptfla-driven Cre alleles results in widespread PanIN development in GEMMs (Aguirre et al. 2003; Hingorani et al. 2003). While precursor lesions consistently bear the characteristics of ductal epithelial cells in this classical model, numerous studies support the view that multiple differentiated pancreatic cell types can serve as the cell of origin for PDAC. Targeting oncogenic Kras expression to various pancreas cell types in GEMMs has demonstrated the malignant potential of duct cells, endocrine cells, and acinar cells (Habbe et al. 2008; Gidekel Friedlander et al. 2009; Bailey et al. 2015), the latter through a reprogramming process known as acinar-to-ductal metaplasia (ADM) (Hruban et al. 2006; Guerra et al. 2007; Kopp et al. 2012). However, there is prevailing uncertainty regarding whether this paradigm holds true in humans, and, although ADM lesions are seen in pancreata from PDAC patients, no conclusive genetic evidence to show progression from ADM to PanIN has ever been shown (Shi et al. 2009; Maitra and Leach 2012).

The commonly used oncogenic Kras-driven GEMMs engineered with loss of key tumor suppressors recapitulate well the classical spectrum of evolving PanINs and PDAC lesions. GEMMs of IPMN and, to a much lesser extent, MCN have also been generated using oncogenic Kras combined with either transforming growth factor a (Tgfa) overexpression, Smad4 deletion, Acvr1b loss, or Smarca4 deficiency (Bardeesy et al. 2006b; Siveke et al. 2007; von Figura et al. 2014; Qiu et al. 2016). Although most studies have reported the contribution of the acinar cells to PanINs and PDAC, the fact that oncogenic Kras and Tgfa lead to IPMN formation when driven by either the Pdx1 or Ptfla promoter, but not the Elal promoter, raises a question of whether acinar cells can readily give rise to IPMN as well (Siveke et al. 2007). The notion of distinct lesions driving the development of IPMN and MCN is reinforced by recent sequencing studies that have identified IPMN/ MCN-specific mutations in GNAS and RNF43 (Wu et al. 2011a,b; Dal Molin et al. 2013). While one recent study in an inducible GEMM has shown that Gnas mutation cooperates with oncogenic Kras to promote the formation of
IPMN (Taki et al. 2015), how these signature mutations function to drive the cystic phenotype during exocrine neoplasia remains an understudied area.

While PDAC likely develops from the spectrum of precursor lesions described above, it is not clear whether all cells in those precursor lesions have equivalent capacities for malignant transformation. The identification of such intralesional cells with malignant potential is essential to accurately and comprehensively define the genetics and biology of disease progression. Along these lines, recent studies have identified a tuft cell-like subpopulation in PanINs that is critical for the formation of precursor lesions (Bailey et al. 2014; Delgiorno et al. 2014). These cells, which express Dclk1 and acetylated tubulin, exhibit enhanced self-renewal capacity and are enriched in the cell population reported to bear PDAC cancer stem cell (CSC) markers, such as CD133 or CD24/CD44/ESA (Hermann et al. 2007; Li et al. 2007; Bailey et al. 2014). In addition, a distinct subpopulation of premalignant cells has been shown to undergo epithelial-mesenchymal transition (EMT) and disseminate from epithelial lesions into the circulation (Rhim et al. 2012). Notably, these disseminated EMT cells are also enriched with CSC features and are associated with PanIN2/3 but not PanIN1 lesions (Rhim et al. 2012; Qu et al. 2015). The routine detection and molecular profiling of these circulating tumor cells (CTCs) may thus provide a "liquid biopsy" strategy for early disease diagnosis and illuminate preventive and interceptive therapeutic strategies targeting disease progression and the metastatic process (Haber and Velculescu 2014). Thus, deep characterization of the genetic profile and surface markers of these CSCs in precursor lesions (Rhim et al. 2014b) as well as CTCs with EMT features are priority areas across the continuum of prevention, detection, and treatment.

\section{The PDAC genome}

Next-generation sequencing and computational biology have transformed our understanding of genetic alterations associated with the genesis and progression of PDAC, highlighting the disease's myriad mutations, gene expression changes, epigenetic alterations, chromosomal rearrangements, and copy number aberrations. Wholeexome sequencing studies (Jones et al. 2008; Biankin et al. 2012; Sausen et al. 2015; Waddell et al. 2015; Witkiewicz et al. 2015; Bailey et al. 2016) have reaffirmed the signature mutations of human pancreatic cancers, including near-ubiquitous oncogenic mutations of KRAS and the frequent inactivation of TP53, SMAD4, and CDKN2A tumor suppressors (Hezel et al. 2006; Maitra and Hruban 2008; Hidalgo 2010; Vincent et al. 2011; Ryan et al. 2014). These unbiased analyses also identified additional novel recurrent mutations in PDAC; however, the prevalence of individual mutations drops sharply to $\leq 10 \%$. On the other hand, it is notable that this large number of diverse gene mutations converge on a handful of pathways and processes, including NOTCH, Hedgehog $(\mathrm{Hh})$, $\beta$-catenin, axon guidance, chromatin remodeling, and 
DNA repair pathways, suggesting that the majority of these mutations may function through certain core processes, which may offer key nodal points for therapeutic intervention. As the roles of $\mathrm{NOTCH}, \mathrm{Hh}$, and Wntcatenin developmental pathways during PDAC development have been reviewed elsewhere (Morris et al. 2010; Rhim and Stanger 2010), below we summarize our current understanding of gene mutations in epigenetics/ chromatin remodeling and DNA repair pathways and the biological functions and clinical implications of these mutations.

\section{PDAC epigenetics}

Similar to other cancer types (Plass et al. 2013), one major class of frequently mutated genes in PDAC is involved in the regulation of the epigenome, including histone modification enzymes ( $24 \%$ of PDAC) and SWI/SNF-mediated chromatin remodeling complexes (14\% of PDAC) (Bailey et al. 2016). Among the mutated histone modification enzymes are the histone methyltransferases MLL, MLL2, and MLL3 and the histone demethylase KDM6A (Biankin et al. 2012; Sausen et al. 2015; Waddell et al. 2015; Witkiewicz et al. 2015). Interestingly, MLL2/3 and KDM6A are present in the same complex, driving transcriptional activation through the coordinated regulation of H3K4 methylation and H3K27 demethylation (Lee et al. 2007b). While the downstream targets of the MLL/ KDM6A machinery during PDAC development remain to be identified, tumors with MLL mutations tend to induce high expression of chromatin-regulating genes together with other genes involved in cell proliferation (Sausen et al. 2015), suggesting that a genetic defect of MLL complexes likely leads to global epigenetic alterations to support tumor development.

The other key PDAC epigenetic drivers are the SWI/ SNF complexes, which are multisubunit complexes mediating ATP-dependent chromatin remodeling involved in transcriptional regulation and DNA repair (Helming et al. 2014a). Genes encoding multiple components of the SWI/SNF complexes, including ARID1A, ARID1B, ARID2, PBRM1, SMARCA2, and SMARCA4, undergo nonsilent mutation or copy number alteration in human PDAC (Biankin et al. 2012; Shain et al. 2012; Sausen et al. 2015; Waddell et al. 2015; Witkiewicz et al. 2015). While the mutation rate for individual genes is low, the overall prevalence of genetic lesions in SWI/SNF complex components is $\sim 14 \%$ (Witkiewicz et al. 2015; Bailey et al. 2016), implicating the general importance of chromatin remodeling in PDAC pathogenesis. Indeed, functional genetic screens have identified the same epigenetic regulators. Specifically, ARID1A, SMARCA4, and PBRM1, together with other histone modification enzymes such as MLL3 and KDMA6, were identified as candidate genes from two independent in vivo transposon-based mutagenesis screens looking for functional genetic events involved in oncogenic KRAS-driven PDAC development (Mann et al. 2012; Perez-Mancera et al. 2012b).

While the roles for SWI/SNF complexes in PDAC remain largely unexplored, recent studies have provided im- portant insights into their tumor suppressor function. Specifically, reconstituted SMARCA4 expression in SMARCA4-deficient human PDAC cells suppresses cell growth (Shain et al. 2012), and a GEMM shows that cooperation with Smarca4 deletion and oncogenic Kras promotes IPMN development and PDAC progression with shortened overall survival compared with mice engineered with oncogenic Kras alone (von Figura et al. 2014). Interestingly, Smarca4 loss leads to dedifferentiation of pancreatic ductal cells and formation of IPMNlike precursor lesions (Roy et al. 2015). This observation, coupled with the multiple cells of origin for PanIN lesions (Gidekel Friedlander et al. 2009; Kopp et al. 2012) and the established critical role of epigenetic modifications during cellular development and lineage specification/Orkin and Hochedlinger 2011), prompts speculation that these chromatin modulators may lie at the nexus of cellular plasticity processes that provide a permissive developmental state for oncogenic KRAS-driven transformation across various cell types. Beyond cellular differentiation, SWI/ SNF and MLL may also impact other hallmarks of cancer such as cell cycle and apoptosis control via epigenetic regulation of the INK4A or PTEN loci, which are silenced in a significant fraction of human PDAC cases (Kia et al. 2008; Watanabe et al. 2011; Ying et al. 2011; Singh and Ellenrieder 2013). Therefore, the mutation or deletion of chromatin modulators may also participate in the epigenetic inactivation of key tumor suppressors to promote neoplastic proliferation.

While chromatin regulators are frequently mutated or deleted in PDAC, the occurrence of MLL2 and MLL3 mutation is associated with better patient outcomes (Sausen et al. 2015). That said, the biology of these chromatin regulators and their impact on cancer progression and/or suppression are not well understood and appear to be highly context-specific. For instance, while Smarca4 deficiency promotes oncogenic Kras-driven PDAC development in GEMMs, its reconstitution in SMARCA4-null tumors provokes an EMT phenotype with dramatically enhanced tumor growth, suggesting different functions in tumor genesis versus tumor maintenance (Roy et al. 2015). Thus, the optimal therapeutic prosecution of these chromatin modulator drivers will necessitate a thorough understanding of their context-dependent actions on both genetic and cell biological levels. Also, while chromatin regulators themselves do not constitute obvious therapeutic targets in specific contexts, their loss of function may confer specific vulnerabilities that can be therapeutically exploited. In this regard, mutations that lead to functional loss of some subunits may promote the addiction of tumor cells to the residual complexes to sustain oncogenic growth (Wang et al. 2009; Helming et al. 2014a). In support of this notion, tumors with ARID1A loss show enhanced sensitivity to ARID1B inhibition, and SMARCA4 deficiency induces vulnerability to SMARCA2 targeting (Helming et al. 2014b; Hoffman et al. 2014; Wilson et al. 2014). In addition to such genetically induced "synthetic lethality," mutations of these chromatin modulators also lead to dysfunction of their corresponding pathways, which can be further perturbed by targeted agents. For 
example, ARID1A is actively recruited to DNA breaks and is required for proper DNA damage response. Loss of ARID1A can lead to defective DNA damage repair (DDR) and sensitize cells to PARP inhibitors (Shen et al. 2015). Due to the high prevalence of mutations in the epigenetic modulators in PDAC, it is evident that a significant portion of patients will likely benefit from further exploration of vulnerabilities induced by these genetic events. Indeed, it is tempting to speculate that the improved survival of patients with loss of chromatin regulators that results in impaired DDR may be due to improved responses to chemotherapy and radiation therapy.

\section{DDR pathway}

Mutations in genes of the DDR pathway also appear to be a rite of passage for PDAC, with greater than one-third of cases harboring deleterious somatic mutations in a DNA damage response gene (Jones et al. 2008; Biankin et al. 2012; Sausen et al. 2015; Waddell et al. 2015; Witkiewicz et al. 2015). Germline mutations of some DDR genes, such as BRCA1, BRCA2, PALB2, ATM, MLH1, MSH2, and $M S H 6$, have been linked to an increased predisposition to PDAC (Goggins et al. 1996; Thompson et al. 2002; Jones et al. 2009; Roberts et al. 2012; Grant et al. 2015; Holter et al. 2015). Defects of DDR may function in disease pathogenesis via the accumulation of genetic alterations that activate oncogenes and eliminate tumor suppressors as well as promote genomic instability, enhancing biological plasticity and potential therapeutic resistance (Lord and Ashworth 2012). Correspondingly, PDACs harboring DDR mutations exhibit increased overall mutational burden and genomic instability (Waddell et al. 2015; Witkiewicz et al. 2015) and poorer prognosis (Witkiewicz et al. 2015). Interestingly, while mutations in key DDR genes such as BRCA1 and BRCA2 have been identified in many cancer types (Mersch et al. 2015), pancreatic cancer is the only known cancer type in addition to breast and ovarian cancer to exhibit a mutational pattern significantly enriched with signatures of BRCA pathway mutations, which is found in $~ 20 \%$ PDAC samples and is characterized by equal representation of each possible nucleotide substitution mutation accompanied by substantial numbers of larger deletions (up to 50 base pairs [bp]) and overlapping microhomology at breakpoint junctions (Alexandrov et al. 2013; Waddell et al. 2015). While the molecular basis for the emergence of the BRCA signature in PDAC is not known, these tumors are enriched with mutations of the DDR pathway such as BRCA1, BRCA2, and PALB2, which accounts for $18 \%$ of tumors (Waddell et al. 2015). Moreover, $\sim 14 \%$ of PDACs are characterized with the genome-unstable phenotype, which harbors a large number of structural variation events and is also enriched for tumors bearing BRCA signature or DDR pathway mutations. Overall, 24\% of PDACs exhibit one or another "DDR-defective criteria," with most exhibiting at least two of these features.

Defining the roles of a majority of these DDR pathway mutations in the maintenance of PDAC genome stabil- ity and tumor development is an area of active investigation. GEMMs of PDAC have provided new insights. BRCA1 and BRCA2, while sharing no structural homology, function via homologous recombination (HR) to maintain chromosomal integrity (Roy et al. 2012). BRCA1 can form distinct complexes that function in a number of biological processes, including cell cycle regulation and DNA repair among others. However, the critical role of its HR-directed DNA repair function in PDAC pathogenesis has been revealed through mutations of BRCA1's BRCT domain, which is central to its DNA repair function (Huen et al. 2010; Roy et al. 2012). These BRCT mutations can cooperate with oncogenic Kras to drive PDAC, whereas mutations neutralizing the E3 ligase domain of Brcal have no impact on disease kinetics (Shakya et al. 2011). In contrast to the pleiotropic functions of BRCA1, BRCA2 is a core mediator of HR during DDR (Roy et al. 2012). In line with the importance of DDR function, Brca2 deletion promotes oncogenic Kras-induced PDAC development, especially in combination with p53 deficiency (Skoulidis et al. 2010; Rowley et al. 2011). Interestingly, in contrast to the prevailing view that the wild-type allele consistently undergoes loss of heterozygosity (LOH) in BRCA2 mutant tumors, germline Brca2 heterozygosity was sufficient in accelerating oncogenic Kras-driven PDAC formation with retained Brca2 expression from the wild-type allele in the aforementioned murine model (Skoulidis et al. 2010), suggesting that BRCA2 may function as a haploinsufficient tumor suppressor for KRASdriven PDAC. These experimental observations align with the retention of the wild-type allele in a minority of cases with germline BRCA2 mutation (Thorlacius et al. 1996; King et al. 2007; Skoulidis et al. 2010). However, the "driver" role for BRCA2 in such cases is unclear, and these patients typically do not have response to DDR targeted therapies (Skoulidis et al. 2010; Rowley et al. 2011; Waddell et al. 2015). Consistent with the differential impact on chromosomal instability and the retention of some DDR function, BRCA2-null tumor cells display enhanced sensitivity to DNA damage agents, such as PARP inhibitor, cisplatin, and mitomycin $\mathrm{C}$, whereas BRCA2 heterozygous tumors are less sensitive (Skoulidis et al. 2010; Rowley et al. 2011). Together, these data suggest that, although some PDAC patients with germline BRCA1 or BRCA2 mutations are responsive to PARP inhibitors, the presence of a hemizygous DDR pathway mutation alone may not be an accurate predictor of increased genomic instability or enhanced therapeutic responses to DNA-damaging agents. It is likely that DDR mutant tumors will respond poorly to therapeutic agents targeting the DNA repair pathways unless the genetic alterations result in functional consequences; i.e., the genome-unstable phenotype (Waddell et al. 2015). With multiple PARP inhibitor trials in PDAC currently ongoing, it will be important to evaluate the functional integrity of the $\mathrm{HR}$ pathway and also conduct in-depth genetic analysis to identify genetic alteration patterns correlating with HR defects and sensitivity to PARP inhibitor. 


\section{Additional amplified oncogenes}

PDAC also exhibits focal regions of gain/amplification that harbor known or putative oncogenes such as MYC and some protein kinases such as ROIK3 (Kimmelman et al. 2008; Waddell et al. 2015; Witkiewicz et al. 2015). MYC amplification confers a poor prognosis (Witkiewicz et al. 2015). Moreover, Myc is critical for oncogenic Kras-driven tumor maintenance in multiple cancer types, and Myc suppression leads to rapid and sustained tumor regression (Soucek et al. 2008, 2013; Ying et al. 2012). Although MYC is not druggable, several tangential approaches have been explored to suppress the oncogenic function of MYC. For example, MYC expression was recently shown to be controlled by BRD4, a member of the BET family of bromodomain-containing proteins, which functions to promote gene expression through the recruitment of the positive transcription elongation factor complex (Yang et al. 2005; Zuber et al. 2011). In a Krasdriven non-small-cell lung cancer model, suppression of Myc expression with a BRD4 inhibitor inhibits tumor growth (Shimamura et al. 2013). Human PDAC cells as well as autochthonous PDAC models indicate that BET inhibition also provokes MYC down-regulation and suppression of pancreatic tumorigenesis in conjunction with HDAC inhibition (Mazur et al. 2015). The attractiveness of MYC as a target also stems from the observation that MYC binds to promoter regions of active genes and causes transcriptional "amplification" (Lin et al. 2012; Nie et al. 2012), which appears to engender vulnerability to blockade of transcriptional elongation by targeting CDK9, a key component of the transcription elongation complex (Huang et al. 2014). Interestingly, a recent study showed that suppression of MYC results in induction of PGCl $\alpha$ and increased mitochondrial respiration, which functions to sustain the PDAC CSC population, implicating the utility of targeting mitochondria oxidative phosphorylation (OXPHOS) in combination with MYC inhibition (Sancho et al. 2015).

Focal amplification of receptor tyrosine kinases (RTKs) such as ERBB2, EGFR, MET, and FGFR1 has been reported in PDAC (Lee et al. 2007a; Waddell et al. 2015). While Egfr has been shown to be essential for Kras-driven PDAC development (Ardito et al. 2012; Navas et al. 2012), an EGFR tyrosine kinase inhibitor in combination with gemcitabine showed minimal benefit in PDAC patients (Moore et al. 2007). Similar meager clinical responses were achieved by targeting ERBB2 (Harder et al. 2012; Assenat et al. 2015). The lack of response may relate to the coactivation of multiple RTKs in tumor cells (Stommel et al. 2007) or to activated signaling downstream from RTKs, including oncogenic KRAS mutations that have been shown in colorectal cancers to negate the effectiveness of anti-EGFR therapy (Bardelli and Siena 2010), although the impact of oncogenic KRAS mutation as a response predictor is not yet established in lung and pancreas cancers (da Cunha Santos et al. 2010; Roberts et al. 2010; Propper et al. 2014). The resolution of these opportunities will require genotype-guided trials. The advance in highthroughput sequencing and analytical technologies is re- shaping the way clinical trials are designed and will eventually help to identify the suitable patient subpopulations for each targeted therapy.

\section{The KRAS oncogene signaling network}

The prevalence of oncogenic KRAS mutation in PDAC ranges from $88 \%$ to $100 \%$ (Jones et al. 2008; Biankin et al. 2012; Sausen et al. 2015; Waddell et al. 2015; Witkiewicz et al. 2015). This mutation is a key initiator, as evidenced by its presence in PanIN lesions (Kanda et al. 2012; Murphy et al. 2013) and the production of PanIN lesions in oncogenic Kras-driven GEMMs (Hezel et al. 2006; Perez-Mancera et al. 2012a). While some PDAC cell lines in two-dimensional (2D) culture can tolerate shRNA-mediated KRAS extinction (Singh et al. 2009), most PDAC cells remain highly addicted to oncogenic KRAS for tumor maintenance in three-dimensional (3D) culture (Zhang et al. 2006; Fujita-Sato et al. 2015) and inducible oncogenic Kras GEMMs with advanced tumors (Collins et al. 2012; Ying et al. 2012). These data strongly support the view that KRAS is a prime therapeutic target for PDAC. However, despite extensive knowledge of oncogenic KRAS and its signaling network, effective strategies to quell its activity in PDAC and other human cancers have been elusive.

\section{Complexity of KRAS oncogene mutations as PDAC drivers}

While G12D or G12V mutations are by far the most common KRAS-activating mutations in human PDAC, codon G13 and Q61 mutations have also been observed, and these alleles may not be equivalent (Jones et al. 2008; Biankin et al. 2012; Prior et al. 2012; Witkiewicz et al. 2015). Specifically, Q61 mutant tumors exhibit less MAPK activity compared with other mutants and are associated with better prognosis (Witkiewicz et al. 2015), a finding consistent with the notion that different KRAS mutations drive diverse signaling outputs with distinct biological consequences (Ihle et al. 2012; Hunter et al. 2015). The complexity of KRAS in PDAC is also manifest by genomic studies identifying the coexistence of multiple different KRAS mutations in the same tumor (Murphy et al. 2013). It is possible that these distinct subpopulations driven by different combinations of KRAS mutations and other cooperating genetic alterations exert a noncell-autonomous impact, which works synergistically to promote tumor expansion, as observed recently in the heterogeneous subclones of breast cancer (Cleary et al. 2014; Marusyk et al. 2014). This concept is consistent with recent genetic studies in Drosophila establishing that oncogenic Kras promotes tumor growth through non-cellautonomous mechanisms (Uhlirova et al. 2005; Ohsawa et al. 2012). In addition, interclonal interaction appears to facilitate the establishment of distal metastasis as shown by lineage tracing in an oncogenic Kras-driven PDAC model (Maddipati and Stanger 2015). While paracrine factors such as interleukin 6 (IL6) and WNT have 
been shown to promote PDAC growth (Morris et al. 2010; Ohsawa et al. 2012; Zhang et al. 2013a,b), additional novel mechanisms involving tumor cell-derived exosomes may also contribute to such interclonal tumor progression by delivering oncogenic miRNAs to target cells and promoting tumor growth (Kharaziha et al. 2012; Melo et al. 2014).

Although the activating mutation per se commandeers KRAS function, it is also important to appreciate that the oncogenic allele is subject to regulation by the wild-type KRAS allele as well as other RAS family members. The wild-type $K R A S$ allele may serve to counter the function of the oncogenic KRAS allele (Zhang et al. 2001; To et al. 2013; Staffas et al. 2015). This concept derives from $\mathrm{LOH}$ of the wild-type KRAS allele in lung cancer and PDAC with oncogenic KRAS mutation (Li et al. 2003; Qiu et al. 2011) and is consistent with the selective amplification of the oncogenic Kras allele in the GEMM of PDAC (Bardeesy et al. 2006a). In contrast, wild-type HRAS and NRAS play a supportive role in tumor growth by keeping the oncogenic KRAS-induced DNA damage response in check (Grabocka et al. 2014). The mechanisms through which the various RAS isoforms influence oncogenic KRAS signaling are not understood, although some recent studies have begun to elucidate how KRAS might play a distinct and dominant oncogenic role in PDAC (Wang et al. 2015b).

\section{KRAS signaling surrogates in tumor development and maintenance}

The major downstream effectors of KRAS signaling include the RAF/MEK/MAPK, PI3K/PTEN/AKT, and RAL-GDS pathways. The MAPK pathway is a critical mediator of the oncogenic KRAS-induced mitogenic effect, and genetic deletion of Mek1/2 or Erk1/2 completely prevents oncogenic Kras-induced lung adenocarcinoma development (Blasco et al. 2011). RAF kinases, including A-RAF, B-RAF, and C-RAF, are the direct KRAS effectors that mediate MAPK activation. B-RAF is generally regarded as the dominant mediator for oncogenic KRAS signaling to activate MAPK (Cseh et al. 2014). Accordingly, in a Kras-driven PDAC GEMM, C-Raf deletion had minimal effect on tumor development (Eser et al. 2013), which is in contrast to significant tumor suppression in an oncogenic Kras-driven lung cancer model with C-Raf deletion (Blasco et al. 2011; Karreth et al. 2011). The importance of BRAF in human PDAC is consistent with the occurrence of BRAF V600E mutation in $~ 3 \%$ of human PDAC cases (Witkiewicz et al. 2015). Moreover, oncogenic BRAF mutations are mutually exclusive with KRAS mutations and are present in $>30 \%$ of the KRAS wild-type PDAC cases (Witkiewicz et al. 2015). Genetic studies in autochthonous models further showed that oncogenic Braf is sufficient to induce PDAC development (Collisson et al. 2012), consistent with a strong epistatic relationship between oncogenic BRAF and KRAS mutations in PDAC and implicating the utility of BRAF inhibitors in PDAC. However it should be stressed that any clinical trial with RAF inhibitors should be restricted to patients with confirmed $B R A F$ mutation, since targeting wild- type BRAF with RAF inhibitors can lead to paradoxical activation of ERK signaling through transactivation of CRAF (Poulikakos et al. 2010) Together, these observations underscore the complex roles of cellular context in oncogenic KRAS signaling and the need for in-depth genetic analysis of the role and requirement of RAF/MEK/ MAPK pathway components in KRAS-driven PDAC genesis and tumor maintenance.

In the PI3K pathway, studies have consistently shown that, among the major kinase subunits of PI3K, p110a, but not $\mathrm{p} 110 \beta$, is the major oncogenic KRAS effector to activate PI3K and promote tumor growth of PDAC and multiple other cancer types (Gupta et al. 2007; Baer et al. 2014; Gritsman et al. 2014; Wu et al. 2014). The essential role of the PI3K pathway is supported by additional genetic studies showing that oncogenic Kras-driven PDAC development is abolished upon deletion of $P d k 1$, the central downstream kinase mediating PI3K signaling (Eser et al. 2013). Human PDAC genomic studies have revealed the presence of oncogenic mutations in components of the PI3K pathway, including activating mutations in the catalytic PI3K subunit (PIK3CA/p110a), mutations in the regulatory $\mathrm{PI} 3 \mathrm{~K}$ subunit (PIK3R1/p85a), amplification of the PI3K downstream effector $A K T 2$, and deletion/loss of tumor suppressor PTEN, a major negative regulator of PI3K (Aguirre et al. 2004; Schonleben et al. 2006; Jaiswal et al. 2009; Ying et al. 2011; Witkiewicz et al. 2015). Mutations in the PI3K pathway, including PIK3CA and $A K T 1$, are relatively common in IPMN-associated PDAC and account for $>10 \%$ of cases (Schonleben et al. 2006; Garcia-Carracedo et al. 2013). Interestingly, the prognosis of these IPMN patients is strongly associated with loss of PTEN expression (Garcia-Carracedo et al. 2013). Although constitutively active Pik3ca can induce PDAC formation in a GEMM (Eser et al. 2013), PIK3CA mutations in human PDAC are largely concurrent with oncogenic KRAS mutation, suggesting that PI3K activation cooperates with oncogenic KRAS during pancreatic tumor development (Witkiewicz et al. 2015). Along these lines, genetic studies have shown that Pten haploinsufficiency or complete deficiency dramatically promotes Kras-driven PDAC development, further underscoring the importance of the PI3K pathway for pancreatic tumorigenesis (Hill et al. 2010; Kennedy et al. 2011; Ying et al. 2011). Indeed, heterozygous or homozygous deletion of the PTEN locus, typically associated with large regions of 10q chromosome loss, was identified in $15 \%$ of human PDAC samples (Ying et al. 2011).

Compared with the RAF and PI3K effector pathways, the role of the RALGDS pathway in KRAS-driven PDAC is less well understood. Among the RALGDS effectors, RALA has been shown to be critical for oncogenic KRAS-mediated tumorigenesis of human PDAC cells, while RALB appears to be more involved in tumor cell invasion and metastasis (Lim et al. 2005, 2006; Martin et al. 2014).

Various in vivo and in vitro studies indicate that all wellestablished RAS effectors are critical for KRAS-induced PDAC initiation and development. However, whether these RAS surrogates are all equally required for tumor 
maintenance remains an open question and is critically important in developing more effective therapeutic strategies. It has been illustrated that RAS transformed human cells rely on the PI3K pathway to sustain their tumorigenic activity (Lim and Counter 2005). The requirement for $\mathrm{PI} 3 \mathrm{~K}$ in tumor maintenance is further supported by a recent GEMM study showing that Kras-driven lung adenocarcinoma growth is halted by the disruption of Pi3k interaction with Ras or inducible p110a deletion in advanced tumors (Castellano et al. 2013). Interestingly, in contrast to the rapid tumor regression observed upon Kras extinction in advanced tumors (Collins et al. 2012; Ying et al. 2012), Pi3k deficiency leads to sustained tumor stasis, and gross tumor regression is only achieved upon cotreatment with a MEK inhibitor, suggesting that both the PI3K and RAF pathways are critical for KRAS-mediated tumor maintenance. However, pharmacological coinhibition of the PI3K and MEK pathways has yielded modest tumor regression in the oncogenic Kras-driven PDAC as well as in a phase Ib trial (Alagesan et al. 2015; Bedard et al. 2015), suggesting that additional signaling circuits may operate to enable oncogenic KRAS signaling in PDAC or that sufficient pharmacological inhibition of these signaling molecules was not adequately achieved.

\section{Targeting the KRAS pathway}

The essential role of KRAS for tumor maintenance underscores the importance of efforts targeting oncogenic KRAS to achieve major therapeutic advances for PDAC. The significant opportunity, coupled with the meager progress so far in achieving this goal, prompted the launch of the National Cancer Institute (NCI) RAS initiative ("Kill RAS") to stimulate novel strategies to attack oncogenic RAS and its signaling surrogates in cancer (http://www. cancer.gov/research/key-initiatives/ras). The direct targeting of RAS has proven elusive due to the lack of a targetable pocket on the RAS protein, the high affinity of mutant RAS to GTP (picomolar range), and the abundance of intracellular GTP (millimolar range) (McCormick 2015; Singh et al. 2015). Nevertheless, the discovery of a new pocket generated by the mutant cysteine of KRAS ${ }^{\mathrm{G} 12 \mathrm{C}}$, a mutant form relatively rare in PDAC (Witkiewicz et al. 2015), has led to the development of a small molecule inhibitor specifically targeting this mutant oncoprotein (Ostrem et al. 2013). Direct RAS targeting is also using "structure-activity relationships (SARs) by NMR" strategies that search for molecules binding to several weak pockets that can then be bridged together as a means of strengthening interactions and improving specificity (Shuker et al. 1996; Sun et al. 2014). Beyond this specific program, other more general oncogenic RAS targeting strategies directly inhibit oncogenic KRAS expression with siRNA nanoparticles, which have shown positive results in xenograft models (Zorde Khvalevsky et al. 2013; Yuan et al. 2014). Current in vivo siRNA delivery methods remain inadequate to target cancer cells (Williford et al. 2014), although exosome-based delivery particles may offer improved pharmacology (Wahlgren et al. 2012).
Pharmacological RAS targeting strategies have explored its requirement to attach to the plasma membrane for activated signaling. In the case of KRAS, this attachment requires the post-translational lipid modification of farnesylation (Cox et al. 2015). While early efforts to target KRAS farnesylation have failed therapeutically, new small molecule inhibitors have been developed that instead target PDE $\delta$, which binds to farnesylated KRAS and enhances its localization to plasma membranes (Chandra et al. 2012; Zimmermann et al. 2013).

As noted above, another important RAS targeting strategy has focused on inhibitor combinations targeting major RAS signaling surrogates such as the MAPK and PI3K pathways. To date, preclinical experimental therapeutics and early stage clinical trials cotargeting MEK and PI3K in PDAC have been disappointing (Alagesan et al. 2015; Bedard et al. 2015). While one of the major limitations of such combination has been the dose-related cutaneous and gastrointestinal (GI) toxicities, these poor results may relate to the need to target additional RAS effectors such as RALGDS. RAL inhibition-either indirectly through the cyclin-dependent kinase CDK5 (Feldmann et al. 2010) or directly with a pharmacological inhibitor of Ral signaling (Yan et al. 2014)-has been shown to inhibit the growth of Ras mutant tumors in preclinical models, underscoring the potential of leveraging this pathway as a therapeutic target. More broadly, the profound tumor regression upon genetic extinction of oncogenic Kras in the GEMM of PDAC provides a platform to compare signaling upon genetic extinction of oncogenic KRAS with pharmacological inhibition of RALGDS, MAPK, and/or PI3K. Such unbiased signaling comparisons may point to bypass "gaps" that are not covered by these agents. Such a genetic versus pharmacological comparative strategy has proven effective in identifying combinations for the targeting of NRAS mutant melanomas with MEK and CDK4 inhibitors that are now in early stage clinical trials with promising results (Kwong et al. 2012). In addition to targeting immediate RAS downstream surrogates, several indirect targets are also emerging as alternative ways to block RAS-driven tumors, including SMYD3, which mediates lysine methylation of MAP3K2 (Mazur et al. 2014), and IQGAP1, which is a scaffold protein critical for MAPK activation (Jameson et al. 2013).

\section{Oncogenic KRAS escapers}

With the ultimate successful targeting of oncogenic KRAS in PDAC, mounting experimental evidence points to the emergence of KRAS-independent resistance mechanisms, hence the need for expanding our therapeutic vistas. That oncogenic KRAS is not an obligate event in PDAC development is suggested by the occurrence of KRAS wild-type PDAC cases. More relevant to the targeting of oncogenic KRAS, recent studies using the inducible Kras GEMM of PDAC, coupled with clinical correlation studies blocking MEK/PI3K pathways, have revealed a quiescent subpopulation of Kras extinction-resistant cells with tumor-initiating potential (Viale et al. 2014). These observations have prompted speculation that the KRAS extinction- 
resistant cells may provide a reservoir for tumor relapse. Indeed, targeting pathways essential to sustain these cell populations, such as mitochondrial respiration or autophagy (see the detailed discussion in "PDAC Metabolism"), can effectively wipe out the KRAS extinction-resistant cells and prevent tumor relapse (Viale et al. 2014).

The inducible oncogenic Kras GEMM of PDAC has also revealed Kras-independent signaling mechanisms of resistance. In this model, oncogenic Kras extinction permanently eliminates most tumors; however, a subset of tumors can bypass Kras dependency and undergoes spontaneous recurrence (Kapoor et al. 2014). Multidimensional genomic, transcriptomic, and proteomic profiling has revealed several distinct mechanisms, including, most prominently, amplification of the Yap1 oncogene of the Hippo pathway (Kapoor et al. 2014). Interestingly, YAP1 was also identified in multiple genetic screens as one of the top hits that confer resistance to KRAS suppression or targeted cancer therapy with RAF and MEK inhibitors (Shao et al. 2014; Lin et al. 2015), further corroborating the role of the YAP1 pathway in driving resistance to targeted therapy. In addition, YAP1 mediates the expansion of pancreatic progenitors during embryonic development and may also cooperate with oncogenic KRAS-driven PDAC development (Zhang et al. 2014a; Cebola et al. 2015). Therefore, the targeting of YAP1 and its pathway may be a critical component of a successful therapeutic strategy for oncogenic KRAS-driven PDAC that would target both the KRAS and YAP1 axes to eliminate bulk tumor as well as potential bypass mechanisms. Finally, in addition to YAP1-mediated resistance, unbiased profiling has also identified the activation of RTK growth factor pathways as another mechanism for oncogenic KRAS-independent tumor growth (Shao et al. 2014). Correspondingly, growth factor receptors such as FGFR1 are amplified in human PDAC cases (Waddell et al. 2015), presaging the need for further evaluation of the role of specific RTKs in both PDAC pathogenesis and bypassing KRAS dependency. More importantly, while multiple mechanisms leading to resistance to KRAS inactivation have been identified in various experimental models, these KRAS-bypass pancreatic tumors exhibit expression signatures reminiscent of a subset of human PDACs; namely, the quasimesenchymal subtype (Kapoor et al. 2014). Transcriptional profiles have defined human PDAC into three subtypes: classical, quasimesenchymal, and exocrine-like (Collisson et al. 2011). Such classification has since been updated into four subgroups by most recent large-scale transcriptional analysis of PDAC samples; namely, (1) the squamous subtype, mostly reflecting the old quasimesenchymal subtype; (2) the pancreatic progenitor subtype, reflecting the old classic subtype; (3) the ADEX (aberrantly differentiated endocrine exocrine) subtype, reflecting the old exocrine-like subtype; and (4) the immunogenic subtype, which is a novel group associated with significant immune infiltration (Bailey et al. 2016). Interestingly, one characteristic of the quasimesenchymal tumors or the squamous type tumors is the decreased reliance on oncogenic KRAS for survival (Singh et al. 2009; Collisson et al. 2011). Therefore, a pre-existing subpopulation of
PDAC cells with an inherent resistance to KRAS pathway blockade may exist up front in which durable therapeutic responses would be anticipated by targeting both the oncogenic KRAS pathway and the aforementioned oncogenic KRAS-bypass mechanisms.

Altogether, the above discussion underscores the extreme complexity and robustness of the oncogenic KRAS signaling network and the capacity of PDAC cells to adopt KRAS-independent bypass mechanisms for sustained tumor growth. While various anti-KRAS approaches such as synthetic-lethal screens and genome-wide genetic epistasis studies have been pursued for more than a decade, these efforts have yet to provide consistent hits effective across multiple experimental systems (Downward 2015). Beyond targeting KRAS directly, these efforts point to the need to expand beyond targeting specific oncogenic drivers to include collateral lethality approaches (Muller 2015) as well as the targeting of PDACspecific metabolic dependencies and immune evasion, among other hallmarks.

\section{PDAC metabolism}

To fuel their elevated demand for energy and macromolecular biosynthesis, cancer cells show augmented nutrient acquisition that is coupled to increased flux through downstream anabolic pathways for the biosynthesis of proteins, lipids, and nucleic acid (Dang 2012; Ward and Thompson 2012; Vander Heiden 2013; Boroughs and DeBerardinis 2015). This reprogramming of cellular metabolism to support continuous proliferation has been recognized in the updated "hallmarks of cancer" (Hanahan and Weinberg 2011). In the case of PDAC, such alterations in metabolic programs may be particularly important for the growth and survival of cancer cells given the nutrientand oxygen-poor tumor microenvironment, perhaps due to dense stroma and hypovascularization (Sousa and Kimmelman 2014). Indeed, a prevailing view posits that a key function of oncogenes such as KRAS is to reprogram cellular metabolism back to the building blocks that sustain unrestricted tumor growth (Kimmelman 2015). These tumor microenvironment- and genotype-specific metabolic adaptations may therefore provide possible cancer-specific therapeutic vulnerabilities with minimal impact on normal cells.

\section{KRAS-dependent glucose metabolism reprogramming}

One of the classic features of tumor metabolism is enhanced glycolysis and conversion of glucose into lactate even when oxygen is available for OXPHOS /Vander Heiden et al. 2009). This phenomenon, known as the Warburg effect, is observed in PDAC and many other tumor types (Zimny et al. 1997; Boros et al. 2002; Ying et al. 2012). Elevated glucose uptake by tumor cells has stimulated studies to exploit this process for therapeutic purposes. Efforts have explored mechanisms to block the enhanced glucose metabolism in cancer cells used to fuel anabolic processes (Vander Heiden et al. 2009) and possibly to restrict anti- 
tumor immune responses, as effector $\mathrm{T}$ cells also rely heavily on glycolysis for activation (Biswas 2015; Chang et al. 2015). In PDAC, oncogenic KRAS plays an important role in rewiring anabolic glucose metabolism (Ying et al. 2012) through its ability to induce glucose uptake and enhance glycolysis (Racker et al. 1985; Yun et al. 2009; Ying et al. 2012), which is achieved in part through the transcriptional up-regulation of multiple key glycolysis enzymes, including glucose transporter type 1 (GLUT1), hexokinase $1 / 2(\mathrm{HK} 1 / 2)$, phosphofructokinase 1 (PFK1), and lactate dehydrogenase A (LDHA) (Fig. 1; Racker et al. 1985; Yun et al. 2009; Gaglio et al. 2011; Ying et al. 2012). Inhibition of LDHA has shown promising effects in preclinical models (Le et al. 2010; Rajeshkumar et al. 2015), underscoring the important role of aerobic glycolysis in PDAC. In addition, oncogenic KRAS signaling induces the expression of monocarboxylate transporter 4 (MCT4), a lactate transporter, in PDAC cells to promote lactate efflux and thus mitigate the toxic effects of intracellular lactate accumulation due to elevated glycolysis (Baek et al. 2014).

Beyond glycolysis, oncogenic KRAS also promotes the expression of rate-limiting metabolic enzymes in multiple biosynthesis pathways in order to coordinate the increased flux of glycolysis intermediates through various anabolic processes. In particular, oncogenic KRAS induces the expression of glucosamine-fructose-6-phosphate aminotransferase 1 (GFPT1), the rate-liming enzyme for the hexosamine biosynthesis pathway (HBP) (Fig. 1; Ying et al. 2012). The HBP provides the precursor for various glycosylation processes, such as protein N-glycosylation or O-glycosylation and glycolipid synthesis. Recent studies indicate that the HBP in tumor cells is important for the coordination of nutrient uptake, partially through modulating the glycosylation and membrane localization of growth factor receptors (Wellen et al. 2010). Inhibition of the HBP in PDAC cells by knocking down GFPT1 strongly suppresses tumorigenic activity in vitro and in

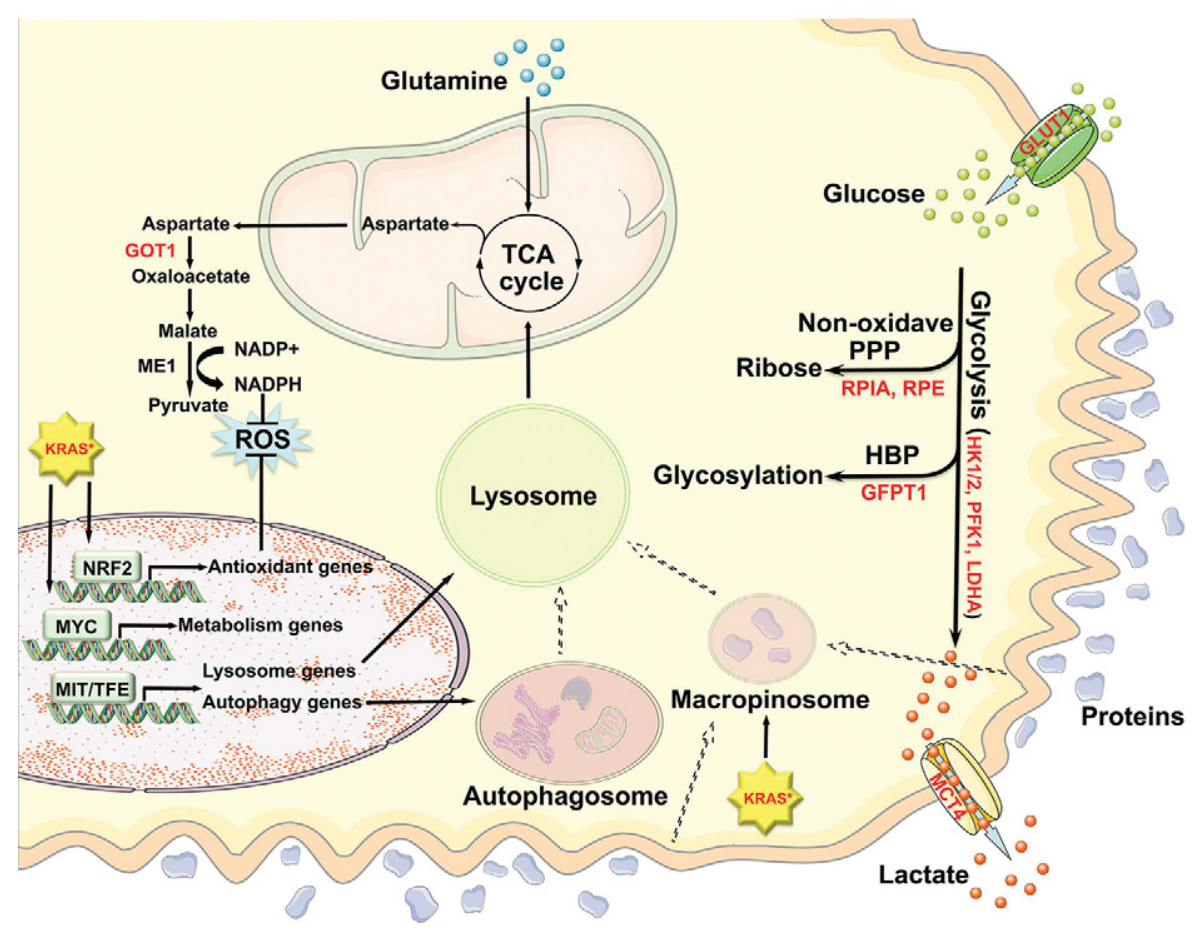

Figure 1. Metabolism reprogramming in PDAC. KRAS-driven PDAC is characterized by enhanced glycolysis, including increased glucose uptake and lactate production. Oncogenic KRAS also promotes the efflux of lactate to mitigate the toxic effect of intracellular lactate accumulation due to elevated glycolysis. The flux of glycolysis intermediates was directed by oncogenic KRAS into biosynthetic pathways, including the nonoxidative pentose phosphate pathway (PPP) for nucleotide biosynthesis and the hexosamine biosynthesis pathway (HBP) to support glycosylation. The reprogramming of glucose metabolism in PDAC cells by oncogenic KRAS is mediated by up-regulation of multiple enzymes in a MYC-dependent manner. Oncogenic KRAS also induces a noncanonical glutamine metabolism pathway to maintain redox homeostasis in PDAC cells through the induction of aspartate transaminase 1 (GOT1) expression. The redox balance is also maintained by KRAS-mediated activation of NRF2, which is a master transcription factor for antioxidant genes. Another feature of PDAC metabolism is the activation of nutrient salvage pathways to fuel tumor growth. Oncogenic KRAS induces macropinocytosis and uptake of protein from extracellular space, which leads to lysosomal degradation and the release of nutrients to support the tricarboxylic acid (TCA) cycle. In addition, KRAS-driven PDAC cells are also characterized by increased autophagy, which leads to the degradation of organelles and proteins and the production of amino acids and other components that support metabolism. The activation of autophagy is achieved through the MiT/TFE-mediated expression of autophagy and lysosome genes. Enzymes whose expression is induced in oncogenic KRAS are indicated in red. (GFPT1) Glucosamine-fructose-6-phosphate aminotransferase 1; (ME1) malic enzyme 1; (ROS) reactive oxygen species; (RPE) ribulose-5-phosphate-3-epimerase; (RPIA) ribulose-5-phosphate isomerase. 
vivo, supporting the critical role of HBP-mediated glucose flux into the glycosylation pathway in the maintenance of PDAC (Ying et al. 2012).

Another key function of oncogenic KRAS in PDAC metabolism reprogramming is the channeling of glycolysis intermediates, specifically through the nonoxidative arm of the pentose phosphate pathway (PPP) (Fig. 1; Ying et al. 2012). The major function of the PPP is to generate ribose-5-phosphate for de novo nucleotide biosynthesis. The PPP is composed of oxidative and nonoxidative arms, both of which function in ribose biogenesis. The oxidative arm also provides NADPH for macromolecule biosynthesis and reactive oxygen species (ROS) detoxification and is regarded as important for tumorigenesis in many cancer types (Deberardinis et al. 2008). Interestingly, the activity of the oxidative PPP is not significantly regulated by KRAS signaling, as shown in a PDAC GEMM driven by inducible Kras ${ }^{\mathrm{G} 12 \mathrm{D}}$ (Ying et al. 2012). In contrast, oncogenic Kras drives the flux of glycolysis intermediates specifically through the nonoxidative arm of the PPP, at least partially through the transcriptional up-regulation of PPP enzymes, including ribulose-5-phosphate isomerase (Rpia) and ribulose-5-phosphate-3-epimerase (Rpe). Inhibition of the nonoxidative PPP blocks the integration of glucose-derived carbon for de novo nucleic acid biosynthesis and impairs PDAC tumorigenicity. This is consistent with the observations that human PDAC cells depend preferentially on the nonoxidative PPP for proliferation (Boros et al. 1997). Therefore, unlike current standard anti-metabolism therapeutics for PDAC such as gemcitabine, which inhibits deoxyribonucleotide synthesis and blocks DNA replication in proliferating cells, targeting the nonoxidative PPP may provide a more effective and cancer-specific therapeutic means of blocking DNA synthesis.

\section{Glutamine metabolism and ROS homeostasis}

It is well documented that oncogenic RAS plays a major role in ROS generation, with several studies establishing that ROS is critical for oncogenic KRAS-mediated transformation and growth of PDAC cells (Irani et al. 1997; Mitsushita et al. 2004; Vaquero et al. 2004; Weinberg et al. 2010; Hu et al. 2012; Du et al. 2013). However, while most cancer cells exhibit elevated ROS levels, excessively high ROS levels are detrimental, thus requiring potent oxidative defense mechanisms in order to maintain redox balance for viability (Gorrini et al. 2013; Schieber and Chandel 2014). Indeed, oncogenic KRAS is known to activate an oxidative defense program to quench intracellular ROS, which is essential for redox homeostasis and PDAC tumorigenesis (DeNicola et al. 2011). One of the major factors for redox balance is the level of reduced glutathione that is maintained by the oxidative PPP through NADPH production (Trachootham et al. 2008). As discussed above, oncogenic KRAS in PDAC has minimal impact on the flux of glucose through the oxidative PPP (Ying et al. 2012), which is in agreement with minimal alteration of the redox state in PDAC cells upon glucose starvation (Son et al. 2013). These observations revealed the presence of alternative metabolism pathways for the maintenance of redox homeostasis in PDAC cells. Specifically, PDAC cells use glutamine metabolism for redox balance, as evidenced by significant induction of ROS upon glutamine withdrawal (Son et al. 2013).

Glutamine is the most abundant and versatile amino acid in the cytoplasm. It has been long established that PDAC cells are addicted to glutamine for survival in tissue culture (Wu et al. 1978; Wang and Permert 2002). Canonical glutamine metabolism in cancer cells is mostly used to fuel the mitochondrial tricarboxylic acid (TCA) cycle for ATP generation and to provide precursors for macromolecular biosynthesis (Hensley et al. 2013). In contrast, in the mitochondria of PDAC cells, glutamine is converted by GOT2 (mitochondrial aspartate transferase 2) into aspartate, which is shuttled to the cytoplasm and further converted into oxaloacetate by GOT1 (cytosolic aspartate aminotransferase 1) (Son et al. 2013). Oxaloacetate is used for the generation of NADPH through the action of malate dehydrogenase 1 (MDH1) and malic enzyme 1 (ME1). NADPH produced by this noncanonical glutamine metabolism pathway is essential to maintain redox homeostasis and support PDAC growth (Fig. 1). Importantly, many of the enzymes involved in the noncanonical pathway are essential for PDAC growth but not normal cells, thus providing a potential PDAC-specific vulnerability.

In addition to the regulation of NADPH production through the GOT1-dependent pathway, oncogenic KRAS signaling also controls the redox balance by the induction of NRF2, a master transcriptional regulator for antioxidant genes (Fig. 1; DeNicola et al. 2011). Interestingly, NRF2 also modulates the expression of multiple glutamine metabolism genes, including ME1 (Mitsuishi et al. 2012). Moreover, oncogenic KRAS also controls the expression of GOT1 (Son et al. 2013). Therefore, oncogenic KRAS controls redox balance in PDAC through the orchestration of multiple mechanisms in which glutamine plays a central role.

\section{Salvage pathways-a hallmark of PDAC metabolism}

As noted above, the PDAC tumor microenvironment sustains local hypoxia and low nutrient availability. Accordingly, PDAC employs an intriguing set of scavenging mechanisms that fuel growth in the face of limited nutrients from the vasculature. One prominent salvage pathway is macroautophagy (referred to here as autophagy). Autophagy is a process of bulk recycling of cellular components (Kroemer et al. 2010). Damaged or dispensable organelles, lipids, or proteins and their aggregates are sequestered in autophagosomes, which eventually fuse with lysosomes, leading to degradation of the cargo. Degraded cargo is recycled back into the cytoplasm, where the amino acid, lipid, and nucleoside building blocks are used in macromolecular biosynthesis and bioenergetics. In addition to its quality control function in clearing damaged structures, autophagy can be triggered by stresses such as starvation and can serve to restore nutrient levels to those consistent with cell survival (Neufeld 2010). However, with sustained autophagy, primary cells can incur critical depletion of organelles and experience 
subsequent cell death. In keeping with these contrasting effects of autophagy, experimental studies reveal a dual function of autophagy in cancer (Kimmelman 2011; White 2013). In normal cells, autophagy serves as a barrier for tumorigenesis through its quality control function; reciprocally, inactivation of autophagy causes accumulation of damaged cellular components, which results in genotoxic levels of ROS and the promotion of early neoplastic changes (Galluzzi et al. 2015). However, autophagy is beneficial for malignant cells through its recycling function, providing various nutrients such as amino acids, fatty acids, nucleotides, and ATP for cancer cell growth (Rabinowitz and White 2010). Indeed, autophagy has been shown to support mitochondrial metabolism as well as glycolysis and is required for the growth of oncogenic RAS-driven tumors, including PDAC (Fig. 1; Guo et al. 2011; Kim et al. 2011; Lock et al. 2011; Wei et al. 2011; Yang et al. 2011; Guo and White 2013). However, a recent study has called into question the role of autophagy in promoting oncogenic KRAS-driven tumor cell lines (Eng et al. 2016). This discrepancy with numerous prior studies may relate to several experimental issues, including the use of short-term in vitro growth assays not mimicking the in vivo situation as well as the possible emergence of autophagy-independent clones through the selective pressures of gene editing. Most importantly, some of the most robust tumor responses to autophagy loss are seen in autochthonous models with homotypic tumor-stromal interactions and an intact immune system (Wei et al. 2011; Guo et al. 2013; Strohecker et al. 2013; Yang et al. 2014) and appear to be even more profound with systemic autophagy loss (Karsli-Uzunbas et al. 2014). Together, this suggests that, in addition to important cell-autonomous effects of autophagy in PDAC and other KRAS mutant tumors, there are also non-cell-autonomous factors for which autophagy is critical yet cannot be assessed in cell culture and standard xenograft studies in immunocompromised mice. Ongoing and future studies, including clinical trials, should explore the role of the immune system and other features of the tumor microenvironment.

In PDAC, exuberant levels of basal autophagy have been observed (Yang et al. 2011), and genetic disruption of autophagy with Atg5 deletion or pharmacological blockade of autophagic flux with hydroxychloroquine (HCQ) has been shown to suppress tumor growth in autochthonous oncogenic Kras-driven PDAC models (Yang et al. 2011, 2014). Furthermore, HCQ treatment in PDAC patient-derived xenograft (PDX) models shows significant inhibition of tumor growth in the majority of cases (Yang et al. 2014). While HCQ inhibits the lysosome and can affect other lyososomal pathways (such as macropinocytosis) (discussed below), studies have shown that, at certain dose ranges, the anti-tumor effects of HCQ are likely through autophagy inhibition (Amaravadi et al. 2007). Mixed outcomes have been observed in various clinical trials using HCQ to target autophagy in several cancer types, including PDAC (Kimmelman 2015). A recent phase I/II clinical trial indicates that neoadjuvant HCQ may have efficacy in PDAC, prompting randomized clinical trials (Boone et al. 2015). Despite this possible clinical activity of $\mathrm{HCQ}$, the therapeutic validation of autophagy inhibition will benefit from the development of more potent and specific inhibitors targeting autophagosome formation and fusion with lysosome as well as the definition of a clear patient responder hypothesis.

While the supporting role of autophagy during tumor progression has been generally recognized (White 2015), the mechanisms that lead to autophagy activation in tumor cells, including PDAC, are less well known. In normal cells, autophagy is tightly controlled, in large part by $\mathrm{mTOR}$ and the FOXO family of transcription factors (Salih and Brunet 2008; Zhang et al. 2011; Efeyan et al. 2015), which are activated when nutrients are plentiful and act to suppress autophagy and other nutrient uptake mechanisms (Palm et al. 2015). Paradoxically, PDAC cells maintain active mTOR signaling while simultaneously sustaining high levels of autophagy (Yang et al. 2011; Ying et al. 2012). This hyperactivation of autophagy in PDAC is mediated in part by the MiT/TFE family of transcription factors (MITF, TFE3, and TFEB), which are critical for lysosome biogenesis (Fig. 1; Perera et al. 2015). In PDAC, MiT/TFE knockdown leads to pronounced impairment in lysosome structure and function, loss of autophagic flux, and abrogation of tumorigenicity. Importantly, while MiT/TFE proteins are normally sequestered in the cytoplasm and inactivated by mTOR-mediated phosphorylation (Settembre et al. 2013), MiT/TFE proteins escape mTOR-mediated inhibition via aberrant nuclear translocation mediated by the nuclear import proteins IPO7 and IPO8 (Perera et al. 2015). Preventing the nuclear accumulation of MiT/TFE may provide an alternative therapeutic strategy to block autophagy specifically in PDAC cells.

In addition to recycling intracellular substrates, PDAC cells are also capable of taking up extracellular macromolecules through macropinocytosis or receptor-mediated uptake to sustain tumor growth. It has been long established that oncogenic RAS strongly activates macropinocytosis, a type of endocytosis designed to engulf large portions of extracellular space through enhanced membrane ruffling (Bar-Sagi and Feramisco 1986; Swanson and Watts 1995). The cargo carried in the large vesicles formed through macropinocytosis, also called macropinosomes, is eventually delivered to the lysosome for degradation to fuel anabolic processes (Swanson and Watts 1995; McMahon and Boucrot 2011). Oncogenic KRAS-induced macropinocytosis in PDAC cells leads to the salvage of extracellular proteins as a source of amino acids and as fuel for the TCA cycle (Fig. 1; Commisso et al. 2013). In addition, oncogenic KRAS-transformed primary pancreatic ductal cells are able to scavenge extracellular lipids to support growth (Kamphorst et al. 2013; Guillaumond et al. 2015). Such nutrient salvage pathways are particularly important to fuel the metabolism in human PDAC in the setting of limiting nutrients in the tumor microenvironment (Kamphorst et al. 2015; Palm et al. 2015). Indeed, inhibition of macropinocytosis attenuates oncogenic KRAS-driven tumorigenesis in vitro and in vivo (Commisso et al. 2013). At the same time, it is important to appreciate that enhanced macropinocytosis in PDAC 
cells may also serve to promote tumor-specific drug delivery, as has been implicated in the clinical success seen with nab-paclitaxel, an albumin-conjugated form of paclitaxel (Von Hoff et al. 2013). Together, multiple levels of therapeutic intervention appear possible, although clear strategies are needed to identify the optimal salvage pathway target in the right patient subpopulation. Along these lines, it is tempting to speculate that, given the lysosome as the common destination for macropinosomes and autophagosome, targeting the lysosome pathway by inhibition of lysosome fusion or MiT/TFE nuclear accumulation (discussed above) may disrupt both nutrient salvage pathways that are critical for PDAC maintenance.

\section{Intratumoral metabolic heterogeneity}

Cancer cells of the same tumor can also exhibit very different metabolic profiles. This characteristic came to light in the inducible oncogenic Kras-driven PDAC model, which showed that, upon extinction of oncogenic Kras, the persistent Kras-independent tumor-initiating cells (TICs) exhibited a metabolic profile very different from that of the Kras-dependent cancer cells of the bulk tumor (Viale et al. 2014). Whereas oncogenic Kras-dependent cancer cells exhibited high levels of glycolysis, the Krasindependent TICs showed impaired glycolysis and increased mitochondrial respiration. Similar observations were made in TICs derived from human PDAC PDX models, which exhibited decreased glucose flux through glycolysis and elevated OXPHOS activity (Sancho et al. 2015). These TICs are equipped with limited metabolic plasticity and are thus particularly sensitive to inhibition of mitochondrial respiration (Viale et al. 2014; Sancho et al. 2015). Similar OXPHOS-addicted subpopulations with TIC properties have also been identified in other cancer types, such as leukemia and melanoma (Lagadinou et al. 2013; Vazquez et al. 2013). It is notable that OXPHOS inhibition works synergistically with targeted therapies directed against driving oncogenes (Haq et al. 2013; Alvarez-Calderon et al. 2015). Thus, it is possible that an effective strategy to eliminate both bulk cancer cells and TICs in PDAC would combine targeted therapy directed against the oncogenic KRAS pathway such as MEK as well as drugs that directly inhibit mitochondrial respiration (Viale et al. 2015).

The PDAC stroma impacts metabolism through key interactions between cancer cells and stromal fibroblasts, involving the exchange of nutrient sources such as glucose, lactate, and other energy-rich molecules (Hanahan and Coussens 2012; Lisanti et al. 2013). Adipocytes have been shown to play a supportive role in cancer progression by providing free fatty acids to fuel ovarian cancer metastasis (Nieman et al. 2011). Similar lipid scavenging may also be operative in PDAC cancer cells, as suggested by increased pancreatic adipocyte infiltration in tumors (Hori et al. 2014; Rebours et al. 2015; Wang et al. 2015a). Metabolic interactions in the microenvironment may also enable tumor progression through suppression of immune responses. Specifically, competition for limiting energy molecules such as glucose was shown to limit the avail- ability of energy sources needed for the activation of effector $\mathrm{T}$ cells, resulting in immune suppression in the tumor microenvironment in a mouse sarcoma model /Chang et al. 2015). In addition, lactate excreted by tumor cells has been shown to suppress anti-tumor immunity by suppressing natural killer (NK) cells and enhancing myeloidderived suppressor cell (MDSC) functions (Fig. 2; Husain et al. 2013). The lack of effector T-cell infiltration and activation is a hallmark of the PDAC microenvironment (Laheru and Jaffee 2005; Clark et al. 2007; Feig et al. 2013), although the basis for immune suppression in PDAC is not completely understood. Understanding the mechanisms of immune suppression and its relationship to cancer metabolism is an area of investigational opportunity in the development of effective therapies for PDAC.

\section{PDAC stroma}

The PDAC stroma exhibits a strong desmoplastic feature, with stromal components outnumbering cancer cells, and can comprise as much as $90 \%$ of the total tumor volume (Maitra and Hruban 2008; Neesse et al. 2011). The PDAC stroma is composed of myofibroblasts, suppressor immune cells such as MDSCs, regulatory $\mathrm{T}\left(\mathrm{T}_{\text {reg }}\right)$ cells, tumor-associated macrophages (TAMs), and acellular components such as collagen, cytokines, and soluble growth factors (Fig. 2; Maitra and Hruban 2008; Neesse et al. 2015). This prominent desmoplastic response has been attributed to signaling between cancer and host cells involving paracrine and autocrine signaling pathways. Several signaling pathways that are potent modulators of the stroma are highly activated in PDAC. For example, Sonic hedgehog (SHH) ligands secreted by cancer cells act on fibroblasts promoting desmoplasia and cell motility (Fig. 2; Berman et al. 2003; Bailey et al. 2008, 2009; SpivakKroizman et al. 2013), and, reciprocally, the SHH pathway inhibitor (IPI-926) in combination with gemcitabine can deplete the pancreatic stroma in GEMMs of PDAC /Olive et al. 2009).

The role of the stroma in PDAC initiation, progression, metastasis, immune infiltration, and drug resistance has been an area of intense investigation and contrasting theories. Pancreatic stellate cells (PSCs) are the predominant fibroblasts present in the PDAC stroma. In the healthy pancreas, PSCs are resident lipid-storing cells that secrete matrix metalloproteinases (MMPs) such as MMP2, MMP9, and MMP13 and play an important role in extracellular matrix (ECM) turnover and normal tissue architecture (Fig. 2; Phillips et al. 2003). In the quiescent state, PSCs store vitamin A in cytoplasmic lipid droplets and produce a lower amount of ECM (Apte et al. 2012). In contrast, upon pancreatic injury, such as chronic pancreatitis and/or PDAC growth, PSCs lose their cytoplasmic lipid storage, increase ECM production, acquire a myofibroblast-like phenotype, and express the fibroblast activation marker a-smooth muscle actin (aSMA) (Wehr et al. 2011). These activated PSCs secrete excessive amounts of ECM components, leading to the classical fibrosis pathology observed in PDAC (Apte and Wilson 2012). 


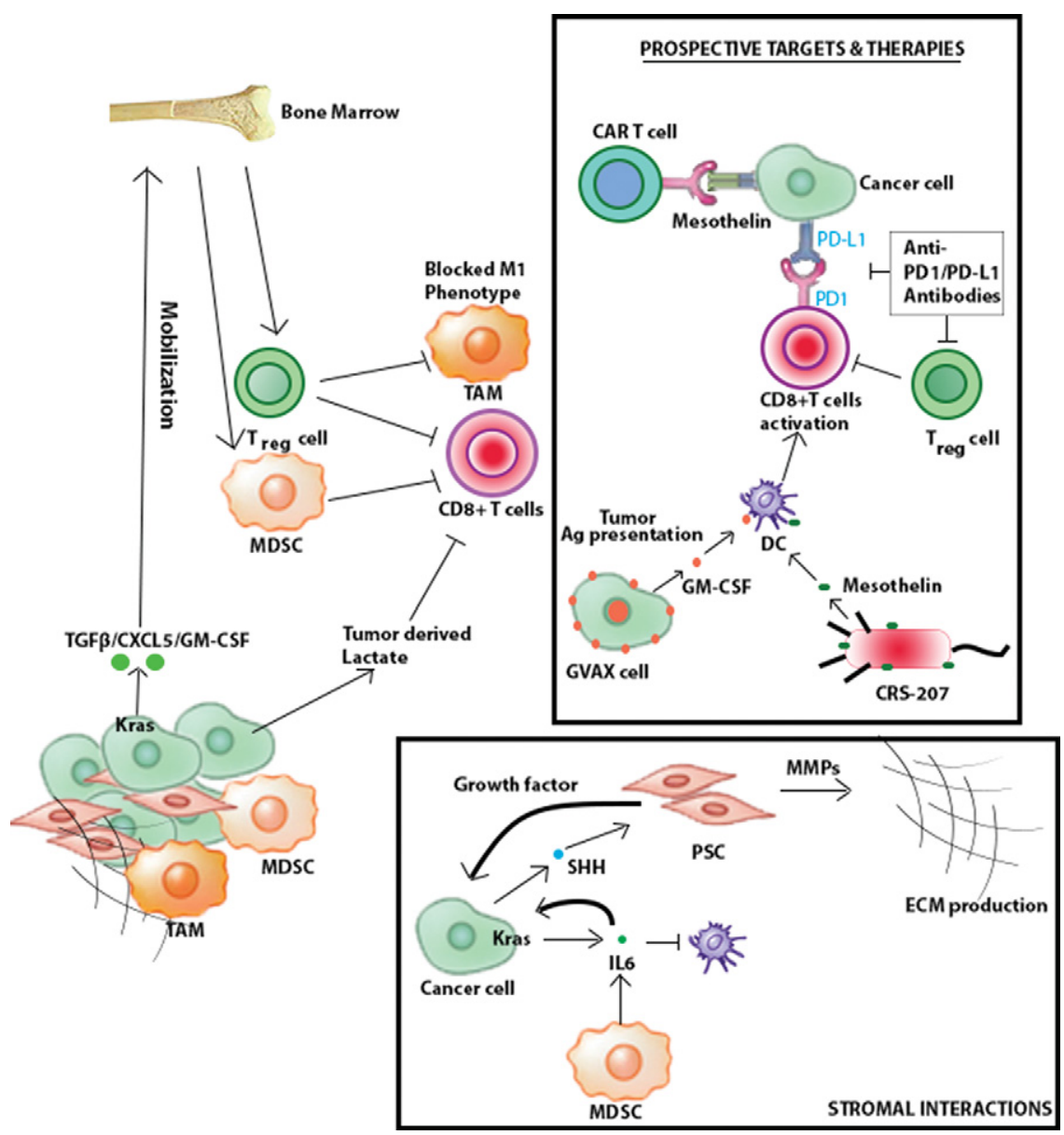

Figure 2. Immune network, prospective targets, and therapies in PDAC. PDAC cancer cells secrete cytokines such as TGF $\beta$, CXCL5, and GM-CSF (granulocyte-macrophage colony-stimulating factor), which mobilizes bone marrow-derived, immunesuppressive immune cells such as myeloid-derived suppressor cells (MDSCs) and regulatory $\mathrm{T}\left(\mathrm{T}_{\text {reg }}\right)$ cells. The secretion of these protumorigenic cytokines by the cancer cells is tightly regulated by oncogenic KRAS-dependent pathways. These tumorinfiltrated MDSCs and $\mathrm{T}_{\text {reg }}$ cells create an immune-suppressive environment by suppressing the activity and functions of $\mathrm{CD}^{+}$cytotoxic $\mathrm{T}$ cells and blocking the M1 phenotype of tumor-associated macrophages (TAMs). PDAC cells also secrete metabolites such as lactate, which suppresses $\mathrm{CD} 8^{+}$cytotoxic T-cell activity. Furthermore, the paracrine network between PDAC cancer cells and myofibroblasts such as pancreatic stellate cells (PSCs) creates a desmoplastic response leading to fibrosis and immune suppression. Also, cancer cells secrete factors such as Sonic hedgehog (SHH) ligands that activate PSCs to produce matrix metalloproetinases (MMPs) that promote invasion and extracellular matrix (ECM)-mostly collagens. In addition, PDAC cancer cells and the infiltrating MDSCs secrete proinflammatory cytokines such as IL6, which further promotes JAK/STAT-mediated pathways, leading to cancer cell survival, proliferation, and diminished tumor antigen presentation to the dendritic cells. Numerous strategies are being pursued to manipulate the immunosuppressive environment in PDAC and reduce immune evasion by cancer cells. Unlike melanoma, the immune modulation strategies such as anti-CTLA4 (cytotoxic T-lymphocyte-associated protein 4) and anti-PD1/PD-L1 (programmed cell death 1 ligand 1) have yet to show any promising outcome as monotherapies, although, in a aSMA-Tk-KPC GEMM, the depletion of stroma creates a therapeutic opportunity for checkpoint blockers such as PD1. Clinical trials involving GVAX (allogeneic pancreatic cancer cells modified to express GM-CSF) alone and/or in combination with CRS207 (live attenuated Listeria monocytogenes expressing mesothelin) have shown positive outcomes and generated excitement among the immunotherapy community. Other immune-modulating therapies currently being tested and showing some efficacy include the adaptive T-cell therapy such as the mesothelin chimeric antigen receptor (CAR) T-cell therapy. (aSMA) $\alpha$-Smooth muscle actin.

In cell culture studies, human PSCs stimulate proliferative, migratory, and invasive activity of PDAC cancer cell lines, and, similarly, orthotopic coinjection of human PSCs and PDAC cancer cells stimulates aggressive tumor progression and metastasis (Hwang et al. 2008; Xu et al. 2010). Moreover, excessive desmoplastic responses, together with a hypovascular microenvironment, have been proposed as a basis for chemoresistance and protection against the host immune system (Bissell and Radisky 2001).

Recently, the vitamin D receptor (VDR) was identified as a master transcriptional inhibitor of the PSC activation state and found to be overexpressed in human and mouse PSCs during PDAC progression. Hypothesizing that VDR may provide a novel therapeutic target for PDAC, Sherman et al. (2014) explored the potential of the VDR ligand, calcipotriol in a murine cerulein-induced pancreatitis model, demonstrating marked reduction in fibrosis. In a GEMM of PDAC, orthotopic allograft growth was im- paired with combined treatment of calcipotriol and gemcitabine, resulting in a $57 \%$ increase in survival relative to gemcitabine treatment alone. Correspondingly, the combination treatment decreased stromal fibrosis and increased intratumoral gemcitabine availability (Sherman et al. 2014).

Along similar lines, the PDAC stroma also contains a large amount of hyaluronic acid, a matrix glycosaminoglycan that increases interstitial fluid pressure and promotes hypovascularity, which impairs perfusion and diffusion and may cause inefficient drug delivery (Toole 2004). Accordingly, intravenous delivery of pegylated hyaluronidase (PEGPH20) has been shown to decrease interstitial fluid pressure in the stroma, increase vascularity, and improve drug delivery in a GEMM of PDAC (Provenzano et al. 2012).

While these and other studies support the view that the stroma plays a vital role in PDAC initiation and 
progression, three recent genetic studies have concluded that the stroma (or at least certain components such as myofibroblasts) serves to restrain rather than promote PDAC progression by facilitating host immune response and opposing vascularization (Lee et al. 2014; Ozdemir et al. 2014; Rhim et al. 2014a). Employing a sophisticated ganciclovir-induced ablation system, Ozdemir et al. (2014) showed that somatic depletion of $\alpha_{S M A}{ }^{+}$myofibroblasts in a GEMM of PDAC carrying a thymidine kinase gene under the control of the aSMA promoter results in more aggressive tumors with prominent stem cell and EMT features, high invasiveness, increased hypoxia, and reduced survival. In this setting, anti-CTLA4 (cytotoxic T-lymphocyte-associated protein 4) therapy reversed this phenotype and increased survival, suggesting that tumor stroma may play important roles in immune modulation and that stroma depletion creates vulnerability for immune checkpoint therapy. In second set of studies, the genetic deletion of the Shh gene in a GEMM of PDAC decreased myofibroblast content, causing increased vascularity, poorly differentiated histology, and increased cancer cell proliferation. These genetic observations align with an earlier study in which a Kras-driven PDAC GEMM treated with a Smoothened inhibitor, vismodegib, experienced enhanced tumor progression and shortened survival. Furthermore, a VEGFR inhibitor reversed the aggressive phenotype, suggesting that the SHH-supported stroma suppresses tumor growth partly by restraining tumor vascularization (Rhim et al. 2014a). Finally, a third study employing pharmacological inhibition of $\mathrm{Hh}$ signaling showed a reduction in the desmoplastic stroma and a more aggressive progression of PanIN lesions. This phenotype could be reversed by a small molecule agonist of $\mathrm{Hh}$ that caused stromal hyperplasia and a corresponding reduction in epithelial proliferation (Lee et al. 2014). Together, these studies highlight the complexity of the PDAC stroma and underscore the need for deep experimentation investigating the role of each stromal component and the complex homotypic and heterotypic signaling interactions in the PDAC microenvironment. Such knowledge may illuminate new avenues for therapy (Bijlsma and van Laarhoven 2015).

\section{Immune components of the pancreatic cancer microenvironment}

Inflammation plays a pivotal role in cancer initiation, progression, invasion, and metastasis (Strobel et al. 2007; Greer and Whitcomb 2009; Solinas et al. 2010; Coffelt and de Visser 2014). In PDAC research, data derived from mouse models, human genetic studies, and clinical and epidemiological investigations have established a modest link between pancreatitis and an increased risk of pancreatic cancer development (i.e., 5\% of patients will develop PDAC over a 20-year period following pancreatitis) (Guerra et al. 2007). Most compelling is the dramatic increase in PDAC in the setting of familial pancreatitis (Malka et al. 2002; Raimondi et al. 2009), in which there is a 69-fold lifetime risk of PDAC in heredi- tary pancreatitis with germline mutations of either PRSS1 or SPINK1 (Becker et al. 2014). Local inflammation may also play a major role in modulating the function of the host immune system in the tumor microenvironment. Here, we summarize the resident immunocytes and their function in PDAC biology.

\section{Tymphocytes}

$\mathrm{T}$ cells constitute the major cellular components of the adaptive immune system and serve to identify nonself antigens that are presented by antigen-presenting cells (APCs) such as dendritic cells. Upon activation by APCs, $T$ cells proliferate and migrate to the site of antigens and perform distinct functions such as cell-mediated cytotoxicity by $\mathrm{CD}^{+}$cytotoxic $\mathrm{T}$ lymphocytes or cytokine production by $\mathrm{CD}^{+} \mathrm{T}$-helper lymphocytes. The presence of $\mathrm{CD}^{+}$effector $\mathrm{T}$ cells (also loosely known as tumor-infiltrating lymphocytes [TILs]) correlates with improved prognosis across many cancer types, including melanoma and cancers of the head and neck, prostate, lung, colon, breast, bladder, and ovary. In human PDAC, the TIL numbers are quite variable and are likely impacted by mutation load in the individual tumor. The problem is likely to be a function of TIL cell activation due to the presence of MDSCs, $\mathrm{T}_{\text {reg }}$ cells, and immune-suppressive cytokines dominating the tumor microenvironment. PDAC mouse models exhibit few TILs and poor anti-tumor immune response (Fogar et al. 2006; Feig et al. 2013). One explanation for poor $\mathrm{CD}^{+} \mathrm{T}$-cell infiltration may be the general lack of neoantigen in PDAC. In contrast to the abundance of mutation-induced neoantigen formation in other major KRAS-driven cancers such as lung and colorectal cancers, the mutational load in PDAC falls below one mutation per megabase, a threshold less likely to express neoantigens that can be recognized by autologous T cells (Alexandrov et al. 2013; Schumacher and Schreiber 2015). Moreover, the function of TILs is largely suppressed in the tumor microenvironment.

As the major modulator for $\mathrm{CD}^{+} \mathrm{T}$ cell's function, the role of $\mathrm{CD}^{+} \mathrm{T}$ cells in PDAC is complicated by many CD4 $^{+}$T-cell variants such as $T_{h} 1, T_{h} 2$, and $T_{h} 17$ cells. The determination of the effector $T_{h} 1$ or $T_{h} 2$ cell response is dependent on the cytokine environment at the tumor site, such as the presence of IL2 and IL12, which trigger a $T_{h} 1$ response, while IL 4 triggers a $T_{h} 2$ response. The importance and immunosuppressive nature of dominant $\mathrm{CD}^{+} \mathrm{T}$-cell subpopulations in PDAC is underscored by observations that depletion of $\mathrm{CD}^{+} \mathrm{T}$ cells in an inducible Kras-driven PDAC GEMM blocks PanIN formation largely through the activation of $\mathrm{CD}^{+} \mathrm{T}$ cells (Zhang et al. 2014c). Indeed, $\mathrm{T}_{\mathrm{h}} 2$-type cells are found to reside in the PDAC microenvironment and suppress the function of $\mathrm{CD}^{+} \mathrm{T}$ cells by producing cytokines such as IL-4, IL-5, and IL-10 (Tassi et al. 2008; De Monte et al. 2011). In contrast to the protumor activity of $T_{h} 2$ cells, $T_{h} 1$ cells likely antagonize tumor growth through the production of IL-2 and IFN- $\gamma$, an essential step for induction of cellular immunity, and both are required for proliferation and activity of $\mathrm{CD}^{+} \mathrm{T}$ cells /Ostrand-Rosenberg 2008; Joyce 
and Pollard 2009). Consistent with the opposing roles of $T_{h} 1$ and $T_{h} 2$ cells, the $T_{h} 1 / T_{h} 2$ ratio is essential for net outcome of the immune response in PDAC (Chen et al. 2010; De Monte et al. 2011; Ochi et al. 2012).

Besides $T_{h} 2$ cells, another major type of immunosuppressive $\mathrm{T}$ cell is the $\mathrm{T}_{\text {reg }}$ cell, which is also abundant in the PDAC microenvironment (Fig. 2; Nummer et al. 2007; Zhang et al. 2014c). While $\mathrm{T}_{\text {reg }}$ cells function primarily as suppressors of host innate and adaptive immunity via production of granzyme B, which further inhibits NK cells (Cao et al. 2007) and B cells (Gondek et al. 2005) and perturbs the maturation of dendritic cells (Tadokoro et al. 2006), $T_{\text {reg }}$ cells may also directly promote tumor progression by secretion of protumorigenic cytokines such as the receptor activator of NF- $\mathrm{BB}$ (RANK) ligand, TGF $\beta 1$, TNFa, and IL-6 (Byrne et al. 2011). The number of $\mathrm{T}_{\text {reg }}$ cells in the tumor correlates positively with advancing histological grade and increased lymph node metastasis (Jiang et al. 2014). In addition, increased levels of $T_{\text {reg }}$ cells and MDSCs are associated with more poorly differentiated tumors (Shibuya et al. 2014). A number of factors attract, convert, and expand $\mathrm{T}_{\text {reg }}$ cells in the tumor microenvironment. For example, tumor hypoxia promotes production of chemokine CCL28 by the cancer cells, which drives $\mathrm{T}_{\text {reg }}$ cell recruitment via the CCL28-CCR10 (CC-chemokine receptor 10) axis (Facciabene et al. 2011). TGF $\beta$ produced by the PDAC stroma can also drive the conversion and expansion of $\mathrm{T}_{\text {reg }}$ cells from conventional $\mathrm{CD}^{+}{ }^{+} \mathrm{T}$ cells in the tumor microenvironment, and this process can be blocked by systemic injection of anti-TGF $\beta$ antibody (Moo-Young et al. 2009). While the exact function of $T_{\text {reg }}$ cells in PDAC development remains to be established using in vivo models, depletion of $\mathrm{T}_{\text {reg }}$ cells with cyclophosphamide has been shown to enhance the inflammatory response induced by a cancer vaccine targeting oncogenic Kras in a Kras-driven PDAC GEMM (Keenan et al. 2014). Compared with the anti-immunity function of $\mathrm{T}_{\mathrm{h}} 2$ and $\mathrm{T}_{\text {reg }}$ cells, the role of $\mathrm{T}_{\mathrm{h}} 17 \mathrm{~T}$ cells in PDAC remains unclear. Although $\mathrm{T}_{\mathrm{h}} 17$ cells have been shown to promote $\mathrm{CD} 8^{+} \mathrm{T}$-cell activation and inhibit tumor growth in a lung melanoma mouse model (Martin-Orozco et al. 2009), $\mathrm{T}_{\mathrm{h}} 17$ cells were found to be required for tumor initiation and progression in a Krasdriven PDAC model through signaling via a hematopoeitic-epithelial axis (McAllister et al. 2014). Understanding these tumor type-specific differences would be useful in accurately prosecuting anti- $\mathrm{T}_{\mathrm{h}} 17$ therapeutic opportunities in the clinic.

\section{MDSCs and TAMs}

Along with $\mathrm{CD}^{+} \mathrm{T}$ cells, MDSCs and TAMs appear to play important regulatory roles in the activation of effector T cells (Fig. 2). Tumor-associated MDSCs are a heterogeneous population of mostly immature cells with immune-suppressive function and are defined by myeloid origin and precursors of granulocytes, macrophages, dendritic cells, and monocytes. MDSC characteristics also include expression of extracellular degradation enzymes, reactive oxygen and nitrogen species, chemokines, and cytokines (Gabrilovich et al. 2001). MDSCs primarily medi- ate immune suppression through inhibition of the T cell's anti-tumor functions by mechanisms that include (1) producing nitric oxide (NO) and ROS such as peroxynitrite and hydrogen peroxide, which cause T-cell apoptosis; (2) interfering with cytokine signaling, such as IFN $\gamma$, which is crucial for T-cell anti-tumor activity and functions; (3) inhibiting T-cell migration to the tumor site by nitration of chemokines, such as CCL2, and T-cell receptors (TCRs); (4) depriving $\mathrm{T}$ cells of essential metabolites such as arginine and cysteine by increasing arginase activity; and (5) mediating T-cell anergy by activation of $\mathrm{T}_{\text {reg }}$ cells (Bogdan 2001; Ezernitchi et al. 2006; Huang et al. 2006; Rodriguez and Ochoa 2006; Ostrand-Rosenberg 2010; Srivastava et al. 2010; Mundy-Bosse et al. 2011). Experimental support of the immunosuppressive function of MDSCs derives from anti-Ly6G antibody depletion of MDSCs in an autochthonous GEMM of PDAC, which increased $\mathrm{CD}^{+} \mathrm{T}$-cell infiltration and activation and induced cancer cell apoptosis (Stromnes et al. 2014).

During tumor development, MDSCs migrate from their normal residence in the bone marrow to secondary and tertiary lymphoid organs, peripheral blood, and the tumor microenvironment (Strober 1984; Bronte et al. 1999). MDSC migration and expansion to peripheral organs and tumor microenvironment are stimulated by secretory factors released from cancer cells and their surrounding stroma. In PDAC, MDSC infiltrations are observed as early as the preinvasive PanIN lesions and progressively increase throughout the evolution of the tumor (Clark et al. 2007; Zhao et al. 2009; Zhang et al. 2014b). G-CSF and GM-CSF (Bayne et al. 2012; Pylayeva-Gupta et al. 2012); IL-3, M-CSF, and IL-6 (Serafini et al. 2006); and CCL2 chemokine (Tjomsland et al. 2011) have been shown to be released by PDAC cancer cells to promote MDSC recruitment to the tumor microenvironment (Porembka et al. 2012) and suppress antigen-specific T cells. G-CSF and GM-CSF expression is driven by oncogenic KRAS via the RAS/MEK/MAPK pathway through the ETS transcription factor (Bayne et al. 2012); correspondingly, MEK or PI3K inhibitors can attenuate the release of G-CSF and improve survival in an orthotopic allograft mouse model established by injecting primary ductal epithelial cells (PDECs) isolated from a GEMM of PDAC into the pancreata of syngeneic $\mathrm{C} 57 \mathrm{Bl} / 6$ mice (Cox and Olive 2012; Pylayeva-Gupta et al. 2012).

TAMs are another prominent population of myeloid cells in the PDAC tumor microenvironment (Hermano et al. 2014). A distinct characteristic of TAMs is their plasticity and polarizability between the proinflammatory M1 phase and anti-inflammatory M2 phase. TAMs originate from circulating monocytes upon activation by CCL2, a chemotactic chemokine secreted by PDAC cancer cells (Baumgart et al. 2013). Similar to MDSCs, TAMs can also be recruited to the tumor microenvironment by cytokines such as M-CSF and VEGF expressed by pancreatic cancer cells (Pollard 2004). In addition, PDAC cancer cells secrete heparenase, which is associated with increased TAM infiltration in human and mouse PDAC (Hermano et al. 2014). These tumor-derived factors can promote the M2 polarized TAM phenotype (Mantovani et al. 
2002, 2004), and M2 TAMs in turn promote tumor growth by secreting immunosuppressive factors such as IL10, arginase I, and TGF $\beta$ to block effector T-cell activation (Biswas and Mantovani 2010). TAMs also express scavenger receptors such as CD206 and CD163, which facilitate tumor angiogenesis and migration (Movahedi et al. 2010; Laoui et al. 2011). These factors are associated with worse prognosis and increased metastasis. TAMs express the chemokine receptors CCR2 and CSF1R, which interact with CCL2 (Mitchem et al. 2013). Inhibitors of CCR2 or CSF1R, while used in combination with gemcitabine treatment, resulted in effective depletion of TAMs and increased infiltration of $\mathrm{CD}^{+} \mathrm{T}$ cells, leading to significantly blunted tumor growth in a syngeneic orthotopic model of PDAC (Mitchem et al. 2013; Zhu et al. 2014). On the other hand, when TAMs acquire a classical M1 phenotype, they can function to oppose tumor growth in PDAC by production of proinflammatory cytokines and presentation of antigen to T cells (Mantovani et al. 2002; Mantovani and Sica 2010). In PDAC patients with a high density of TAMs at the tumor-stroma interface, chemotherapy treatment modulated TAMs to acquire an anti-tumor phenotype and was associated with improved clinical outcome (Klug et al. 2013; Di Caro et al. 2015).

\section{Inflammatory cytokines and chemokines}

The PDAC tumor microenvironment produces a complex mix of cytokines that collectively favor tumor growth and metastasis. Proinflammatory and anti-inflammatory cytokine production is increased in PDAC and acts on cancer cells and other cells in the tumor microenvironment (Ling et al. 2012). Specifically, proinflammatory cytokines such as IL6, TNFa, MIF, IL-1 $\beta$, and IL8 play critical roles in proliferation, angiogenesis, invasion, migration, and EMT (Miron et al. 2010; Lesina et al. 2011; Dima et al. 2012; Funamizu et al. 2013), whereas anti-inflammatory cytokines such as TGF $\beta$ and IL10 are involved in immune evasion and immune tolerance.

IL6 is a well-studied protumor cytokine that plays prominent and diverse roles in PDAC progression. Oncogenic KRAS induces secretion of IL6, which is essential for maintenance and progression of PDAC through both cellautonomous and paracrine mechanisms (Fig. 2), as genetic or pharmacological inhibition of IL6 eliminates KRASdriven tumorigenesis (Ancrile et al. 2007; Zhang et al. 2013b). For example, IL6 cooperates with oncogenic KRAS to amplify MAPK/ERK signaling. In addition, IL6 is required for oxidative defense in PDAC, as the KRASmediated IL6 pathway activates the ROS detoxification program, leading to cancer cell survival and generation of a protumorigenic microenvironment (Ancrile et al. 2007; Zhang et al. 2013b). Elevated circulating IL6 is observed in advanced PDAC and correlates with poor survival and cancer cachexia (Bellone et al. 2006b; Holmer et al. 2014), prompting its use as a biomarker for cancer cachexia (Scheede-Bergdahl et al. 2012). Furthermore, IL6 is secreted by myeloid cells in the tumor microenvironment and promotes activation of the Stat3/Socs3 pathway via IL6 trans-signaling in the development of early PanIN le- sions and in more advanced PDAC (Fig. 2; Lesina et al. 2011). Furthermore, IL6, along with TGF $\beta$ and IL10, creates an immunosuppressive tumor microenvironment by inhibition of dendritic cell proliferation and function (Bellone et al. 2006a). These many functions of IL6 elevate the need for its further study as a key therapeutic target in PDAC. A multidose, phase I/II dose escalation study to assess the safety, efficacy, and pharmacokinetics of intravenous anti-IL6 antibody (siltuximab) has been recently completed for multiple solid tumors, including PDAC, and is awaiting final analysis (clinical trial information: NCT00841191). Another approach is to use JAK inhibitors that block the IL6-induced STAT3 pathway. Indeed, a randomized, double-blind, phase II study of an antiJAK1/JAK2 inhibitor (ruxolitinib) in combination with capecitabine showed improved survival in patients with metastatic PDAC that failed gemcitabine therapy (Hurwitz et al. 2015).

\section{Prospect of PDAC immunotherapy}

In evaluating the immune biology and immune therapy opportunities for PDAC, it is important to appreciate that a key aspect of anti-tumor immunity is the effector to tumor ratio (i.e., the level of the functioning effector $\mathrm{T}$ cells present in the vicinity of the cancer cell). Multiple factors can affect effector T-cell infiltration, survival, proliferation, and cytotoxic activity. Heterotypic interactions among different immune effector cells in the tumor microenvironment challenge our ability to fully understand the basis for reduced T-cell activation in PDAC. While one perspective posits that PDAC is a nonimmunogenic tumor that displays a paucity of antigens to be recognized as foreign by the host immune system, the presence of peripheral $\mathrm{T}$ cells specific for an abundant PDAC antigen, mesothelin, and the lack of these T cells in the tumor microenvironment are consistent with the existence of local immunosuppression (Johnston et al. 2009).

Many studies have now demonstrated the importance of $\mathrm{T}$ cells in anti-tumor immunity and the profound clinical benefits of T-cell-based immunotherapy in many cancer types by harnessing the cytotoxic potential of $\mathrm{T}$ cells (Houot et al. 2015). This has led to the development of numerous therapies tailor-made to activate T-cell proliferation or function, including T-cell checkpoint inhibitors such as anti-CTLA4 and anti-PD1/PD-L1 (programmed cell death 1 ligand 1), which have revolutionized the treatment of melanoma, renal cell carcinoma, and lung cancer and show promising clinical responses in other cancer types (Sharma and Allison 2015). However, a notable exception to checkpoint blockade success is PDAC, where treatment of PDAC patients with the single agent checkpoint inhibitors ipilimumab (anti-CTLA-4 antibody) or nivolumimab (anti-PD1/PD-L1 antibody) has been disappointing and without survival benefit despite the observation of PD1 expression in such patients (Nomi et al. 2007; Brahmer et al. 2010; Royal et al. 2010). Interestingly, recent work in Kras-driven PDAC GEMMs has shown that depletion of tumor stroma or targeting Cxcl12 from tumor-associated fibroblasts exhibits a synergistic effect 
with immune checkpoint therapies (Feig et al. 2013; Ozdemir et al. 2014), suggesting that conditioning of the PDAC stroma might be a prerequisite for attaining therapeutic responses to immunotherapies. In addition, stroma-derived Cxcl13 has been shown to induce the infiltration of B-cell subpopulations and promote tumor growth, likely through programming TAMs toward an M2 phenotype (Gunderson et al. 2015; Lee et al. 2015; Pylayeva-Gupta et al. 2015). Importantly, targeting Bruton's tyrosine kinase (BTK), a key kinase for B-cell and TAM function, suppresses tumor progression in an orthotopic PDAC mouse model through the induction of TILs (Gunderson et al. 2015). These preclinical data strongly support the ongoing clinical trials combining inhibitors of BTK and checkpoint blockade.

A path forward has been suggested by recent work showing that a therapeutic cancer vaccine, GVAX, may stimulate immune responses in PDAC (Le et al. 2013), supporting the idea that nonimmunogenic tumors can be converted to more immunogenic ones via T-cell priming with vaccination. GVAX is an irradiated allogeneic PDAC cell line that expresses GM-CSF, which is administered into patients with a low dose of cyclophosphamide to eliminate $T_{\text {reg }}$ cells. In these patients, post-GVAX treatment revealed intratumoral tertiary lymphoid aggregates, and microarray analysis of those aggregates revealed a gene expression signature of immune cell activation and trafficking. T-cell infiltration was associated with up-regulation of immunosuppressive regulatory mechanisms, including up-regulation of the PD-1/PD-L1 pathway, an observation that suggests that a combination of cancer vaccine and immune checkpoint blockade might facilitate effector T-cell function (Lutz et al. 2014). In a recent early stage clinical trial, combination of GVAX with another vaccine, CRS-207, led to improved outcome in previously treated PDAC patients with metastatic disease (Fig. 2; Le et al. 2015). CRS-207 is a live attenuated form of Listeria monocytogenes engineered to promote the expression of mesothelin and induce both innate and adaptive immunity. Strikingly, overall survival in pretreated PDAC patients receiving combination GVAX/CRS-207 therapy was significantly longer $(6.1 \mathrm{mo})$ compared with GVAX alone (3.9 mo), a meaningful improvement in the treatment of previously refractory metastatic PDAC, where many other therapies have failed (clinical trial information: NCT02243371) (Le et al. 2015).

An alternative T-cell therapy approach uses cloned TCR or chimeric antigen receptor (CAR) therapy, in which autologous $\mathrm{T}$ cells are isolated from a patient, and their TCRs are modified to recognize the cancer cell antigen. These modified T cells are then transferred back into the patient. Robust clinical responses have been observed in a number of cancer types such as chronic lymphocytic leukemia and B-cell lymphoma (Lee et al. 2012; Kochenderfer and Rosenberg 2013). Although TCRs against mesothelin, a native antigen highly expressed in PDAC, exhibited a promising survival benefit in a Kras-driven PDAC GEMM (Stromnes et al. 2015), the effectiveness of these engineered T-cell therapies for human tumors remains to be determined. While multiple clinical trials are ongoing to test the safety and anti-tumor effects of various anti-mesothelin-based CARs in PDAC patients /clinical trial information: NCT01583686, NCT02465983, and NCT02580747), a phase I trial in six PDAC patients indicated that it was well tolerated (Fig. 2; Beatty et al. 2015). Another potential tool is endogenous T-cell therapy, a strategy used effectively in melanoma, where antigen-specific $\mathrm{T}$ cells are isolated from peripheral blood, enriched and expanded ex vivo, and infused into patients (Hunder et al. 2008; Yee 2014).

Beyond PD1/PD-L1 and CTLA4 checkpoint blockers, other ongoing modulation strategies focusing on immune checkpoints include targeting additional coinhibitory molecules (Lag-3, TIM-3, VISTA, etc.), costimulatory molecules (4-1BB, OX40, CD27, GITR, etc.) and indoleamine2,3-dioxygenase (IDO) (Colombo and Piconese 2007; Pardoll 2012; Moran et al. 2013; Lines et al. 2014). One ongoing trial is testing the use of IDO inhibitors in PDAC. IDO is a tryptophan-metabolizing enzyme targeting the kynurenine pathway, whose products, tryptophan metabolites, are toxic to effector $\mathrm{T}$ cells, thereby creating an immunosuppressive microenvironment in tumors by increasing $\mathrm{T}_{\text {reg }}$ cell survival (Witkiewicz et al. 2008; Lob et al. 2009). Moreover, studies show that IDO expression in PDAC is associated with poor disease outcome and correlates with aggressive disease progression (Godin-Ethier et al. 2011). In a preclinical study, IDO inhibition increased Tcell response and showed a synergistic effect along with chemotherapy (Muller et al. 2005). A phase Ib clinical trial is currently evaluating the IDO inhibitor indoximod in combination with nab-paclitaxel plus gemcitabine in advanced PDAC (clinical trial information: NCT02077881).

\section{Major frontiers and opportunities}

The vast knowledge accumulated for PDAC research in recent years has laid a strong foundation of discoveries with the potential for practice-changing advances. Given the rising incidence of disease, current efforts must now focus on accelerating the translation of such knowledge into early detection diagnostics and truly effective therapeutics with a survival benefit.

Due to the low incidence of PDAC in the general population, screening for asymptomatic early stage cancers is not feasible. Rather, we propose smart screening strategies that incorporate major risk factors, including a strong family history of PDAC with two or more first-degree relatives (FDRs) (Canto et al. 2013), germline-predisposing mutations such as BRCA2 or PALB2, familial pancreatitis, patients with mucinous pancreatic cysts, and those with new-onset diabetes in the elderly population. PDAC is a diabetogenic cancer, with $50 \%-66 \%$ of cancers associated with paraneoplastic hyperglycemia irrespective of the volume of disease and loss of pancreatic parenchyma. This newly recognized subtype of pancreatogenic or type $3 \mathrm{c}$ diabetes provides an unprecedented opportunity for early diagnosis of PDAC, as one in 100 elderly new-onset diabetics will harbor an occult malignancy (Andersen 2013; Sah et al. 2013). The ideal early detection diagnostic 
strategy will likely use multiple biomarkers of various analytes and also incorporate confirmatory dynamic imaging with robust specificity for high-risk PanINs and early PDAC lesions. Rapid progress in biomarker discovery is now possible as a result of in-depth genomic, proteomic, transcriptomic, and metabolomic profiles of human PDAC as well as faithful GEMMs of PDAC, which have proven to be effective filters in the prioritization of these myriad human PDAC biomarkers.

This fast-evolving area is converging on the development of "liquid biopsy" strategies, including the detection and molecular profiling of CTCs with EMT features that likely represent more advanced precursor lesions (Rhim et al. 2012; Qu et al. 2015). Cell-free circulating tumor DNA (ctDNA) offers another avenue for the development of blood-based material for the detection of cancer-associated mutations. Indeed, ctDNA and associated KRAS mutations have been detected in almost half of the pancreatic cancer patients, including patients with localized PDAC (Bettegowda et al. 2014; Sausen et al. 2015). However, given that PDAC signature mutations, specifically KRAS, are also found in low-grade precursors such as PanIN1 (Kanda et al. 2012), the development of a clinically useful ctDNAbased diagnostic for the detection and monitoring of PanIN2/3 and PDAC and their associated mutations will require a combination of markers specific for these pancreatic lesions. Along these lines, the glycoprotein GPC1 was recently identified on the surface of serum exosomes from pancreatic cancer patients and patients with precursor lesions such as noninvasive IPMN with high sensitivity and specificity (Melo et al. 2015). Significantly, oncogenic KRAS mutations were found exclusively in $\mathrm{GPC}^{+}$, but not $\mathrm{GPC1}^{-}$, exosomes. Moreover, genetic alterations spanning the whole tumor genome have been identified in these serum-derived exosomes (Kahlert et al. 2014), underscoring the potential translational significance of exosome-based detection methods combined with genetic profiling for accurate detection and profiling of much earlier stage malignancies. Finally, cross-species serum proteomic analysis has proven to be another productive avenue for the identification of novel protein biomarkers that can detect early PDAC neoplasms well before the onset of clinical signs and symptoms of PDAC (Faca et al. 2008; Day et al. 2015; Mirus et al. 2015). Such protein biomarkers may add sensitivity and specificity when combined with ctDNA and exosome strategies and accelerate the development of reliable early detection and liquid biopsy technologies.

In addition, novel probes need to be developed for molecular imaging to target tumor-specific surface proteins, metabolites, enzymatic reactions, or infiltrating cells specific for the tumor microenvironment. While many biomarkers will emerge from such efforts, a concerted effort is needed to convert these biomarkers into a robust diagnostic for use in the clinic and at-risk populations. Such efforts will require strong academia-industry partnerships for the stringent prospective validation of such markers in large clinical samples as well as sufficient resources for the full development and commercialization of the diagnostic - both elements need to be addressed to bridge the valley of death in the development of tests for early PDAC detection.

On the therapeutic front, recent advancements in the development of targeting strategies against oncogenic drivers, epigenetic programs, DDR pathways, tumor metabolism, and immune modulation have offered unprecedented opportunity to break the current status quo of PDAC treatment. However, significant knowledge gaps remain to be filled to inform smart clinical trials with patient responder and target engagement biomarkers.

(1) While the development of agents that directly target oncogenic KRAS could be anticipated in the future, our knowledge on the roles of various KRAS mutations during PDAC development/maintenance, the dependency on their signaling surrogates, and the developmental stage and microenvironment factors influencing KRAS dependency remains largely superficial in PDAC. In-depth studies using robust model systems, including GEMMs and genetically edited primary human organoid or PDX models, are needed to understand the function of driving pathways in various genetic contexts and elucidate mechanisms leading to resistance upon targeting oncogenic drivers. Given that oncogenic KRAS will likely be successfully targeted in the near future, drug development should also include targeting these bypass mechanisms for combination therapies. Finally, additional efforts are also needed toward unveiling the epidemiology and molecular underpinning of KRAS wild-type PDACs.

(2) While the epigenetic pathway components are frequently targeted during PDAC development, further investigation is needed to define their specific contributions to tumor genesis and maintenance. Moreover, the characterization of the functional interaction between the oncogenic KRAS pathway and mutant epigenetic regulators may inform the development of novel combinatory strategies. The development of small molecule inhibitors for BET domain proteins and other key components of transcriptional machinery such as CDK7 and CDK9 has made it possible to target transcriptional programs for cancer therapy. One key issue is to understand how these transcriptional modulators are involved in defining the biological phenotype of PDAC_-such as deregulated proliferation/apoptosis, metabolism reprogramming, and immune modulation-and identify the associated master transcriptional factors. In addition, knowledge on how epigenetic reprogramming and transcriptional modulation may hijack normal pancreatic development programs will offer novel actionable targets specific for PDAC cells. It has been shown in an inducible Kras-driven PDAC GEMM that the resistance to Kras extinction in the TIC subpopulation is not due to acquisition of genetic alterations (Viale et al. 2014), indicating that such subclones are likely driven by epigenetic modulations. Defining the epigenetic regulators in the TIC population versus bulk tumors will certainly help in designing more effective targeting strategies. It is clear that the 
tumor microenvironment, including stroma and immune infiltration, plays an important role for tumor development and therapeutic responses. While the dynamic change of the tumor microenvironment is mostly regulated at the epigenetic level, the molecular mechanism remains largely unknown. It is critical to identify the epigenetic drivers that mediate the remodeling of the tumor microenvironment and understand their cross-talk with tumor cells.

(3) Deep analysis of PDAC metabolism programs has revealed multiple tumor-specific pathways for nutrient utilization such as the activation for the nonoxidative PPP for nucleotide biosynthesis and the novel GOT1dependent mechanism for redox homeostasis. Such PDAC-specific metabolism rewiring has provided unique and targetable vulnerabilities. However, given the highly adaptive nature of metabolism regulation, it is critical to characterize the coping mechanisms upon targeting key metabolism pathways to provide rational anti-metabolism combinations. An alternative approach to directly targeting cancer-specific metabolism pathways would be targeting the oncogenic signaling pathways that drive metabolism reprogramming, including the oncogenic KRAS pathway. At the same time, the identification of TIC subpopulations resistant to KRAS extinction and their unique oxidative metabolism features clearly indicates that the targeted approaches should be used in conjunction with OXPHOS or autophagy inhibitors to eliminate both KRAS-dependent bulk cancer cells and these KRAS extinction-resistant TICs.

(4) The lack of meaningful responses to date for PDAC immunotherapy trials points to the urgent need to understand patient response mechanisms. More emphasis is required to exhaustively profile the dynamic population of intratumoral immune cells using modern tools such as CyTOF, stratification of tumors based on immune cells (Immunoscore), and PanCancer Immune Profiling Panel in both preclinical and clinical settings. In addition, it remains to be addressed how the oncogenic KRAS pathway may lead to the immune evasion of PDAC cells. The involvement of tumor metabolism and epigenetic programs in PDAC immune modulation is also an uncharted area. Combinatory targeting of PDAC-specific oncogenic signaling, metabolism programs, or epigenetic pathways may help to improve or thwart the efficacy of immunotherapy.

(5) In addition to immune checkpoint therapies, we need to expand our efforts to include other immunotherapy modalities, such as the adoptive T-cell therapies (CAR and TCR therapies) as well as DNA-based, peptidebased, and autologous dendritic cell-based vaccines. We need to engineer novel CARs with new T-cell specificities based on the PDAC antigens, increase in vivo persistence by humanizing Fcv built-in costimulatory anchors into the CAR, and prevent toxicity by incor- porating inducible suicide genes. We also need to pay attention to other T-cell immunomodulators-such as $4-1 \mathrm{BB}, \mathrm{OX} 40$, GITR, CD27, vista, Lag-3, and Tim3 - to re-energize the pre-existing cytotoxic $\mathrm{T}$ cells. Also, a rational combination of immunotherapy needs to be explored to treat nonresponsive tumors and broaden the therapeutic window. A recent success in the combination of vaccines with checkpoint blockers (GVAX/CRS-207 + anti-CTLA4) provides some optimism in that direction (Le et al. 2015).

Overall, current technology development has allowed in-depth molecular profiling of patient samples, including blood and tumor samples, for the detailed characterization of systematic and local alterations in tumor cells, the stroma, and infiltrating immune cells. These comprehensive characterizations should be included in all future clinical trials for serial analysis in real time of the response to various therapies. Such information will also be instructive for patient stratification and prediction of therapeutic responses. We have made significant advances during the last decade in understanding the genetics and biology of PDAC. The focus for the coming decade is to translate our knowledge into meaningful patient benefit.

\section{Acknowledgments}

We thank Alan Wang and Denise Spring for critical reading of the manuscript and insightful comments. H.Y. and G.F.D. are supported by the Sheikh Ahmed Center for Pancreatic Cancer Research and Pancreatic Cancer Moon Shot at the University of Texas MD Anderson Cancer Center. H.Y. is also supported by University of Texas Star Award. P.D. is supported by W81XWH-14-1-0429 (Department of Defense). W.Y. is supported by an Odyssey Fellowship and the Anne Eastland Spears Fellowship in GI Cancer Research at the University of Texas MD Anderson Cancer Center. A.C.K. is supported by RSG-13-298-01-TBG (American Cancer Society), R01GM095567, R01CA157490, and R01CA188048 (National Institutes of Health). G.F.D. is supported by 14-90-25-DRAE (American Association for Cancer Research) and W81XWH-11-1-0418 (Department of Defense). A.M. is supported by U01DK108328 and U01CA196403 (National Institutes of Health). R.A.D is supported by P01CA117969 (National Institutes of Health).

\section{References}

Aguirre AJ, Bardeesy N, Sinha M, Lopez L, Tuveson DA, Horner J, Redston MS, DePinho RA. 2003. Activated Kras and Ink4a/ Arf deficiency cooperate to produce metastatic pancreatic ductal adenocarcinoma. Genes Dev 17: 3112-3126.

Aguirre AJ, Brennan C, Bailey G, Sinha R, Feng B, Leo C, Zhang Y, Zhang J, Gans JD, Bardeesy N, et al. 2004. High-resolution characterization of the pancreatic adenocarcinoma genome. Proc Natl Acad Sci 101: 9067-9072.

Alagesan B, Contino G, Guimaraes AR, Corcoran RB, Deshpande V, Wojtkiewicz GR, Hezel AF, Wong KK, Loda M, Weissleder $\mathrm{R}$, et al. 2015. Combined MEK and PI3K inhibition in a mouse model of pancreatic cancer. Clin Cancer Res 21: 396-404.

Alexandrov LB, Nik-Zainal S, Wedge DC, Aparicio SA, Behjati S, Biankin AV, Bignell GR, Bolli N, Borg A, Borresen-Dale AL, 
et al. 2013. Signatures of mutational processes in human cancer. Nature 500: 415-421.

Alvarez-Calderon F, Gregory MA, Pham-Danis C, DeRyckere D, Stevens BM, Zaberezhnyy V, Hill AA, Gemta L, Kumar A, Kumar V, et al. 2015. Tyrosine kinase inhibition in leukemia induces an altered metabolic state sensitive to mitochondrial perturbations. Clin Cancer Res 21: 1360-1372.

Amaravadi RK, Yu D, Lum JJ, Bui T, Christophorou MA, Evan GI, Thomas-Tikhonenko A, Thompson CB. 2007. Autophagy inhibition enhances therapy-induced apoptosis in a Myc-induced model of lymphoma. J Clin Invest 117: 326-336.

Ancrile B, Lim K-H, Counter CM. 2007. Oncogenic Ras-induced secretion of IL6 is required for tumorigenesis. Genes Dev 21: 1714-1719.

Andea A, Sarkar F, Adsay VN. 2003. Clinicopathological correlates of pancreatic intraepithelial neoplasia: a comparative analysis of 82 cases with and 152 cases without pancreatic ductal adenocarcinoma. Mod Pathol 16: 996-1006.

Andersen DK. 2013. Diabetes and cancer: placing the association in perspective. Curr Opin Endocrinol Diabetes Obes 20: 81-86.

Apte MV, Wilson JS. 2012. Dangerous liaisons: pancreatic stellate cells and pancreatic cancer cells. J Gastroenterol Hepatol 27: 69-74.

Apte MV, Pirola RC, Wilson JS. 2012. Pancreatic stellate cells: a starring role in normal and diseased pancreas. Front Physiol 3: 344.

Ardito CM, Gruner BM, Takeuchi KK, Lubeseder-Martellato C, Teichmann N, Mazur PK, Delgiorno KE, Carpenter ES, Halbrook CI, Hall JC, et al. 2012. EGF receptor is required for KRAS-induced pancreatic tumorigenesis. Cancer Cell 22: 304-317.

Assenat E, Azria D, Mollevi C, Guimbaud R, Tubiana-Mathieu N, Smith D, Delord JP, Samalin E, Portales F, Larbouret C, et al. 2015. Dual targeting of HER1/EGFR and HER2 with cetuximab and trastuzumab in patients with metastatic pancreatic cancer after gemcitabine failure: results of the "THERAPY' phase 1-2 trial. Oncotarget 6: 12796-12808.

Baek G, Tse YF, Hu Z, Cox D, Buboltz N, McCue P, Yeo CJ, White MA, DeBerardinis RJ, Knudsen ES, et al. 2014. MCT4 defines a glycolytic subtype of pancreatic cancer with poor prognosis and unique metabolic dependencies. Cell Rep 9: 2233-2249.

Baer R, Cintas C, Dufresne M, Cassant-Sourdy S, Schonhuber N, Planque L, Lulka H, Couderc B, Bousquet C, Garmy-Susini B, et al. 2014. Pancreatic cell plasticity and cancer initiation induced by oncogenic Kras is completely dependent on wildtype PI 3-kinase p110a. Genes Dev 28: 2621-2635.

Bailey JM, Swanson BJ, Hamada T, Eggers JP, Singh PK, Caffery T, Ouellette MM, Hollingsworth MA. 2008. Sonic hedgehog promotes desmoplasia in pancreatic cancer. Clin Cancer Res 14: 5995-6004.

Bailey JM, Mohr AM, Hollingsworth MA. 2009. Sonic hedgehog paracrine signaling regulates metastasis and lymphangiogenesis in pancreatic cancer. Oncogene 28: 3513-3525.

Bailey JM, Alsina J, Rasheed ZA, McAllister FM, Fu YY, Plentz R, Zhang H, Pasricha PJ, Bardeesy N, Matsui W, et al. 2014. DCLK1 marks a morphologically distinct subpopulation of cells with stem cell properties in preinvasive pancreatic cancer. Gastroenterology 146: 245-256.

Bailey JM, Hendley AM, Lafaro KJ, Pruski MA, Jones NC, Alsina J, Younes M, Maitra A, McAllister F, Iacobuzio-Donahue CA, et al. 2015. p53 mutations cooperate with oncogenic Kras to promote adenocarcinoma from pancreatic ductal cells. Oncogene doi: 10.1038/onc.2015.441.
Bailey P, Chang DK, Nones K, Johns AL, Patch A, Gingras M, Miller DK, Christ AN, Bruxner TJC, Quinn MC, et al. 2016. The molecular pathology of pancreatic cancer. Nature (in press).

Bardeesy N, Aguirre AJ, Chu GC, Cheng KH, Lopez LV, Hezel AF, Feng B, Brennan C, Weissleder R, Mahmood U, et al. 2006a. Both p16(Ink4a) and the p19(Arf)-p53 pathway constrain progression of pancreatic adenocarcinoma in the mouse. Proc Natl Acad Sci 103: 5947-5952.

Bardeesy N, Cheng KH, Berger JH, Chu GC, Pahler J, Olson P, Hezel AF, Horner J, Lauwers GY, Hanahan D, et al. 2006b. Smad4 is dispensable for normal pancreas development yet critical in progression and tumor biology of pancreas cancer. Genes Dev 20: 3130-3146.

Bardelli A, Siena S. 2010. Molecular mechanisms of resistance to cetuximab and panitumumab in colorectal cancer. I Clin Oncol 28: 1254-1261.

Bar-Sagi D, Feramisco JR. 1986. Induction of membrane ruffling and fluid-phase pinocytosis in quiescent fibroblasts by ras proteins. Science 233: 1061-1068.

Basturk O, Hong SM, Wood LD, Adsay NV, Albores-Saavedra J, Biankin AV, Brosens LA, Fukushima N, Goggins M, Hruban $\mathrm{RH}$, et al. 2015. A revised classification system and recommendations from the Baltimore consensus meeting for neoplastic precursor lesions in the pancreas. Am I Surg Pathol 39: 1730-1741.

Baumgart S, Ellenrieder V, Fernandez-Zapico ME. 2013. Oncogenic transcription factors: cornerstones of inflammationlinked pancreatic carcinogenesis. Gut 62: 310-316.

Bayne LJ, Beatty GL, Jhala N, Clark CE, Rhim AD, Stanger BZ, Vonderheide RH. 2012. Tumor-derived granulocyte-macrophage colony-stimulating factor regulates myeloid inflammation and $\mathrm{T}$ cell immunity in pancreatic cancer. Cancer Cell 21: 822-835.

Beatty GL, O'Hara MH, Nelson AM, McGarvey M, Torigian DA, Lacey SF, Melenhorst JJ, Levine B, Plesa G, June CH. 2015. Safety and antitumor activity of chimeric antigen receptor modified $\mathrm{T}$ cells in patients with chemotherapy refractory metastatic pancreatic cancer. J Clin Oncol 33: 3007.

Becker AE, Hernandez YG, Frucht H, Lucas AL. 2014. Pancreatic ductal adenocarcinoma: risk factors, screening, and early detection. World J Gastroenterol 20: 11182-11198.

Bedard PL, Tabernero J, Janku F, Wainberg ZA, Paz-Ares L, Vansteenkiste J, Van Cutsem E, Perez-Garcia J, Stathis A, Britten CD, et al. 2015. A phase Ib dose-escalation study of the oral pan-PI3K inhibitor buparlisib (BKM120) in combination with the oral MEK1/2 inhibitor trametinib (GSK1120212) in patients with selected advanced solid tumors. Clin Cancer Res 21: 730-738.

Bellone G, Carbone A, Smirne C, Scirelli T, Buffolino A, Novarino A, Stacchini A, Bertetto O, Palestro G, Sorio C, et al. 2006a. Cooperative induction of a tolerogenic dendritic cell phenotype by cytokines secreted by pancreatic carcinoma cells. I Immunol 177: 3448-3460.

Bellone G, Smirne C, Mauri FA, Tonel E, Carbone A, Buffolino A, Dughera L, Robecchi A, Pirisi M, Emanuelli G. 2006b. Cytokine expression profile in human pancreatic carcinoma cells and in surgical specimens: implications for survival. Cancer Immunol Immunother 55: 684-698.

Berman DM, Karhadkar SS, Maitra A, Montes De Oca R, Gerstenblith MR, Briggs K, Parker AR, Shimada Y, Eshleman JR, Watkins DN, et al. 2003. Widespread requirement for Hedgehog ligand stimulation in growth of digestive tract tumours. $\mathrm{Na}$ ture 425: 846-851.

Bettegowda C, Sausen M, Leary RJ, Kinde I, Wang Y, Agrawal N, Bartlett BR, Wang H, Luber B, Alani RM, et al. 2014. Detection 
of circulating tumor DNA in early- and late-stage human malignancies. Sci Transl Med 6: $224 \mathrm{ra} 224$.

Biankin AV, Waddell N, Kassahn KS, Gingras MC, Muthuswamy LB, Johns AL, Miller DK, Wilson PJ, Patch AM, Wu J, et al. 2012. Pancreatic cancer genomes reveal aberrations in axon guidance pathway genes. Nature 491: 399-405.

Bijlsma MF, van Laarhoven HW. 2015. The conflicting roles of tumor stroma in pancreatic cancer and their contribution to the failure of clinical trials: a systematic review and critical appraisal. Cancer Metastasis Rev 34: 97-114.

Bissell MJ, Radisky D. 2001. Putting tumours in context. Nat Rev Cancer 1: 46-54.

Biswas SK. 2015. Metabolic reprogramming of immune cells in cancer progression. Immunity 43: 435-449.

Biswas SK, Mantovani A. 2010. Macrophage plasticity and interaction with lymphocyte subsets: cancer as a paradigm. Nat Immunol 11: 889-896.

Blasco RB, Francoz S, Santamaria D, Canamero M, Dubus P, Charron J, Baccarini M, Barbacid M. 2011. c-Raf, but not BRaf, is essential for development of K-Ras oncogene-driven non-small cell lung carcinoma. Cancer Cell 19: 652-663.

Bogdan C. 2001. Nitric oxide and the immune response. Nat Immunol 2: 907-916.

Boone BA, Bahary N, Zureikat AH, Moser AJ, Normolle DP, Wu WC, Singhi AD, Bao P, Bartlett DL, Liotta LA, et al. 2015. Safety and biologic response of pre-operative autophagy inhibition in combination with gemcitabine in patients with pancreatic adenocarcinoma. Ann Surg Oncol 22: 4402-4410.

Boros LG, Puigjaner J, Cascante M, Lee WN, Brandes JL, Bassilian S, Yusuf FI, Williams RD, Muscarella P, Melvin WS, et al. 1997. Oxythiamine and dehydroepiandrosterone inhibit the nonoxidative synthesis of ribose and tumor cell proliferation. Cancer Res 57: 4242-4248.

Boros LG, Lee WN, Go VL. 2002. A metabolic hypothesis of cell growth and death in pancreatic cancer. Pancreas 24: 26-33.

Boroughs LK, DeBerardinis RJ. 2015. Metabolic pathways promoting cancer cell survival and growth. Nat Cell Biol 17: 351-359.

Brahmer JR, Drake CG, Wollner I, Powderly JD, Picus J, Sharfman WH, Stankevich E, Pons A, Salay TM, McMiller TL, et al. 2010. Phase I study of single-agent anti-programmed death-1 (MDX-1106) in refractory solid tumors: safety, clinical activity, pharmacodynamics, and immunologic correlates. $J$ Clin Oncol 28: 3167-3175.

Bronte V, Chappell DB, Apolloni E, Cabrelle A, Wang M, Hwu P, Restifo NP. 1999. Unopposed production of granulocyte-macrophage colony-stimulating factor by tumors inhibits $\mathrm{CD} 8^{+} \mathrm{T}$ cell responses by dysregulating antigen-presenting cell maturation. J Immunol 162: 5728-5737.

Brune K, Abe T, Canto M, O'Malley L, Klein AP, Maitra A, Volkan Adsay N, Fishman EK, Cameron JL, Yeo CJ, et al. 2006. Multifocal neoplastic precursor lesions associated with lobular atrophy of the pancreas in patients having a strong family history of pancreatic cancer. Am J Surg Pathol 30: 1067-1076.

Byrne WL, Mills KH, Lederer JA, O'Sullivan GC. 2011. Targeting regulatory T cells in cancer. Cancer Res 71: 6915-6920.

Canto MI, Harinck F, Hruban RH, Offerhaus GJ, Poley JW, Kamel I, Nio Y, Schulick RS, Bassi C, Kluijt I, et al. 2013. International Cancer of the Pancreas Screening (CAPS) Consortium summit on the management of patients with increased risk for familial pancreatic cancer. Gut 62: 339-347.

Cao X, Cai SF, Fehniger TA, Song J, Collins LI, Piwnica-Worms DR, Ley TJ. 2007. Granzyme B and perforin are important for regulatory $\mathrm{T}$ cell-mediated suppression of tumor clearance. Immunity 27: 635-646.
Castellano E, Sheridan C, Thin MZ, Nye E, Spencer-Dene B, Diefenbacher ME, Moore C, Kumar MS, Murillo MM, Gronroos E, et al. 2013. Requirement for interaction of PI3-kinase p110 $\alpha$ with RAS in lung tumor maintenance. Cancer Cell 24: 617-630.

Cebola I, Rodriguez-Segui SA, Cho CH, Bessa J, Rovira M, Luengo M, Chhatriwala M, Berry A, Ponsa-Cobas J, Maestro MA, et al. 2015. TEAD and YAP regulate the enhancer network of human embryonic pancreatic progenitors. Nat Cell Biol 17: 615-626.

Chandra A, Grecco HE, Pisupati V, Perera D, Cassidy L, Skoulidis F, Ismail SA, Hedberg C, Hanzal-Bayer M, Venkitaraman AR, et al. 2012. The GDI-like solubilizing factor PDE $\delta$ sustains the spatial organization and signalling of Ras family proteins. Nat Cell Biol 14: 148-158.

Chang CH, Qiu J, O'Sullivan D, Buck MD, Noguchi T, Curtis JD, Chen Q, Gindin M, Gubin MM, van der Windt GJ, et al. 2015. Metabolic competition in the tumor microenvironment is a driver of cancer progression. Cell 162: 1229-1241.

Chen L, Lei L, Chang X, LiZ, Lu C, Zhang X, Wu Y, YehIT, Zhong G. 2010. Mice deficient in MyD88 develop a Th2-dominant response and severe pathology in the uppergenital tract following Chlamydia muridarum infection. I Immunol 184: 2602-2610.

Clark CE, Hingorani SR, Mick R, Combs C, Tuveson DA, Vonderheide RH. 2007. Dynamics of the immune reaction to pancreatic cancer from inception to invasion. Cancer Res 67: 9518-9527.

Cleary AS, Leonard TL, Gestl SA, Gunther EJ. 2014. Tumour cell heterogeneity maintained by cooperating subclones in Wntdriven mammary cancers. Nature 508: 113-117.

Coffelt SB, de Visser KE. 2014. Cancer: inflammation lights the way to metastasis. Nature 507: 48-49.

Collins MA, Bednar F, Zhang Y, Brisset JC, Galban S, Galban CJ, Rakshit S, Flannagan KS, Adsay NV, Pasca di Magliano M. 2012. Oncogenic Kras is required for both the initiation and maintenance of pancreatic cancer in mice. J Clin Invest 122: 639-653.

Collisson EA, Sadanandam A, Olson P, Gibb WJ, Truitt M, Gu S, Cooc J, Weinkle J, Kim GE, Jakkula L, et al. 2011. Subtypes of pancreatic ductal adenocarcinoma and their differing responses to therapy. Nat Med 17: 500-503.

Collisson EA, Trejo CL, Silva JM, Gu S, Korkola JE, Heiser LM, Charles RP, Rabinovich BA, Hann B, Dankort D, et al. 2012. A central role for $\mathrm{RAF} \rightarrow \mathrm{MEK} \rightarrow \mathrm{ERK}$ signaling in the genesis of pancreatic ductal adenocarcinoma. Cancer Discov 2: 685-693.

Colombo MP, Piconese S. 2007. Regulatory-T-cell inhibition versus depletion: the right choice in cancer immunotherapy. Nat Rev Cancer 7: 880-887.

Commisso C, Davidson SM, Soydaner-Azeloglu RG, Parker SI, Kamphorst JJ, Hackett S, Grabocka E, Nofal M, Drebin JA, Thompson CB, et al. 2013. Macropinocytosis of protein is an amino acid supply route in Ras-transformed cells. Nature 497: 633-637.

Cox AD, Olive KP. 2012. Silencing the killers: paracrine immune suppression in pancreatic cancer. Cancer cell 21: 715-716.

Cox AD, Der CJ, Philips MR. 2015. Targeting RAS membrane association: back to the future for anti-RAS drug discovery? Clin Cancer Res 21: 1819-1827.

Cseh B, Doma E, Baccarini M. 2014. 'RAF' neighborhood: protein-protein interaction in the Raf/Mek/Erk pathway. FEBS Lett 588: 2398-2406.

Cubilla AL, Fitzgerald PJ. 1976. Morphological lesions associated with human primary invasive nonendocrine pancreas cancer. Cancer Res 36: 2690-2698. 
da Cunha Santos G, Dhani N, Tu D, Chin K, Ludkovski O, Kamel-Reid S, Squire J, Parulekar W, Moore MJ, Tsao MS. 2010. Molecular predictors of outcome in a phase 3 study of gemcitabine and erlotinib therapy in patients with advanced pancreatic cancer: National Cancer Institute of Canada Clinical Trials Group Study PA.3. Cancer 116: 5599-5607.

Dal Molin M, Matthaei H, Wu J, Blackford A, Debeljak M, Rezaee N, Wolfgang CL, Butturini G, Salvia R, Bassi C, et al. 2013. Clinicopathological correlates of activating GNAS mutations in intraductal papillary mucinous neoplasm (IPMN) of the pancreas. Ann Surg Oncol 20: 3802-3808.

Dang CV. 2012. Links between metabolism and cancer. Genes Dev 26: 877-890.

Day CP, Merlino G, Van Dyke T. 2015. Preclinical mouse cancer models: a maze of opportunities and challenges. Cell 163: 39-53.

Deberardinis RJ, Sayed N, Ditsworth D, Thompson CB. 2008. Brick by brick: metabolism and tumor cell growth. Curr Opin Genet Dev 18: 54-61.

Delgiorno KE, Hall JC, Takeuchi KK, Pan FC, Halbrook CJ, Washington MK, Olive KP, Spence JR, Sipos B, Wright CV, et al. 2014. Identification and manipulation of biliary metaplasia in pancreatic tumors. Gastroenterology 146: 233-244.e5.

De Monte L, Reni M, Tassi E, Clavenna D, Papa I, Recalde H, Braga M, Di Carlo V, Doglioni C, Protti MP. 2011. Intratumor T helper type 2 cell infiltrate correlates with cancer-associated fibroblast thymic stromal lymphopoietin production and reduced survival in pancreatic cancer. J Exp Med 208: 469-478.

DeNicola GM, Karreth FA, Humpton TJ, Gopinathan A, Wei C, Frese K, Mangal D, Yu KH, Yeo CJ, Calhoun ES, et al. 2011. Oncogene-induced Nrf2 transcription promotes ROS detoxification and tumorigenesis. Nature 475: 106-109.

Di Caro G, Cortese N, Castino GF, Grizzi F, Gavazzi F, Ridolfi C, Capretti G, Mineri R, Todoric J, Zerbi A, et al. 2015. Dual prognostic significance of tumour-associated macrophages in human pancreatic adenocarcinoma treated or untreated with chemotherapy. Gut doi: 10.1136/gutinl-2015-309193.

Dima SO, Tanase C, Albulescu R, Herlea V, Chivu-Economescu M, Purnichescu-Purtan R, Dumitrascu T, Duda DG, Popescu I. 2012. An exploratory study of inflammatory cytokines as prognostic biomarkers in patients with ductal pancreatic adenocarcinoma. Pancreas 41: 1001-1007.

Downward J. 2015. RAS synthetic lethal screens revisited: still seeking the elusive prize? Clin Cancer Res 21: 1802-1809.

Du J, Nelson ES, Simons AL, Olney KE, Moser JC, Schrock HE, Wagner BA, Buettner GR, Smith BJ, Teoh ML, et al. 2013. Regulation of pancreatic cancer growth by superoxide. Mol Carcinog 52: 555-567.

Efeyan A, Comb WC, Sabatini DM. 2015. Nutrient-sensing mechanisms and pathways. Nature 517: 302-310.

Eng CH, Wang Z, Tkach D, Toral-Barza L, Ugwonali S, Liu S, Fitzgerald SL, George E, Frias E, Cochran N, et al. 2016. Macroautophagy is dispensable for growth of KRAS mutant tumors and chloroquine efficacy. Proc Natl Acad Sci 113: 182-187.

Eser S, Messer M, Eser P, von Werder A, Seidler B, Bajbouj M, Vogelmann R, Meining A, von Burstin J, Algul H, et al. 2011. In vivo diagnosis of murine pancreatic intraepithelial neoplasia and early-stage pancreatic cancer by molecular imaging. Proc Natl Acad Sci 108: 9945-9950.

Eser S, Reiff N, Messer M, Seidler B, Gottschalk K, Dobler M, Hieber M, Arbeiter A, Klein S, Kong B, et al. 2013. Selective requirement of PI3K/PDK1 signaling for Kras oncogene-driven pancreatic cell plasticity and cancer. Cancer Cell 23: 406-420.
Ezernitchi AV, Vaknin I, Cohen-Daniel L, Levy O, Manaster E, Halabi A, Pikarsky E, Shapira L, Baniyash M. 2006. TCR zeta down-regulation under chronic inflammation is mediated by myeloid suppressor cells differentially distributed between various lymphatic organs. I Immunol 177: 4763-4772.

Faca VM, Song KS, Wang H, Zhang Q, Krasnoselsky AL, Newcomb LF, Plentz RR, Gurumurthy S, Redston MS, Pitteri SJ, et al. 2008. A mouse to human search for plasma proteome changes associated with pancreatic tumor development. PLoS Med 5: e123.

Facciabene A, Peng X, Hagemann IS, Balint K, Barchetti A, Wang LP, Gimotty PA, Gilks CB, Lal P, Zhang L, et al. 2011. Tumour hypoxia promotes tolerance and angiogenesis via CCL28 and T(reg) cells. Nature 475: 226-230.

Feig C, Jones JO, Kraman M, Wells RJ, Deonarine A, Chan DS, Connell CM, Roberts EW, Zhao Q, Caballero OL, et al. 2013. Targeting CXCL12 from FAP-expressing carcinoma-associated fibroblasts synergizes with anti-PD-L1 immunotherapy in pancreatic cancer. Proc Natl Acad Sci 110: 2021220217.

Feldmann G, Mishra A, Hong SM, Bisht S, Strock CJ, Ball DW, Goggins M, Maitra A, Nelkin BD. 2010. Inhibiting the cyclin-dependent kinase CDK5 blocks pancreatic cancer formation and progression through the suppression of Ras-Ral signaling. Cancer Res 70: 4460-4469.

Fogar P, Sperti C, Basso D, Sanzari MC, Greco E, Davoli C, Navaglia F, Zambon CF, Pasquali C, Venza E, et al. 2006. Decreased total lymphocyte counts in pancreatic cancer: an index of adverse outcome. Pancreas 32: 22-28.

Fujita-Sato S, Galeas I, Truitt M, Pitt C, Urisman A, Bandyopadhyay S, Ruggero D, McCormick F. 2015. Enhanced MET translation and signaling sustains K-Ras-driven proliferation under anchorage-independent growth conditions. Cancer Res 75: 2851-2862.

Funamizu N, Hu C, Lacy C, Schetter A, Zhang G, He P, Gaedcke J, Ghadimi MB, Ried T, Yfantis HG, et al. 2013. Macrophage migration inhibitory factor induces epithelial to mesenchymal transition, enhances tumor aggressiveness and predicts clinical outcome in resected pancreatic ductal adenocarcinoma. Int I Cancer 132: 785-794.

Gabrilovich DI, Velders MP, Sotomayor EM, Kast WM. 2001. Mechanism of immune dysfunction in cancer mediated by immature Gr- $1^{+}$myeloid cells. J Immunol 166: 5398-5406.

Gaglio D, Metallo CM, Gameiro PA, Hiller K, Danna LS, Balestrieri C, Alberghina L, Stephanopoulos G, Chiaradonna F. 2011. Oncogenic K-Ras decouples glucose and glutamine metabolism to support cancer cell growth. Mol Syst Biol 7: 523.

Galluzzi L, Pietrocola F, Bravo-San Pedro JM, Amaravadi RK, Baehrecke EH, Cecconi F, Codogno P, Debnath J, Gewirtz DA, Karantza V, et al. 2015. Autophagy in malignant transformation and cancer progression. EMBO J 34: 856-880.

Garcia-Carracedo D, Turk AT, Fine SA, Akhavan N, Tweel BC, Parsons R, Chabot JA, Allendorf JD, Genkinger JM, Remotti $\mathrm{HE}$, et al. 2013. Loss of PTEN expression is associated with poor prognosis in patients with intraductal papillary mucinous neoplasms of the pancreas. Clin Cancer Res 19: 6830-6841.

Gidekel Friedlander SY, Chu GC, Snyder EL, Girnius N, Dibelius G, Crowley D, Vasile E, DePinho RA, Jacks T. 2009. Contextdependent transformation of adult pancreatic cells by oncogenic K-Ras. Cancer Cell 16: 379-389.

Godin-Ethier J, Hanafi LA, Piccirillo CA, Lapointe R. 2011. Indoleamine 2,3-dioxygenase expression in human cancers: clinical and immunologic perspectives. Clin Cancer Res 17: 6985-6991. 
Goggins M, Schutte M, Lu J, Moskaluk CA, Weinstein CL, Petersen GM, Yeo CJ, Jackson CE, Lynch HT, Hruban RH, et al. 1996. Germline BRCA2 gene mutations in patients with apparently sporadic pancreatic carcinomas. Cancer Res 56: $5360-5364$.

Gondek DC, Lu LF, Quezada SA, Sakaguchi S, Noelle RJ. 2005. Cutting edge: contact-mediated suppression by $\mathrm{CD} 4{ }^{+} \mathrm{CD} 25^{+}$ regulatory cells involves a granzyme B-dependent, perforin-independent mechanism. J Immunol 174: 1783-1786.

Gorrini C, Harris IS, Mak TW. 2013. Modulation of oxidative stress as an anticancer strategy. Nat Rev Drug Discov 12: 931-947.

Grabocka E, Pylayeva-Gupta Y, Jones MJ, Lubkov V, Yemanaberhan E, Taylor L, Jeng HH, Bar-Sagi D. 2014. Wild-type H- and $\mathrm{N}$-Ras promote mutant K-Ras-driven tumorigenesis by modulating the DNA damage response. Cancer Cell 25: 243-256.

Grant RC, Selander I, Connor AA, Selvarajah S, Borgida A, Briollais L, Petersen GM, Lerner-Ellis J, Holter S, Gallinger S. 2015. Prevalence of germline mutations in cancer predisposition genes in patients with pancreatic cancer. Gastroenterology 148: $556-564$.

Greer JB, Whitcomb DC. 2009. Inflammation and pancreatic cancer: an evidence-based review. Curr Opin Pharmacol 9: 411-418.

Gritsman K, Yuzugullu H, Von T, Yan H, Clayton L, Fritsch C, Maira SM, Hollingworth G, Choi C, Khandan T, et al. 2014. Hematopoiesis and RAS-driven myeloid leukemia differentially require PI3K isoform p110a. I Clin Invest 124: 1794-1809.

Guerra C, Schuhmacher AJ, Canamero M, Grippo PJ, Verdaguer L, Perez-Gallego L, Dubus P, Sandgren EP, Barbacid M. 2007. Chronic pancreatitis is essential for induction of pancreatic ductal adenocarcinoma by K-Ras oncogenes in adult mice. Cancer Cell 11: 291-302.

Guillaumond F, Bidaut G, Ouaissi M, Servais S, Gouirand V, Olivares O, Lac S, Borge L, Roques J, Gayet O, et al. 2015. Cholesterol uptake disruption, in association with chemotherapy, is a promising combined metabolic therapy for pancreatic adenocarcinoma. Proc Natl Acad Sci 112: 2473-2478.

Gunderson AJ, Kaneda MM, Tsujikawa T, Nguyen AV, Affara NI, Ruffell B, Gorjestani S, Liudahl SM, Truitt M, Olson P, et al. 2015. Bruton's tyrosine kinase (BTK)-dependent immune cell crosstalk drives pancreas cancer. Cancer Discov doi: 10.1158/2159-8290.CD-15-0827.

Guo JY, White E. 2013. Autophagy is required for mitochondrial function, lipid metabolism, growth, and fate of KRAS (G12D)-driven lung tumors. Autophagy 9: 1636-1638.

Guo JY, Chen HY, Mathew R, Fan J, Strohecker AM, Karsli-Uzunbas G, Kamphorst JJ, Chen G, Lemons JM, Karantza V, et al. 2011. Activated Ras requires autophagy to maintain oxidative metabolism and tumorigenesis. Genes Dev 25: 460-470.

Guo JY, Karsli-Uzunbas G, Mathew R, Aisner SC, Kamphorst JJ, Strohecker AM, Chen G, Price S, Lu W, Teng X, et al. 2013. Autophagy suppresses progression of K-ras-induced lung tumors to oncocytomas and maintains lipid homeostasis. Genes Dev 27: 1447-1461.

Gupta S, Ramjaun AR, Haiko P, Wang Y, Warne PH, Nicke B, Nye E, Stamp G, Alitalo K, Downward J. 2007. Binding of ras to phosphoinositide 3-kinase p110 a is required for ras-driven tumorigenesis in mice. Cell 129: 957-968.

Habbe N, Shi G, Meguid RA, Fendrich V, Esni F, Chen H, Feldmann G, Stoffers DA, Konieczny SF, Leach SD, et al. 2008. Spontaneous induction of murine pancreatic intraepithelial neoplasia (mPanIN) by acinar cell targeting of oncogenic Kras in adult mice. Proc Natl Acad Sci 105: 18913-18918.
Haber DA, Velculescu VE. 2014. Blood-based analyses of cancer: circulating tumor cells and circulating tumor DNA. Cancer Discov 4: 650-661.

Hanahan D, Coussens LM. 2012. Accessories to the crime: functions of cells recruited to the tumor microenvironment. Cancer Cell 21: 309-322.

Hanahan D, Weinberg RA. 2011. Hallmarks of cancer: the next generation. Cell 144: 646-674.

Haq R, Shoag J, Andreu-Perez P, Yokoyama S, Edelman H, Rowe GC, Frederick DT, Hurley AD, Nellore A, Kung AL, et al. 2013. Oncogenic BRAF regulates oxidative metabolism via PGCl $\alpha$ and MITF. Cancer Cell 23: 302-315.

Harder J, Ihorst G, Heinemann V, Hofheinz R, Moehler M, Buechler P, Kloeppel G, Rocken C, Bitzer M, Boeck S, et al. 2012. Multicentre phase II trial of trastuzumab and capecitabine in patients with HER2 overexpressing metastatic pancreatic cancer. Br J Cancer 106: 1033-1038.

Helming KC, Wang X, Roberts CW. 2014a. Vulnerabilities of mutant SWI/SNF complexes in cancer. Cancer Cell 26: 309-317.

Helming KC, Wang X, Wilson BG, Vazquez F, Haswell JR, Manchester HE, Kim Y, Kryukov GV, Ghandi M, Aguirre AJ, et al. 2014b. ARID1B is a specific vulnerability in ARID1Amutant cancers. Nat Med 20: 251-254.

Hensley CT, Wasti AT, DeBerardinis RJ. 2013. Glutamine and cancer: cell biology, physiology, and clinical opportunities. I Clin Invest 123: 3678-3684.

Hermann PC, Huber SL, Herrler T, Aicher A, Ellwart JW, Guba M, Bruns CI, Heeschen C. 2007. Distinct populations of cancer stem cells determine tumor growth and metastatic activity in human pancreatic cancer. Cell Stem Cell 1: 313-323.

Hermano E, Meirovitz A, Meir K, Nussbaum G, Appelbaum L, Peretz T, Elkin M. 2014. Macrophage polarization in pancreatic carcinoma: role of heparanase enzyme. J Natl Cancer Inst 106: dju332.

Hezel AF, Kimmelman AC, Stanger BZ, Bardeesy N, DePinho RA. 2006. Genetics and biology of pancreatic ductal adenocarcinoma. Genes Dev 20: 1218-1249.

Hidalgo M. 2010. Pancreatic cancer. N Engl J Med 362: 16051617.

Hill R, Calvopina JH, Kim C, Wang Y, Dawson DW, Donahue TR, Dry S, Wu H. 2010. PTEN loss accelerates KrasG12D-induced pancreatic cancer development. Cancer Res 70: 7114-7124.

Hingorani SR, Petricoin EF, Maitra A, Rajapakse V, King C, Jacobetz MA, Ross S, Conrads TP, Veenstra TD, Hitt BA, et al. 2003. Preinvasive and invasive ductal pancreatic cancer and its early detection in the mouse. Cancer Cell 4: 437-450.

Hoffman GR, Rahal R, Buxton F, Xiang K, McAllister G, Frias E, Bagdasarian L, Huber J, Lindeman A, Chen D, et al. 2014. Functional epigenetics approach identifies BRM/SMARCA2 as a critical synthetic lethal target in BRG1-deficient cancers. Proc Natl Acad Sci 111: 3128-3133.

Holmer R, Goumas FA, Waetzig GH, Rose-John S, Kalthoff H. 2014. Interleukin-6: a villain in the drama of pancreatic cancer development and progression. Hepatobiliary Pancreat Dis Int 13: $371-380$.

Holter S, Borgida A, Dodd A, Grant R, Semotiuk K, Hedley D, Dhani N, Narod S, Akbari M, Moore M, et al. 2015. Germline BRCA mutations in a large clinic-based cohort of patients with pancreatic adenocarcinoma. J Clin Oncol 33:3124-3129.

Hori M, Takahashi M, Hiraoka N, Yamaji T, Mutoh M, Ishigamori R, Furuta K, Okusaka T, Shimada K, Kosuge T, et al. 2014. Association of pancreatic Fatty infiltration with pancreatic ductal adenocarcinoma. Clin Transl Gastroenterol 5: e53. 
Houot R, Schultz LM, Marabelle A, Kohrt H. 2015. T-cell-based immunotherapy: adoptive cell transfer and checkpoint inhibition. Cancer Immunol Res 3: 1115-1122.

Hruban RH, Takaori K, Klimstra DS, Adsay NV, Albores-Saavedra J, Biankin AV, Biankin SA, Compton C, Fukushima N, Furukawa T, et al. 2004. An illustrated consensus on the classification of pancreatic intraepithelial neoplasia and intraductal papillary mucinous neoplasms. Am J Surg Pathol 28: 977-987.

Hruban RH, Adsay NV, Albores-Saavedra J, Anver MR, Biankin AV, Boivin GP, Furth EE, Furukawa T, Klein A, Klimstra DS, et al. 2006. Pathology of genetically engineered mouse models of pancreatic exocrine cancer: consensus report and recommendations. Cancer Res 66: 95-106.

Hruban RH, Pitman MB, Klimstra DS. 2007. Tumors of the pancreas. AFIP atlas of tumor pathology, 4th series. American Registry of Pathology, Armed Forces Institute of Pathology, Washington, DC.

Hu Y, Lu W, Chen G, Wang P, Chen Z, Zhou Y, Ogasawara M, Trachootham D, Feng L, Pelicano H, et al. 2012. K-ras G12V transformation leads to mitochondrial dysfunction and a metabolic switch from oxidative phosphorylation to glycolysis. Cell Res 22: 399-412.

Huang B, Pan PY, Li Q, Sato AI, Levy DE, Bromberg J, Divino CM, Chen SH. 2006. Gr- $1^{+} \mathrm{CD} 115^{+}$immature myeloid suppressor cells mediate the development of tumor-induced $\mathrm{T}$ regulatory cells and T-cell anergy in tumor-bearing host. Cancer Res 66: $1123-1131$.

Huang $\mathrm{CH}$, Lujambio A, Zuber J, Tschaharganeh DF, Doran MG, Evans MJ, Kitzing T, Zhu N, de Stanchina E, Sawyers CL, et al. 2014. CDK9-mediated transcription elongation is required for MYC addiction in hepatocellular carcinoma. Genes Dev 28: 1800-1814.

Huen MS, Sy SM, Chen J. 2010. BRCA1 and its toolbox for the maintenance of genome integrity. Nat Rev Mol Cell Biol 11: $138-148$.

Hunder NN, Wallen H, Cao J, Hendricks DW, Reilly JZ, Rodmyre R, Jungbluth A, Gnjatic S, Thompson JA, Yee C. 2008. Treatment of metastatic melanoma with autologous $\mathrm{CD}^{+} \mathrm{T}$ cells against NY-ESO-1. N Engl J Med 358: 2698-2703.

Hunter JC, Manandhar A, Carrasco MA, Gurbani D, Gondi S, Westover KD. 2015. Biochemical and structural analysis of common cancer-associated KRAS mutations. Mol Cancer Res 13: 1325-1335.

Hurwitz HI, Uppal N, Wagner SA, Bendell JC, Beck JT, Wade SM III, Nemunaitis JJ, Stella PJ, Pipas JM, Wainberg ZA, et al. 2015. Randomized, double-blind, phase II study of ruxolitinib or placebo in combination with capecitabine in patients with metastatic pancreatic cancer for whom therapy with gemcitabine has failed. J Clin Oncol 33: 4039-4047.

Husain Z, Huang Y, Seth P, Sukhatme VP. 2013. Tumor-derived lactate modifies antitumor immune response: effect on myeloid-derived suppressor cells and NK cells. I Immunol 191: 1486-1495.

Hwang RF, Moore T, Arumugam T, Ramachandran V, Amos KD, Rivera A, Ji B, Evans DB, Logsdon CD. 2008. Cancer-associated stromal fibroblasts promote pancreatic tumor progression. Cancer Res 68: 918-926.

Ihle NT, Byers LA, Kim ES, Saintigny P, Lee JJ, Blumenschein GR, Tsao A, Liu S, Larsen JE, Wang J, et al. 2012. Effect of KRAS oncogene substitutions on protein behavior: implications for signaling and clinical outcome. I Natl Cancer Inst 104: 228-239.

Irani K, Xia Y, Zweier JL, Sollott SJ, Der CJ, Fearon ER, Sundaresan M, Finkel T, Goldschmidt-Clermont PJ. 1997. Mitogenic signaling mediated by oxidants in Ras-transformed fibroblasts. Science 275: 1649-1652.

Jaiswal BS, Janakiraman V, Kljavin NM, Chaudhuri S, Stern HM, Wang W, Kan Z, Dbouk HA, Peters BA, Waring P, et al. 2009. Somatic mutations in $\mathrm{p} 85 \mathrm{a}$ promote tumorigenesis through class IA PI3K activation. Cancer Cell 16: 463-474.

Jameson KL, Mazur PK, Zehnder AM, Zhang J, Zarnegar B, Sage J, Khavari PA. 2013. IQGAP1 scaffold-kinase interaction blockade selectively targets RAS-MAP kinase-driven tumors. Nat Med 19: 626-630.

Jiang Y, Du Z, Yang F, Di Y, Li J, Zhou Z, Pillarisetty VG, Fu D. 2014. FOXP3 ${ }^{+}$lymphocyte density in pancreatic cancer correlates with lymph node metastasis. PLoS One 9: e106741.

Johnston FM, Tan MC, Tan BR Jr, Porembka MR, Brunt EM, Linehan DC, Simon PO Jr, Plambeck-Suess S, Eberlein TJ, Hellstrom KE, et al. 2009. Circulating mesothelin protein and cellular antimesothelin immunity in patients with pancreatic cancer. Clin Cancer Res 15: 6511-6518.

Jones S, Zhang X, Parsons DW, Lin JC, Leary RJ, Angenendt P, Mankoo P, Carter H, Kamiyama H, Jimeno A, et al. 2008. Core signaling pathways in human pancreatic cancers revealed by global genomic analyses. Science 321: 1801-1806.

Jones S, Hruban RH, Kamiyama M, Borges M, Zhang X, Parsons DW, Lin JC, Palmisano E, Brune K, Jaffee EM, et al. 2009. Exomic sequencing identifies PALB2 as a pancreatic cancer susceptibility gene. Science 324: 217.

Joyce JA, Pollard JW. 2009. Microenvironmental regulation of metastasis. Nat Rev Cancer 9: 239-252.

Kahlert C, Melo SA, Protopopov A, Tang J, Seth S, Koch M, Zhang J, Weitz J, Chin L, Futreal A, et al. 2014. Identification of double-stranded genomic DNA spanning all chromosomes with mutated KRAS and p53 DNA in the serum exosomes of patients with pancreatic cancer. J Biol Chem 289: 3869-3875.

Kamphorst J,, Cross JR, Fan J, de Stanchina E, Mathew R, White EP, Thompson CB, Rabinowitz JD. 2013. Hypoxic and Rastransformed cells support growth by scavenging unsaturated fatty acids from lysophospholipids. Proc Natl Acad Sci 110: 8882-8887.

Kamphorst JJ, Nofal M, Commisso C, Hackett SR, Lu W, Grabocka E, Vander Heiden MG, Miller G, Drebin JA, Bar-Sagi $D$, et al. 2015. Human pancreatic cancer tumors are nutrient poor and tumor cells actively scavenge extracellular protein. Cancer Res 75: 544-553.

Kanda M, Matthaei H, Wu J, Hong SM, Yu J, Borges M, Hruban RH, Maitra A, Kinzler K, Vogelstein B, et al. 2012. Presence of somatic mutations in most early-stage pancreatic intraepithelial neoplasia. Gastroenterology 142: 730-733 e739.

Kapoor A, Yao W, Ying H, Hua S, Liewen A, Wang Q, Zhong Y, Wu CI, Sadanandam A, Hu B, et al. 2014. Yap1 activation enables bypass of oncogenic Kras addiction in pancreatic cancer. Cell 158: 185-197.

Karreth FA, Frese KK, DeNicola GM, Baccarini M, Tuveson DA. 2011. C-Raf is required for the initiation of lung cancer by $\mathrm{K}$ Ras(G12D). Cancer Discov 1: 128-136.

Karsli-Uzunbas G, Guo JY, Price S, Teng X, Laddha SV, Khor S, Kalaany NY, Jacks T, Chan CS, Rabinowitz JD, et al. 2014. Autophagy is required for glucose homeostasis and lung tumor maintenance. Cancer Discov 4: 914-927.

Keenan BP, Saenger Y, Kafrouni MI, Leubner A, Lauer P, Maitra A, Rucki AA, Gunderson AJ, Coussens LM, Brockstedt DG, et al. 2014. A listeria vaccine and depletion of T-regulatory cells activate immunity against early stage pancreatic intraepithelial neoplasms and prolong survival of mice. Gastroenterology 146: 1784-1794.e6. 
Kennedy AL, Morton JP, Manoharan I, Nelson DM, Jamieson NB, Pawlikowski JS, McBryan T, Doyle B, McKay C, Oien KA, et al. 2011. Activation of the PIK3CA/AKT pathway suppresses senescence induced by an activated RAS oncogene to promote tumorigenesis. Mol Cell 42: 36-49.

Kharaziha P, Ceder S, Li Q, Panaretakis T. 2012. Tumor cell-derived exosomes: a message in a bottle. Biochim Biophys Acta 1826: 103-111.

Kia SK, Gorski MM, Giannakopoulos S, Verrijzer CP. 2008. SWI/ SNF mediates polycomb eviction and epigenetic reprogramming of the INK4b-ARF-INK4a locus. Mol Cell Biol 28: 3457-3464.

Kim MJ, Woo SJ, Yoon CH, Lee JS, An S, Choi YH, Hwang SG, Yoon G, Lee SJ. 2011. Involvement of autophagy in oncogenic K-Ras-induced malignant cell transformation. I Biol Chem 286: 12924-12932.

Kimmelman AC. 2011. The dynamic nature of autophagy in cancer. Genes Dev 25: 1999-2010.

Kimmelman AC. 2015. Metabolic dependencies in RAS-driven cancers. Clin Cancer Res 21: 1828-1834.

Kimmelman AC, Hezel AF, Aguirre AJ, Zheng H, Paik JH, Ying H, Chu GC, Zhang JX, Sahin E, Yeo G, et al. 2008. Genomic alterations link Rho family of GTPases to the highly invasive phenotype of pancreas cancer. Proc Natl Acad Sci 105: 19372-19377.

King TA, Li W, Brogi E, Yee CJ, Gemignani ML, Olvera N, Levine DA, Norton L, Robson ME, Offit K, et al. 2007. Heterogenic loss of the wild-type BRCA allele in human breast tumorigenesis. Ann Surg Oncol 14: 2510-2518.

Kloppel G. 2000. WHO classification of tumours. IARC Press, Lyon, France.

Klug F, Prakash H, Huber PE, Seibel T, Bender N, Halama N, Pfirschke C, Voss RH, Timke C, Umansky L, et al. 2013. Low-dose irradiation programs macrophage differentiation to an iNOS $/ \mathrm{M} 1$ phenotype that orchestrates effective $\mathrm{T}$ cell immunotherapy. Cancer Cell 24: 589-602.

Kochenderfer JN, Rosenberg SA. 2013. Treating B-cell cancer with T cells expressing anti-CD19 chimeric antigen receptors. Nat Rev Clin Oncol 10: 267-276.

Kopp JL, von Figura G, Mayes E, Liu FF, Dubois CL, Morris JPT, Pan FC, Akiyama H, Wright CV, Jensen K, et al. 2012. Identification of Sox9-dependent acinar-to-ductal reprogramming as the principal mechanism for initiation of pancreatic ductal adenocarcinoma. Cancer Cell 22: 737-750.

Kroemer G, Marino G, Levine B. 2010. Autophagy and the integrated stress response. Mol Cell 40: 280-293.

Kwong LN, Costello JC, Liu H, Jiang S, Helms TL, Langsdorf AE, Jakubosky D, Genovese G, Muller FL, Jeong JH, et al. 2012. Oncogenic NRAS signaling differentially regulates survival and proliferation in melanoma. Nat Med 18: 1503-1510.

Lagadinou ED, Sach A, Callahan K, Rossi RM, Neering SJ, Minhajuddin M, Ashton JM, Pei S, Grose V, O'Dwyer KM, et al. 2013. BCL-2 inhibition targets oxidative phosphorylation and selectively eradicates quiescent human leukemia stem cells. Cell Stem Cell 12: 329-341.

Laheru D, Jaffee EM. 2005. Immunotherapy for pancreatic cancer -science driving clinical progress. Nat Rev Cancer 5: 459-467.

Laoui D, Van Overmeire E, Movahedi K, Van den Bossche J, Schouppe E, Mommer C, Nikolaou A, Morias Y, De Baetselier P, Van Ginderachter JA. 2011. Mononuclear phagocyte heterogeneity in cancer: different subsets and activation states reaching out at the tumor site. Immunobiology 216: 1192-1202.

Le A, Cooper CR, Gouw AM, Dinavahi R, Maitra A, Deck LM, Royer RE, Vander Jagt DL, Semenza GL, Dang CV. 2010. Inhi- bition of lactate dehydrogenase A induces oxidative stress and inhibits tumor progression. Proc Natl Acad Sci 107: 20372042.

Le DT, Lutz E, Uram JN, Sugar EA, Onners B, Solt S, Zheng L, Diaz LA Jr, Donehower RC, Jaffee EM, et al. 2013. Evaluation of ipilimumab in combination with allogeneic pancreatic tumor cells transfected with a GM-CSF gene in previously treated pancreatic cancer. J Immunother 36: 382-389.

Le DT, Wang-Gillam A, Picozzi V, Greten TF, Crocenzi T, Springett G, Morse M, Zeh H, Cohen D, Fine RL, et al. 2015. Safety and survival with GVAX pancreas prime and listeria monocytogenes-expressing mesothelin (CRS-207) boost vaccines for metastatic pancreatic cancer. J Clin Oncol 33: 1325-1333.

Lee J, Jang KT, Ki CS, Lim T, Park YS, Lim HY, Choi DW, Kang WK, Park K, Park JO. 2007a. Impact of epidermal growth factor receptor (EGFR) kinase mutations, EGFR gene amplifications, and KRAS mutations on survival of pancreatic adenocarcinoma. Cancer 109: 1561-1569.

Lee MG, Villa R, Trojer P, Norman J, Yan KP, Reinberg D, Di Croce L, Shiekhattar R. 2007b. Demethylation of H3K27 regulates polycomb recruitment and $\mathrm{H} 2 \mathrm{~A}$ ubiquitination. Science 318: 447-450.

Lee DW, Barrett DM, Mackall C, Orentas R, Grupp SA. 2012. The future is now: chimeric antigen receptors as new targeted therapies for childhood cancer. Clin Cancer Res 18: 27802790.

Lee JJ, Perera RM, Wang H, Wu DC, Liu XS, Han S, Fitamant J, Jones PD, Ghanta KS, Kawano S, et al. 2014. Stromal response to Hedgehog signaling restrains pancreatic cancer progression. Proc Natl Acad Sci 111: E3091-E3100.

Lee KE, Spata M, Bayne LJ, Buza EL, Durham AC, Allman D, Vonderheide RH, Simon MC. 2015. Hifla deletion reveals proneoplastic function of B cells in pancreatic neoplasia. Cancer Discov doi: 10.1158/2159-8290.CD-15-0822.

Lesina M, Kurkowski MU, Ludes K, Rose-John S, Treiber M, Kloppel G, Yoshimura A, Reindl W, Sipos B, Akira S, et al. 2011. Stat3/Socs3 activation by IL-6 transsignaling promotes progression of pancreatic intraepithelial neoplasia and development of pancreatic cancer. Cancer Cell 19: 456-469.

Li J, Zhang Z, Dai Z, Plass C, Morrison C, Wang Y, Wiest JS, Anderson MW, You M. 2003. LOH of chromosome 12p correlates with Kras 2 mutation in non-small cell lung cancer. Oncogene 22: 1243-1246.

Li C, Heidt DG, Dalerba P, Burant CF, Zhang L, Adsay V, Wicha M, Clarke MF, Simeone DM. 2007. Identification of pancreatic cancer stem cells. Cancer Res 67: 1030-1037.

Lim K-H, Counter CM. 2005. Reduction in the requirement of oncogenic Ras signaling to activation of PI3K/AKT pathway during tumor maintenance. Cancer Cell 8: 381-392.

Lim KH, Baines AT, Fiordalisi JJ, Shipitsin M, Feig LA, Cox AD, Der CJ, Counter CM. 2005. Activation of RalA is critical for Ras-induced tumorigenesis of human cells. Cancer Cell 7: 533-545.

Lim KH, O'Hayer K, Adam SJ, Kendall SD, Campbell PM, Der CJ, Counter CM. 2006. Divergent roles for RalA and RalB in malignant growth of human pancreatic carcinoma cells. Curr Biol 16: 2385-2394.

Lin CY, Loven J, Rahl PB, Paranal RM, Burge CB, Bradner JE, Lee TI, Young RA. 2012. Transcriptional amplification in tumor cells with elevated c-Myc. Cell 151: 56-67.

Lin L, Sabnis AJ, Chan E, Olivas V, Cade L, Pazarentzos E, Asthana S, Neel D, Yan J,, Lu X, et al. 2015. The Hippo effector YAP promotes resistance to RAF- and MEK-targeted cancer therapies. Nat Genet 47: 250-256. 
Lines JL, Pantazi E, Mak J, Sempere LF, Wang L, O'Connell S, Ceeraz S, Suriawinata AA, Yan S, Ernstoff MS, et al. 2014. VIS$\mathrm{TA}$ is an immune checkpoint molecule for human $\mathrm{T}$ cells. Cancer Res 74: 1924-1932.

Ling J, Kang Y, Zhao R, Xia Q, Lee DF, Chang Z, Li J, Peng B, Fleming JB, Wang $\mathrm{H}$, et al. 2012. KrasG12D-induced IKK2/ $\beta / \mathrm{NF}-\kappa \mathrm{B}$ activation by IL-1 $\alpha$ and p62 feedforward loops is required for development of pancreatic ductal adenocarcinoma. Cancer Cell 21: 105-120.

Lisanti MP, Martinez-Outschoorn UE, Sotgia F. 2013. Oncogenes induce the cancer-associated fibroblast phenotype: metabolic symbiosis and 'fibroblast addiction' are new therapeutic targets for drug discovery. Cell Cycle 12: 2723-2732.

Lob S, Konigsrainer A, Rammensee HG, Opelz G, Terness P. 2009. Inhibitors of indoleamine-2,3-dioxygenase for cancer therapy: can we see the wood for the trees? Nat Rev Cancer 9: 445-452.

Lock R, Roy S, Kenific CM, Su JS, Salas E, Ronen SM, Debnath J. 2011. Autophagy facilitates glycolysis during Ras-mediated oncogenic transformation. Mol Biol Cell 22: 165-178.

Lord CJ, Ashworth A. 2012. The DNA damage response and cancer therapy. Nature 481: 287-294.

Lutz ER, Wu AA, Bigelow E, Sharma R, Mo G, Soares K, Solt S, Dorman A, Wamwea A, Yager A, et al. 2014. Immunotherapy converts nonimmunogenic pancreatic tumors into immunogenic foci of immune regulation. Cancer Immunol Res 2: 616-631.

Maddipati R, Stanger BZ. 2015. Pancreatic cancer metastases harbor evidence of polyclonality. Cancer Discov 5: 1086-1097.

Maitra A, Hruban RH. 2008. Pancreatic cancer. Annu Rev Pathol 3: 157-188.

Maitra A, Leach SD. 2012. Disputed paternity: the uncertain ancestry of pancreatic ductal neoplasia. Cancer Cell 22: 701-703.

Malka D, Hammel P, Maire F, Rufat P, Madeira I, Pessione F, Levy P, Ruszniewski P. 2002. Risk of pancreatic adenocarcinoma in chronic pancreatitis. Gut 51: 849-852.

Mann KM, Ward JM, Yew CC, Kovochich A, Dawson DW, Black MA, Brett BT, Sheetz TE, Dupuy AJ, Australian Pancreatic Cancer Genome Initiative, et al. 2012. Sleeping Beauty mutagenesis reveals cooperating mutations and pathways in pancreatic adenocarcinoma. Proc Natl Acad Sci 109: 5934-5941.

Mantovani A, Sica A. 2010. Macrophages, innate immunity and cancer: balance, tolerance, and diversity. Curr Opin Immunol 22: 231-237.

Mantovani A, Sozzani S, Locati M, Allavena P, Sica A. 2002. Macrophage polarization: tumor-associated macrophages as a paradigm for polarized M2 mononuclear phagocytes. Trends Immunol 23: 549-555.

Mantovani A, Sica A, Sozzani S, Allavena P, Vecchi A, Locati M. 2004. The chemokine system in diverse forms of macrophage activation and polarization. Trends Immunol 25: 677-686.

Martin TD, Chen XW, Kaplan RE, Saltiel AR, Walker CL, Reiner DJ, Der CJ. 2014. Ral and Rheb GTPase activating proteins integrate $\mathrm{mTOR}$ and GTPase signaling in aging, autophagy, and tumor cell invasion. Mol Cell 53: 209-220.

Martin-Orozco N, Muranski P, Chung Y, Yang XO, Yamazaki T, Lu S, Hwu P, Restifo NP, Overwijk WW, Dong C. 2009. Thelper 17 cells promote cytotoxic $\mathrm{T}$ cell activation in tumor immunity. Immunity 31: 787-798.

Marusyk A, Tabassum DP, Altrock PM, Almendro V, Michor F, Polyak K. 2014. Non-cell-autonomous driving of tumour growth supports sub-clonal heterogeneity. Nature 514: 54-58.
Matthaei H, Schulick RD, Hruban RH, Maitra A. 2011. Cystic precursors to invasive pancreatic cancer. Nat Rev Gastroenterol Hepatol 8: 141-150.

Mazur PK, Reynoird N, Khatri P, Jansen PW, Wilkinson AW, Liu S, Barbash O, Van Aller GS, Huddleston M, Dhanak D, et al. 2014. SMYD3 links lysine methylation of MAP3K2 to Rasdriven cancer. Nature 510: 283-287.

Mazur PK, Herner A, Mello SS, Wirth M, Hausmann S, SanchezRivera FJ, Lofgren SM, Kuschma T, Hahn SA, Vangala D, et al. 2015. Combined inhibition of BET family proteins and histone deacetylases as a potential epigenetics-based therapy for pancreatic ductal adenocarcinoma. Nat Med 21: 11631171.

McAllister F, Bailey JM, Alsina J, Nirschl CJ, Sharma R, Fan H, Rattigan Y, Roeser JC, Lankapalli RH, Zhang H, et al. 2014. Oncogenic Kras activates a hematopoietic-to-epithelial IL-17 signaling axis in preinvasive pancreatic neoplasia. Cancer Cell 25: 621-637.

McCormick F. 2015. KRAS as a therapeutic target. Clin Cancer Res 21: 1797-1801.

McMahon HT, Boucrot E. 2011. Molecular mechanism and physiological functions of clathrin-mediated endocytosis. Nat Rev Mol Cell Biol 12: 517-533.

Melo SA, Sugimoto H, O'Connell JT, Kato N, Villanueva A, Vidal A, Qiu L, Vitkin E, Perelman LT, Melo CA, et al. 2014. Cancer exosomes perform cell-independent microRNA biogenesis and promote tumorigenesis. Cancer Cell 26: 707-721.

Melo SA, Luecke LB, Kahlert C, Fernandez AF, Gammon ST, Kaye J, LeBleu VS, Mittendorf EA, Weitz J, Rahbari N, et al. 2015. Glypican-1 identifies cancer exosomes and detects early pancreatic cancer. Nature 523: 177-182.

Mersch J, Jackson MA, Park M, Nebgen D, Peterson SK, Singletary C, Arun BK, Litton JK. 2015. Cancers associated with BRCA1 and BRCA 2 mutations other than breast and ovarian. Cancer 121: 269-275.

Miron N, Miron MM, Milea VG, Cristea V. 2010. Proinflammatory cytokines: an insight into pancreatic oncogenesis. Roum Arch Microbiol Immunol 69: 183-189.

Mirus JE, Zhang Y, Li CI, Lokshin AE, Prentice RL, Hingorani SR, Lampe PD. 2015. Cross-species antibody microarray interrogation identifies a 3-protein panel of plasma biomarkers for early diagnosis of pancreas cancer. Clin Cancer Res 21: 1764-1771.

Mitchem JB, Brennan DJ, Knolhoff BL, Belt BA, Zhu Y, Sanford DE, Belaygorod L, Carpenter D, Collins L, Piwnica-Worms D, et al. 2013. Targeting tumor-infiltrating macrophages decreases tumor-initiating cells, relieves immunosuppression, and improves chemotherapeutic responses. Cancer Res 73: $1128-1141$.

Mitsuishi Y, Taguchi K, Kawatani Y, Shibata T, Nukiwa T, Aburatani H, Yamamoto M, Motohashi H. 2012. Nrf2 redirects glucose and glutamine into anabolic pathways in metabolic reprogramming. Cancer Cell 22: 66-79.

Mitsushita J, Lambeth JD, Kamata T. 2004. The superoxide-generating oxidase Nox1 is functionally required for Ras oncogene transformation. Cancer Res 64: 3580-3585.

Moore MJ, Goldstein D, Hamm J, Figer A, Hecht JR, Gallinger S, Au HJ, Murawa P, Walde D, Wolff RA, et al. 2007. Erlotinib plus gemcitabine compared with gemcitabine alone in patients with advanced pancreatic cancer: a phase III trial of the National Cancer Institute of Canada Clinical Trials Group. J Clin Oncol 25: 1960-1966.

Moo-Young TA, Larson JW, Belt BA, Tan MC, Hawkins WG, Eberlein TJ, Goedegebuure PS, Linehan DC. 2009. Tumor-derived TGF- $\beta$ mediates conversion of $\mathrm{CD}^{+}{ }^{+} \mathrm{Foxp}^{+}{ }^{+}$regulatory $\mathrm{T}$ 
cells in a murine model of pancreas cancer. I Immunother 32: $12-21$.

Moran AE, Kovacsovics-Bankowski M, Weinberg AD. 2013. The TNFRs OX40, 4-1BB, and CD40 as targets for cancer immunotherapy. Curr Opin Immunol 25: 230-237.

Morris JPT, Wang SC, Hebrok M. 2010. KRAS, Hedgehog, Wnt and the twisted developmental biology of pancreatic ductal adenocarcinoma. Nat Rev Cancer 10: 683-695.

Movahedi K, Laoui D, Gysemans C, Baeten M, Stange G, Van den Bossche J, Mack M, Pipeleers D, In't Veld P, De Baetselier P, et al. 2010. Different tumor microenvironments contain functionally distinct subsets of macrophages derived from Ly6C (high) monocytes. Cancer Res 70: 5728-5739.

Muller AJ, DuHadaway JB, Donover PS, Sutanto-Ward E, Prendergast GC. 2005. Inhibition of indoleamine 2,3-dioxygenase, an immunoregulatory target of the cancer suppression gene Bin1, potentiates cancer chemotherapy. Nat Med 11: 312-319.

Muller FL, Aquilanti EA, DePinho RA. 2015. Collateral lethality: a new therapeutic strategy in oncology. Trends Cancer 1: 161-173.

Mundy-Bosse BL, Lesinski GB, Jaime-Ramirez AC, Benninger K, Khan M, Kuppusamy P, Guenterberg K, Kondadasula SV, Chaudhury AR, La Perle KM, et al. 2011. Myeloid-derived suppressor cell inhibition of the IFN response in tumor-bearing mice. Cancer Res 71: 5101-5110.

Murphy SJ, Hart SN, Lima JF, Kipp BR, Klebig M, Winters JL, Szabo C, Zhang L, Eckloff BW, Petersen GM, et al. 2013. Genetic alterations associated with progression from pancreatic intraepithelial neoplasia to invasive pancreatic tumor. Gastroenterology 145: 1098-1109.e1.

Navas C, Hernandez-Porras I, Schuhmacher AJ, Sibilia M, Guerra C, Barbacid M. 2012. EGF receptor signaling is essential for $\mathrm{k}$ ras oncogene-driven pancreatic ductal adenocarcinoma. Cancer Cell 22: 318-330.

Neesse A, Michl P, Frese KK, Feig C, Cook N, Jacobetz MA, Lolkema MP, Buchholz M, Olive KP, Gress TM, et al. 2011. Stromal biology and therapy in pancreatic cancer. Gut 60: 861-868.

Neesse A, Algul H, Tuveson DA, Gress TM. 2015. Stromal biology and therapy in pancreatic cancer: a changing paradigm. Gut 64: 1476-1484.

Neufeld TP. 2010. TOR-dependent control of autophagy: biting the hand that feeds. Curr Opin Cell Biol 22: 157-168.

Nie Z, Hu G, Wei G, Cui K, Yamane A, Resch W, Wang R, Green DR, Tessarollo L, Casellas R, et al. 2012. c-Myc is a universal amplifier of expressed genes in lymphocytes and embryonic stem cells. Cell 151: 68-79.

Nieman KM, Kenny HA, Penicka CV, Ladanyi A, Buell-Gutbrod R, Zillhardt MR, Romero IL, Carey MS, Mills GB, Hotamisligil GS, et al. 2011. Adipocytes promote ovarian cancer metastasis and provide energy for rapid tumor growth. Nat Med 17: 1498-1503.

Nomi T, Sho M, Akahori T, Hamada K, Kubo A, Kanehiro H, Nakamura S, Enomoto K, Yagita H, Azuma M, et al. 2007. Clinical significance and therapeutic potential of the programmed death-1 ligand/programmed death-1 pathway in human pancreatic cancer. Clin Cancer Res 13: 2151-2157.

Nummer D, Suri-Payer E, Schmitz-Winnenthal H, Bonertz A, Galindo L, Antolovich D, Koch M, Buchler M, Weitz J, Schirrmacher V, et al. 2007. Role of tumor endothelium in CD4 ${ }^{+}$ $\mathrm{CD} 25^{+}$regulatory $\mathrm{T}$ cell infiltration of human pancreatic carcinoma. J Nat1 Cancer Inst 99: 1188-1199.

Ochi A, Nguyen AH, Bedrosian AS, Mushlin HM, Zarbakhsh S, Barilla R, Zambirinis CP, Fallon NC, Rehman A, PylayevaGupta Y, et al. 2012. MyD88 inhibition amplifies dendritic cell capacity to promote pancreatic carcinogenesis via Th2 cells. J Exp Med 209: 1671-1687.

Ohsawa S, Sato Y, Enomoto M, Nakamura M, Betsumiya A, Igaki T. 2012. Mitochondrial defect drives non-autonomous tumour progression through Hippo signalling in Drosophila. Nature 490: 547-551.

Olive KP, Jacobetz MA, Davidson CI, Gopinathan A, McIntyre D, Honess D, Madhu B, Goldgraben MA, Caldwell ME, Allard D, et al. 2009. Inhibition of Hedgehog signaling enhances delivery of chemotherapy in a mouse model of pancreatic cancer. Science 324: 1457-1461.

Orkin SH, Hochedlinger K. 2011. Chromatin connections to pluripotency and cellular reprogramming. Cell 145: 835-850.

Ostrand-Rosenberg S. 2008. Immune surveillance: a balance between protumor and antitumor immunity. Curr Opin Genet Dev 18: 11-18.

Ostrand-Rosenberg S. 2010. Myeloid-derived suppressor cells: more mechanisms for inhibiting antitumor immunity. Cancer Immunol Immunother 59: 1593-1600.

Ostrem JM, Peters U, Sos ML, Wells JA, Shokat KM. 2013. K-Ras (G12C) inhibitors allosterically control GTP affinity and effector interactions. Nature 503: 548-551.

Ozdemir BC, Pentcheva-Hoang T, Carstens JL, Zheng X, Wu CC, Simpson TR, Laklai H, Sugimoto H, Kahlert C, Novitskiy SV, et al. 2014. Depletion of carcinoma-associated fibroblasts and fibrosis induces immunosuppression and accelerates pancreas cancer with reduced survival. Cancer Cell 25: 719-734.

Palm W, Park Y, Wright K, Pavlova NN, Tuveson DA, Thompson CB. 2015. The utilization of extracellular proteins as nutrients is suppressed by mTORC1. Cell 162: 259-270.

Pardoll DM. 2012. The blockade of immune checkpoints in cancer immunotherapy. Nat Rev Cancer 12: 252-264.

Perera RM, Stoykova S, Nicolay BN, Ross KN, Fitamant J, Boukhali M, Lengrand J, Deshpande V, Selig MK, Ferrone CR, et al. 2015. Transcriptional control of autophagy-lysosome function drives pancreatic cancer metabolism. Nature 524: 361-365.

Perez-Mancera PA, Guerra C, Barbacid M, Tuveson DA. 2012a. What we have learned about pancreatic cancer from mouse models. Gastroenterology 142: 1079-1092.

Perez-Mancera PA, Rust AG, van der Weyden L, Kristiansen G, Li A, Sarver AL, Silverstein KA, Grutzmann R, Aust D, Rummele P, et al. 2012b. The deubiquitinase USP9X suppresses pancreatic ductal adenocarcinoma. Nature 486: 266-270.

Phillips PA, McCarroll JA, Park S, Wu MJ, Pirola R, Korsten M, Wilson JS, Apte MV. 2003. Rat pancreatic stellate cells secrete matrix metalloproteinases: implications for extracellular matrix turnover. Gut 52: 275-282.

Plass C, Pfister SM, Lindroth AM, Bogatyrova O, Claus R, Lichter P. 2013. Mutations in regulators of the epigenome and their connections to global chromatin patterns in cancer. Nat Rev Genet 14: 765-780.

Pollard JW. 2004. Tumour-educated macrophages promote tumour progression and metastasis. Nat Rev Cancer 4: 71-78.

Porembka MR, Mitchem JB, Belt BA, Hsieh CS, Lee HM, Herndon J, Gillanders WE, Linehan DC, Goedegebuure P. 2012. Pancreatic adenocarcinoma induces bone marrow mobilization of myeloid-derived suppressor cells which promote primary tumor growth. Cancer Immunol Immunother 61: 1373-1385.

Poulikakos PI, Zhang C, Bollag G, Shokat KM, Rosen N. 2010. RAF inhibitors transactivate RAF dimers and ERK signalling in cells with wild-type BRAF. Nature 464: 427-430.

Prior IA, Lewis PD, Mattos C. 2012. A comprehensive survey of Ras mutations in cancer. Cancer Res 72: 2457-2467. 
Propper D, Davidenko I, Bridgewater J, Kupcinskas L, Fittipaldo A, Hillenbach C, Klughammer B, Ducreux M. 2014. Phase II, randomized, biomarker identification trial (MARK) for erlotinib in patients with advanced pancreatic carcinoma. Ann Oncol 25: 1384-1390.

Provenzano PP, Cuevas C, Chang AE, Goel VK, Von Hoff DD, Hingorani SR. 2012. Enzymatic targeting of the stroma ablates physical barriers to treatment of pancreatic ductal adenocarcinoma. Cancer Cell 21: 418-429.

Pylayeva-Gupta Y, Lee KE, Hajdu CH, Miller G, Bar-Sagi D. 2012. Oncogenic Kras-induced GM-CSF production promotes the development of pancreatic neoplasia. Cancer Cell 21: 836-847.

Pylayeva-Gupta Y, Das S, Handler JS, Hajdu CH, Coffre M, Koralov S, Bar-Sagi D. 2015. IL-35 producing B cells promote the development of pancreatic neoplasia. Cancer Discov doi: 10.1158/2159-8290.CD-15-0843.

Qiu W, Sahin F, Iacobuzio-Donahue CA, Garcia-Carracedo D, Wang WM, Kuo CY, Chen D, Arking DE, Lowy AM, Hruban $\mathrm{RH}$, et al. 2011. Disruption of p16 and activation of Kras in pancreas increase ductal adenocarcinoma formation and metastasis in vivo. Oncotarget 2: 862-873.

Qiu W, Tang SM, Lee S, Turk AT, Sireci AN, Qiu A, Rose C, Xie C, Kitajewski J, Wen HJ, et al. 2016. Loss of activin receptor type $1 \mathrm{~B}$ accelerates development of intraductal papillary mucinous neoplasms in mice with activated KRAS. Gastroenterology 150: 218-228.

Qu D, Johnson J, Chandrakesan P, Weygant N, May R, Aiello N, Rhim A, Zhao L, Zheng W, Lightfoot S, et al. 2015. Doublecortin-like kinase 1 is elevated serologically in pancreatic ductal adenocarcinoma and widely expressed on circulating tumor cells. PLoS One 10: e0118933.

Rabinowitz JD, White E. 2010. Autophagy and metabolism. Science 330: 1344-1348.

Racker E, Resnick RJ, Feldman R. 1985. Glycolysis and methylaminoisobutyrate uptake in rat-1 cells transfected with ras or myc oncogenes. Proc Natl Acad Sci 82: 3535-3538.

Raimondi S, Maisonneuve P, Lowenfels AB. 2009. Epidemiology of pancreatic cancer: an overview. Nat Rev Gastroenterol Hepatol 6: 699-708.

Rajeshkumar NV, Dutta P, Yabuuchi S, de Wilde RF, Martinez GV, Le A, Kamphorst JJ, Rabinowitz JD, Jain SK, Hidalgo M, et al. 2015. Therapeutic targeting of the Warburg effect in pancreatic cancer relies on an absence of $\mathrm{p} 53$ function. Cancer Res 75: 3355-3364.

Rebours V, Gaujoux S, d'Assignies G, Sauvanet A, Ruszniewski P, Levy P, Paradis V, Bedossa P, Couvelard A. 2015. Obesity and fatty pancreatic infiltration are risk factors for pancreatic precancerous lesions (PanIN). Clin Cancer Res 21: 3522-3528.

Rhim AD, Stanger BZ. 2010. Molecular biology of pancreatic ductal adenocarcinoma progression: aberrant activation of developmental pathways. Prog Mol Biol Transl Sci 97: 41-78.

Rhim AD, Mirek ET, Aiello NM, Maitra A, Bailey JM, McAllister F, Reichert M, Beatty GL, Rustgi AK, Vonderheide RH, et al. 2012. EMT and dissemination precede pancreatic tumor formation. Cell 148: 349-361.

Rhim AD, Oberstein PE, Thomas DH, Mirek ET, Palermo CF, Sastra SA, Dekleva EN, Saunders T, Becerra CP, Tattersall IW, et al. 2014a. Stromal elements act to restrain, rather than support, pancreatic ductal adenocarcinoma. Cancer Cell 25: 735-747.

Rhim AD, Thege FI, Santana SM, Lannin TB, Saha TN, Tsai S, Maggs LR, Kochman ML, Ginsberg GG, Lieb JG, et al. 2014b. Detection of circulating pancreas epithelial cells in pa- tients with pancreatic cystic lesions. Gastroenterology 146: 647-651.

Roberts PJ, Stinchcombe TE, Der CJ, Socinski MA. 2010. Personalized medicine in non-small-cell lung cancer: is KRAS a useful marker in selecting patients for epidermal growth factor receptor-targeted therapy? J Clin Oncol 28: 4769-4777.

Roberts NJ, Jiao Y, Yu J, Kopelovich L, Petersen GM, Bondy ML, Gallinger S, Schwartz AG, Syngal S, Cote ML, et al. 2012. ATM mutations in patients with hereditary pancreatic cancer. Cancer Discov 2: 41-46.

Rodriguez PC, Ochoa AC. 2006. T cell dysfunction in cancer: role of myeloid cells and tumor cells regulating amino acid availability and oxidative stress. Semin Cancer Biol 16: 66-72.

Rowley M, Ohashi A, Mondal G, Mills L, Yang L, Zhang L, Sundsbak R, Shapiro V, Muders MH, Smyrk T, et al. 2011. Inactivation of Brca2 promotes Trp53-associated but inhibits KrasG12D-dependent pancreatic cancer development in mice. Gastroenterology 140: 1303-1313.e3.

Roy R, Chun J, Powell SN. 2012. BRCA1 and BRCA2: different roles in a common pathway of genome protection. Nat Rev Cancer 12: 68-78.

Roy N, Malik S, Villanueva KE, Urano A, Lu X, Von Figura G, Seeley ES, Dawson DW, Collisson EA, Hebrok M. 2015. Brg1 promotes both tumor-suppressive and oncogenic activities at distinct stages of pancreatic cancer formation. Genes Dev 29: 658-671.

Royal RE, Levy C, Turner K, Mathur A, Hughes M, Kammula US, Sherry RM, Topalian SL, Yang JC, Lowy I, et al. 2010. Phase 2 trial of single agent ipilimumab (anti-CTLA-4) for locally advanced or metastatic pancreatic adenocarcinoma. J Immunother 33: 828-833.

Ryan DP, Hong TS, Bardeesy N. 2014. Pancreatic adenocarcinoma. N Engl J Med 371: 1039-1049.

Sah RP, Nagpal SI, Mukhopadhyay D, Chari ST. 2013. New insights into pancreatic cancer-induced paraneoplastic diabetes. Nat Rev Gastroenterol Hepatol 10: 423-433.

Salih DA, Brunet A. 2008. FoxO transcription factors in the maintenance of cellular homeostasis during aging. Curr Opin Cell Biol 20: 126-136.

Sancho P, Burgos-Ramos E, Tavera A, Bou Kheir T, Jagust P, Schoenhals M, Barneda D, Sellers K, Campos-Olivas R, Grana O, et al. 2015. MYC/PGC-1 $\alpha$ balance determines the metabolic phenotype and plasticity of pancreatic cancer stem cells. Cell Metab 22: 590-605.

Sausen M, Phallen J, Adleff V, Jones S, Leary RJ, Barrett MT, Anagnostou V, Parpart-Li S, Murphy D, Kay Li Q, et al. 2015. Clinical implications of genomic alterations in the tumour and circulation of pancreatic cancer patients. Nat Commun 6: 7686.

Scheede-Bergdahl C, Watt HL, Trutschnigg B, Kilgour RD, Haggarty A, Lucar E, Vigano A. 2012. Is IL-6 the best pro-inflammatory biomarker of clinical outcomes of cancer cachexia? Clin Nutr 31: 85-88.

Schieber M, Chandel NS. 2014. ROS function in redox signaling and oxidative stress. Curr Biol 24: R453-R462.

Schonleben F, Qiu W, Ciau NT, Ho DJ, Li X, Allendorf JD, Remotti HE, Su GH. 2006. PIK3CA mutations in intraductal papillary mucinous neoplasm/carcinoma of the pancreas. Clin Cancer Res 12: 3851-3855.

Schumacher TN, Schreiber RD. 2015. Neoantigens in cancer immunotherapy. Science 348: 69-74.

Serafini P, Borrello I, Bronte V. 2006. Myeloid suppressor cells in cancer: recruitment, phenotype, properties, and mechanisms of immune suppression. Semin Cancer Biol 16: 53-65. 
Settembre C, Fraldi A, Medina DL, Ballabio A. 2013. Signals from the lysosome: a control centre for cellular clearance and energy metabolism. Nat Rev Mol Cell Biol 14: 283-296.

Shain AH, Giacomini CP, Matsukuma K, Karikari CA, Bashyam MD, Hidalgo M, Maitra A, Pollack JR. 2012. Convergent structural alterations define Switch/sucrose nonfermentable (SWI/ SNF) chromatin remodeler as a central tumor suppressive complex in pancreatic cancer. Proc Natl Acad Sci 109: E252-E259.

Shakya R, Reid LJ, Reczek CR, Cole F, Egli D, Lin CS, deRooij DG, Hirsch S, Ravi K, Hicks JB, et al. 2011. BRCA1 tumor suppression depends on BRCT phosphoprotein binding, but not its E3 ligase activity. Science 334: 525-528.

Shao DD, Xue W, Krall EB, Bhutkar A, Piccioni F, Wang X, Schinzel AC, Sood S, Rosenbluh J, Kim JW, et al. 2014. KRAS and YAP1 converge to regulate EMT and tumor survival. Cell 158: $171-184$.

Sharma P, Allison JP. 2015. Immune checkpoint targeting in cancer therapy: toward combination strategies with curative potential. Cell 161: 205-214.

Shen J, Peng Y, Wei L, Zhang W, Yang L, Lan L, Kapoor P, Ju Z, Mo Q, Shih Ie M, et al. 2015. ARID1A deficiency impairs the DNA damage checkpoint and sensitizes cells to PARP inhibitors. Cancer Discov 5: 752-767.

Sherman MH, Yu RT, Engle DD, Ding N, Atkins AR, Tiriac H, Collisson EA, Connor F, Van Dyke T, Kozlov S, et al. 2014. Vitamin $\mathrm{D}$ receptor-mediated stromal reprogramming suppresses pancreatitis and enhances pancreatic cancer therapy. Cell 159: 80-93.

Shi C, Hong SM, Lim P, Kamiyama H, Khan M, Anders RA, Goggins M, Hruban RH, Eshleman JR. 2009. KRAS2 mutations in human pancreatic acinar-ductal metaplastic lesions are limited to those with PanIN: implications for the human pancreatic cancer cell of origin. Mol Cancer Res 7: 230-236.

Shibuya KC, Goel VK, Xiong W, Sham JG, Pollack SM, Leahy AM, Whiting SH, Yeh MM, Yee C, Riddell SR, et al. 2014. Pancreatic ductal adenocarcinoma contains an effector and regulatory immune cell infiltrate that is altered by multimodal neoadjuvant treatment. PLoS One 9: e96565.

Shimamura T, Chen Z, Soucheray M, Carretero J, Kikuchi E, Tchaicha JH, Gao Y, Cheng KA, Cohoon TJ, Qi J, et al. 2013. Efficacy of BET bromodomain inhibition in Kras-mutant non-small cell lung cancer. Clin Cancer Res 19: 6183-6192.

Shuker SB, Hajduk PJ, Meadows RP, Fesik SW. 1996. Discovering high-affinity ligands for proteins: SAR by NMR. Science $\mathbf{2 7 4 :}$ 1531-1534.

Singh SK, Ellenrieder V. 2013. Senescence in pancreatic carcinogenesis: from signalling to chromatin remodelling and epigenetics. Gut 62: 1364-1372.

Singh A, Greninger P, Rhodes D, Koopman L, Violette S, Bardeesy $\mathrm{N}$, Settleman J. 2009. A gene expression signature associated with 'K-Ras addiction' reveals regulators of EMT and tumor cell survival. Cancer Cell 15: 489-500.

Singh H, Longo DL, Chabner BA. 2015. Improving prospects for targeting RAS. J Clin Oncol 33: 3650-3659.

Sipos B, Frank S, Gress T, Hahn S, Kloppel G. 2009. Pancreatic intraepithelial neoplasia revisited and updated. Pancreatology 9: 45-54.

Siveke JT, Einwachter H, Sipos B, Lubeseder-Martellato C, Kloppel G, Schmid RM. 2007. Concomitant pancreatic activation of Kras $(\mathrm{G} 12 \mathrm{D})$ and Tgfa results in cystic papillary neoplasms reminiscent of human IPMN. Cancer Cell 12: 266-279.

Skoulidis F, Cassidy LD, Pisupati V, Jonasson JG, Bjarnason H, Eyfjord JE, Karreth FA, Lim M, Barber LM, Clatworthy SA, et al. 2010. Germline Brca2 heterozygosity promotes Kras
(G12D)-driven carcinogenesis in a murine model of familial pancreatic cancer. Cancer Cell 18: 499-509.

Solinas G, Marchesi F, Garlanda C, Mantovani A, Allavena P. 2010. Inflammation-mediated promotion of invasion and metastasis. Cancer Metastasis Rev 29: 243-248.

Son J, Lyssiotis CA, Ying H, Wang X, Hua S, Ligorio M, Perera RM, Ferrone CR, Mullarky E, Shyh-Chang N, et al. 2013. Glutamine supports pancreatic cancer growth through a KRASregulated metabolic pathway. Nature 496: 101-105.

Soucek L, Whitfield J, Martins CP, Finch AJ, Murphy DJ, Sodir NM, Karnezis AN, Swigart LB, Nasi S, Evan GI. 2008. Modelling Myc inhibition as a cancer therapy. Nature 455: 679-683.

Soucek L, Whitfield JR, Sodir NM, Masso-Valles D, Serrano E, Karnezis AN, Swigart LB, Evan GI. 2013. Inhibition of Myc family proteins eradicates KRas-driven lung cancer in mice. Genes Dev 27: 504-513.

Sousa CM, Kimmelman AC. 2014. The complex landscape of pancreatic cancer metabolism. Carcinogenesis 35: 14411450.

Spivak-Kroizman TR, Hostetter G, Posner R, Aziz M, Hu C, Demeure MJ, Von Hoff D, Hingorani SR, Palculict TB, Izzo J, et al. 2013. Hypoxia triggers hedgehog-mediated tumor-stromal interactions in pancreatic cancer. Cancer Res 73: 3235-3247.

Srivastava MK, Sinha P, Clements VK, Rodriguez P, Ostrand-Rosenberg S. 2010. Myeloid-derived suppressor cells inhibit Tcell activation by depleting cystine and cysteine. Cancer Res 70: $68-77$.

Staffas A, Karlsson C, Persson M, Palmqvist L, Bergo MO. 2015. Wild-type KRAS inhibits oncogenic KRAS-induced T-ALL in mice. Leukemia 29: 1032-1040.

Stommel JM, Kimmelman AC, Ying H, Nabioullin R, Ponugoti $\mathrm{AH}$, Wiedemeyer R, Stegh AH, Bradner JE, Ligon KL, Brennan C, et al. 2007. Coactivation of receptor tyrosine kinases affects the response of tumor cells to targeted therapies. Science 318: 287-290.

Strobel O, Dor Y, Alsina J, Stirman A, Lauwers G, Trainor A, Castillo CF, Warshaw AL, Thayer SP. 2007. In vivo lineage tracing defines the role of acinar-to-ductal transdifferentiation in inflammatory ductal metaplasia. Gastroenterology 133: 1999-2009.

Strober S. 1984. Natural suppressor (NS) cells, neonatal tolerance, and total lymphoid irradiation: exploring obscure relationships. Annu Rev Immunol 2: 219-237.

Strohecker AM, Guo JY, Karsli-Uzunbas G, Price SM, Chen GJ, Mathew R, McMahon M, White E. 2013. Autophagy sustains mitochondrial glutamine metabolism and growth of BrafV600E-driven lung tumors. Cancer Discov 3: 1272-1285.

Stromnes IM, Brockenbrough JS, Izeradjene K, Carlson MA, Cuevas C, Simmons RM, Greenberg PD, Hingorani SR. 2014. Targeted depletion of an MDSC subset unmasks pancreatic ductal adenocarcinoma to adaptive immunity. Gut 63: 1769-1781.

Stromnes IM, Schmitt TM, Hulbert A, Brockenbrough IS, Nguyen HN, Cuevas C, Dotson AM, Tan X, Hotes JL, Greenberg PD, et al. 2015. T cells engineered against a native antigen can surmount immunologic and physical barriers to treat pancreatic ductal adenocarcinoma. Cancer Cell 28: 638-652.

Sun Q, Phan J, Friberg AR, Camper DV, Olejniczak ET, Fesik SW. 2014. A method for the second-site screening of K-Ras in the presence of a covalently attached first-site ligand. I Biomol NMR 60: 11-14.

Swanson JA, Watts C. 1995. Macropinocytosis. Trends Cell Biol 5: 424-428. 
Tadokoro CE, Shakhar G, Shen S, Ding Y, Lino AC, Maraver A, Lafaille JJ, Dustin ML. 2006. Regulatory T cells inhibit stable contacts between $\mathrm{CD}^{+} \mathrm{T}$ cells and dendritic cells in vivo. If Exp Med 203: 505-511.

Taki K, Ohmuraya M, Tanji E, Komatsu H, Hashimoto D, Semba K, Araki K, Kawaguchi Y, Baba H, Furukawa T. 2015. GNAS and Kras cooperate to promote murine pancreatic tumorigenesis recapitulating human intraductal papillary mucinous neoplasm. Oncogene doi: 10.1038/onc.2015.294.

Tassi E, Gavazzi F, Albarello L, Senyukov V, Longhi R, Dellabona P, Doglioni C, Braga M, Di Carlo V, Protti MP. 2008. Carcinoembryonic antigen-specific but not antiviral $\mathrm{CD}^{+} \mathrm{T}$ cell immunity is impaired in pancreatic carcinoma patients. $I$ Immunol 181: 6595-6603.

Thompson D, Easton DF, Breast Cancer Linkage Consortium. 2002. Cancer incidence in BRCA1 mutation carriers. I Natl Cancer Inst 94: 1358-1365.

Thorlacius S, Olafsdottir G, Tryggvadottir L, Neuhausen S, Jonasson JG, Tavtigian SV, Tulinius H, Ogmundsdottir HM, Eyfjord JE. 1996. A single BRCA2 mutation in male and female breast cancer families from Iceland with varied cancer phenotypes. Nat Genet 13: 117-119.

Tjomsland V, Niklasson L, Sandstrom P, Borch K, Druid H, Bratthall C, Messmer D, Larsson M, Spangeus A. 2011. The desmoplastic stroma plays an essential role in the accumulation and modulation of infiltrated immune cells in pancreatic adenocarcinoma. Clin Dev Immunol 2011: 212810.

To MD, Rosario RD, Westcott PM, Banta KL, Balmain A. 2013. Interactions between wild-type and mutant Ras genes in lung and skin carcinogenesis. Oncogene 32: 4028-4033.

Toole BP. 2004. Hyaluronan: from extracellular glue to pericellular cue. Nat Rev Cancer 4: 528-539.

Trachootham D, Lu W, Ogasawara MA, Nilsa RD, Huang P. 2008. Redox regulation of cell survival. Antioxid Redox Signal 10: 1343-1374.

Uhlirova M, Jasper H, Bohmann D. 2005. Non-cell-autonomous induction of tissue overgrowth by JNK/Ras cooperation in a Drosophila tumor model. Proc Natl Acad Sci 102: 1312313128.

Vander Heiden MG. 2013. Exploiting tumor metabolism: challenges for clinical translation. J Clin Invest 123: 3648-3651.

Vander Heiden MG, Cantley LC, Thompson CB. 2009. Understanding the Warburg effect: the metabolic requirements of cell proliferation. Science 324: 1029-1033.

Vaquero EC, Edderkaoui M, Pandol SJ, Gukovsky I, Gukovskaya AS. 2004. Reactive oxygen species produced by NAD(P)H oxidase inhibit apoptosis in pancreatic cancer cells. J Biol Chem 279: 34643-34654.

Vazquez F, Lim JH, Chim H, Bhalla K, Girnun G, Pierce K, Clish CB, Granter SR, Widlund HR, Spiegelman BM, et al. 2013. PGCla expression defines a subset of human melanoma tumors with increased mitochondrial capacity and resistance to oxidative stress. Cancer Cell 23: 287-301.

Viale A, Pettazzoni P, Lyssiotis CA, Ying H, Sanchez N, Marchesini M, Carugo A, Green T, Seth S, Giuliani V, et al. 2014. Oncogene ablation-resistant pancreatic cancer cells depend on mitochondrial function. Nature 514: 628-632.

Viale A, Corti D, Draetta GF. 2015. Tumors and mitochondrial respiration: a neglected connection. Cancer Res 75: 3687-3691.

Vincent A, Herman J, Schulick R, Hruban RH, Goggins M. 2011. Pancreatic cancer. Lancet 378: 607-620.

von Figura G, Fukuda A, Roy N, Liku ME, Morris Iv JP, Kim GE, Russ HA, Firpo MA, Mulvihill SJ, Dawson DW, et al. 2014. The chromatin regulator Brg1 suppresses formation of intra- ductal papillary mucinous neoplasm and pancreatic ductal adenocarcinoma. Nat Cell Biol 16: 255-267.

Von Hoff DD, Ervin T, Arena FP, Chiorean EG, Infante J, Moore M, Seay T, Tjulandin SA, Ma WW, Saleh MN, et al. 2013. Increased survival in pancreatic cancer with nab-paclitaxel plus gemcitabine. N Engl J Med 369: 1691-1703.

Waddell N, Pajic M, Patch AM, Chang DK, Kassahn KS, Bailey P, Johns AL, Miller D, Nones K, Quek K, et al. 2015. Whole genomes redefine the mutational landscape of pancreatic cancer. Nature 518: 495-501.

Wahlgren J, De LKT, Brisslert M, Vaziri Sani F, Telemo E, Sunnerhagen P, Valadi H. 2012. Plasma exosomes can deliver exogenous short interfering RNA to monocytes and lymphocytes. Nucleic Acids Res 40: e130.

Wang F, Permert J. 2002. Specific amino acid profile in culture media conditioned by human pancreatic cancer cell lines. Pancreatology 2: 402-406.

Wang X, Sansam CG, Thom CS, Metzger D, Evans JA, Nguyen PT, Roberts CW. 2009. Oncogenesis caused by loss of the SNF5 tumor suppressor is dependent on activity of BRG1, the ATPase of the SWI/SNF chromatin remodeling complex. Cancer Res 69: 8094-8101.

Wang H, Maitra A, Wang H. 2015a. Obesity, intrapancreatic fatty infiltration, and pancreatic cancer. Clin Cancer Res 21: 3369-3371.

Wang MT, Holderfield M, Galeas J, Delrosario R, To MD, Balmain A, McCormick F. 2015b. K-Ras promotes tumorigenicity through suppression of non-canonical wnt signaling. Cell 163: 1237-1251.

Ward PS, Thompson CB. 2012. Metabolic reprogramming: a cancer hallmark even warburg did not anticipate. Cancer Cell 21: 297-308.

Watanabe T, Semba S, Yokozaki H. 2011. Regulation of PTEN expression by the SWI/SNF chromatin-remodelling protein BRG1 in human colorectal carcinoma cells. Br J Cancer 104: 146-154.

Wehr AY, Furth EE, Sangar V, Blair IA, Yu KH. 2011. Analysis of the human pancreatic stellate cell secreted proteome. Pancreas 40: $557-566$.

Wei H, Wei S, Gan B, Peng X, Zou W, Guan JL. 2011. Suppression of autophagy by FIP200 deletion inhibits mammary tumorigenesis. Genes Dev 25: 1510-1527.

Weinberg F, Hamanaka R, Wheaton WW, Weinberg S, Joseph J, Lopez M, Kalyanaraman B, Mutlu GM, Budinger GR, Chandel NS. 2010. Mitochondrial metabolism and ROS generation are essential for Kras-mediated tumorigenicity. Proc Natl Acad Sci 107: 8788-8793.

Wellen KE, Lu C, Mancuso A, Lemons JM, Ryczko M, Dennis JW, Rabinowitz JD, Coller HA, Thompson CB. 2010. The hexosamine biosynthetic pathway couples growth factor-induced glutamine uptake to glucose metabolism. Genes Dev 24: 2784-2799.

White E. 2013. Exploiting the bad eating habits of Ras-driven cancers. Genes Dev 27: 2065-2071.

White E. 2015. The role for autophagy in cancer. J Clin Invest 125: 42-46.

Williford JM, Wu J, Ren Y, Archang MM, Leong KW, Mao HQ. 2014. Recent advances in nanoparticle-mediated siRNA delivery. Annu Rev Biomed Eng 16: 347-370.

Wilson BG, Helming KC, Wang X, Kim Y, Vazquez F, Jagani Z, Hahn WC, Roberts CW. 2014. Residual complexes containing SMARCA2 (BRM) underlie the oncogenic drive of SMARCA4 (BRG1) mutation. Mol Cell Biol 34: 1136-1144.

Witkiewicz A, Williams TK, Cozzitorto J, Durkan B, Showalter SL, Yeo CJ, Brody JR. 2008. Expression of indoleamine 2,3- 
dioxygenase in metastatic pancreatic ductal adenocarcinoma recruits regulatory $\mathrm{T}$ cells to avoid immune detection. J Am Coll Surg 206: 849-854.

Witkiewicz AK, McMillan EA, Balaji U, Baek G, Lin WC, Mansour J, Mollaee M, Wagner KU, Koduru P, Yopp A, et al. 2015. Whole-exome sequencing of pancreatic cancer defines genetic diversity and therapeutic targets. Nat Commun 6: 6744.

Wu MC, Arimura GK, Yunis AA. 1978. Mechanism of sensitivity of cultured pancreatic carcinoma to asparaginase. Int $J$ Cancer 22: $728-733$.

Wu J, Jiao Y, Dal Molin M, Maitra A, de Wilde RF, Wood LD, Eshleman JR, Goggins MG, Wolfgang CL, Canto MI, et al. 2011 a. Whole-exome sequencing of neoplastic cysts of the pancreas reveals recurrent mutations in components of ubiquitin-dependent pathways. Proc Natl Acad Sci 108: 21188-21193.

Wu J, Matthaei H, Maitra A, Dal Molin M, Wood LD, Eshleman JR, Goggins M, Canto MI, Schulick RD, Edil BH, et al. 2011b. Recurrent GNAS mutations define an unexpected pathway for pancreatic cyst development. Sci Transl Med 3: 92ra66.

Wu CY, Carpenter ES, Takeuchi KK, Halbrook CJ, Peverley LV, Bien H, Hall JC, DelGiorno KE, Pal D, Song Y, et al. 2014. $\mathrm{PI} 3 \mathrm{~K}$ regulation of RAC1 is required for KRAS-induced pancreatic tumorigenesis in mice. Gastroenterology 147: 1405-1416.e7.

Xu Z, Vonlaufen A, Phillips PA, Fiala-Beer E, Zhang X, Yang L, Biankin AV, Goldstein D, Pirola RC, Wilson JS, et al. 2010. Role of pancreatic stellate cells in pancreatic cancer metastasis. Am J Pathol 177: 2585-2596.

Yachida S, Jones S, Bozic I, Antal T, Leary R, Fu B, Kamiyama M, Hruban RH, Eshleman JR, Nowak MA, et al. 2010. Distant metastasis occurs late during the genetic evolution of pancreatic cancer. Nature 467: 1114-1117.

Yan C, Liu D, Li L, Wempe MF, Guin S, Khanna M, Meier J, Hoffman B, Owens C, Wysoczynski CL, et al. 2014. Discovery and characterization of small molecules that target the GTPase Ral. Nature 515: 443-447.

Yang Z, Yik JH, Chen R, He N, Jang MK, Ozato K, Zhou Q. 2005. Recruitment of P-TEFb for stimulation of transcriptional elongation by the bromodomain protein Brd4. Mol Cell 19: 535-545.

Yang S, Wang X, Contino G, Liesa M, Sahin E, Ying H, Bause A, Li Y, Stommel JM, Dell'antonio G, et al. 2011. Pancreatic cancers require autophagy for tumor growth. Genes Dev 25: 717-729.

Yang A, Rajeshkumar NV, Wang X, Yabuuchi S, Alexander BM, Chu GC, Von Hoff DD, Maitra A, Kimmelman AC. 2014. Autophagy is critical for pancreatic tumor growth and progression in tumors with p53 alterations. Cancer Discov 4: 905-913.

Yee C. 2014. The use of endogenous T cells for adoptive transfer. Immunol Rev 257: 250-263.

Ying H, Elpek KG, Vinjamoori A, Zimmerman SM, Chu GC, Yan $\mathrm{H}$, Fletcher-Sananikone E, Zhang H, Liu Y, Wang W, et al. 2011. PTEN is a major tumor suppressor in pancreatic ductal adenocarcinoma and regulates an NF-kB-cytokine network. Cancer Discov 1: 158-169.

Ying H, Kimmelman AC, Lyssiotis CA, Hua S, Chu GC, FletcherSananikone E, Locasale JW, Son J, Zhang H, Coloff JL, et al. 2012. Oncogenic Kras maintains pancreatic tumors through regulation of anabolic glucose metabolism. Cell 149: 656-670.

Yuan TL, Fellmann C, Lee CS, Ritchie CD, Thapar V, Lee LC, Hsu DJ, Grace D, Carver JO, Zuber J, et al. 2014. Development of siRNA payloads to target KRAS-mutant cancer. Cancer Discov 4: 1182-1197.
Yun J, Rago C, Cheong I, Pagliarini R, Angenendt P, Rajagopalan H, Schmidt K, Willson JK, Markowitz S, Zhou S, et al. 2009. Glucose deprivation contributes to the development of KRAS pathway mutations in tumor cells. Science 325: 1555-1559.

Zhang Z, Wang Y, Vikis HG, Johnson L, Liu G, Li J, Anderson MW, Sills RC, Hong HL, Devereux TR, et al. 2001. Wildtype Kras 2 can inhibit lung carcinogenesis in mice. Nat Genet 29: 25-33.

Zhang Z, Jiang G, Yang F, Wang J. 2006. Knockdown of mutant Kras expression by adenovirus-mediated siRNA inhibits the in vitro and in vivo growth of lung cancer cells. Cancer Biol Ther 5: 1481-1486.

Zhang Y, Gan B, Liu D, Paik JH. 2011. FoxO family members in cancer. Cancer Biol Ther 12: 253-259.

Zhang Y, Morris JPT, Yan W, Schofield HK, Gurney A, Simeone DM, Millar SE, Hoey T, Hebrok M, Pasca di Magliano M. 2013a. Canonical Wnt signaling is required for pancreatic carcinogenesis. Cancer Res 73: 4909-4922.

Zhang Y, Yan W, Collins MA, Bednar F, Rakshit S, Zetter BR, Stanger BZ, Chung I, Rhim AD, di Magliano MP. 2013b. Interleukin-6 is required for pancreatic cancer progression by promoting MAPK signaling activation and oxidative stress resistance. Cancer Res 73: 6359-6374.

Zhang W, Nandakumar N, Shi Y, Manzano M, Smith A, Graham G, Gupta S, Vietsch EE, Laughlin SZ, Wadhwa M, et al. 2014a. Downstream of mutant KRAS, the transcription regulator YAP is essential for neoplastic progression to pancreatic ductal adenocarcinoma. Sci Signal 7: ra42.

Zhang Y, McAllister F, Pasca di Magliano M. 2014b. Immune cells in pancreatic cancer: joining the dark side. Oncoimmunology 3: e29125.

Zhang Y, Yan W, Mathew E, Bednar F, Wan S, Collins MA, Evans RA, Welling TH, Vonderheide RH, di Magliano MP. 2014c. $\mathrm{CD}^{+} \mathrm{T}$ lymphocyte ablation prevents pancreatic carcinogenesis in mice. Cancer Immunol Res 2: 423-435.

Zhao F, Obermann S, von Wasielewski R, Haile L, Manns MP, Korangy F, Greten TF. 2009. Increase in frequency of myeloid-derived suppressor cells in mice with spontaneous pancreatic carcinoma. Immunology 128: 141-149.

Zhu Y, Knolhoff BL, Meyer MA, Nywening TM, West BL, Luo J, Wang-Gillam A, Goedegebuure SP, Linehan DC, DeNardo DG. 2014. CSF1/CSF1R blockade reprograms tumor-infiltrating macrophages and improves response to T-cell checkpoint immunotherapy in pancreatic cancer models. Cancer Res 74: 5057-5069.

Zimmermann G, Papke B, Ismail S, Vartak N, Chandra A, Hoffmann M, Hahn SA, Triola G, Wittinghofer A, Bastiaens PI, et al. 2013. Small molecule inhibition of the KRAS-PDE $\delta$ interaction impairs oncogenic KRAS signalling. Nature 497: 638-642.

Zimny M, Bares R, Fass J, Adam G, Cremerius U, Dohmen B, Klever P, Sabri O, Schumpelick V, Buell U. 1997. Fluorine-18 fluorodeoxyglucose positron emission tomography in the differential diagnosis of pancreatic carcinoma: a report of 106 cases. Eur J Nucl Med 24: 678-682.

Zorde Khvalevsky E, Gabai R, Rachmut IH, Horwitz E, Brunschwig Z, Orbach A, Shemi A, Golan T, Domb AJ, Yavin E, et al. 2013. Mutant KRAS is a druggable target for pancreatic cancer. Proc Natl Acad Sci 110: 20723-20728.

Zuber J, Shi J, Wang E, Rappaport AR, Herrmann H, Sison EA, Magoon D, Qi J, Blatt K, Wunderlich M, et al. 2011. RNAi screen identifies Brd4 as a therapeutic target in acute myeloid leukaemia. Nature 478: 524-528. 


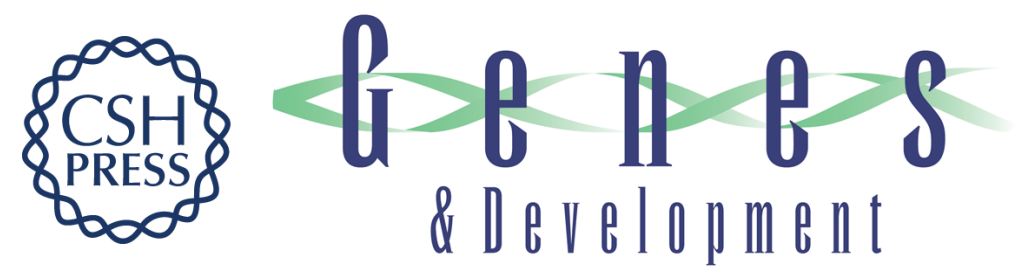

\title{
Genetics and biology of pancreatic ductal adenocarcinoma
}

\author{
Haoqiang Ying, Prasenjit Dey, Wantong Yao, et al.
}

Genes Dev. 2016, 30:

Access the most recent version at doi:10.1101/gad.275776.115

References This article cites 390 articles, 146 of which can be accessed free at: http://genesdev.cshlp.org/content/30/4/355.full.html\#ref-list-1

Creative This article is distributed exclusively by Cold Spring Harbor Laboratory Press for the first Commons License six months after the full-issue publication date (see http://genesdev.cshlp.org/site/misc/terms.xhtml). After six months, it is available under a Creative Commons License (Attribution-NonCommercial 4.0 International), as described at http://creativecommons.org/licenses/by-nc/4.0/.

Email Alerting Receive free email alerts when new articles cite this article - sign up in the box at the top Service right corner of the article or click here.

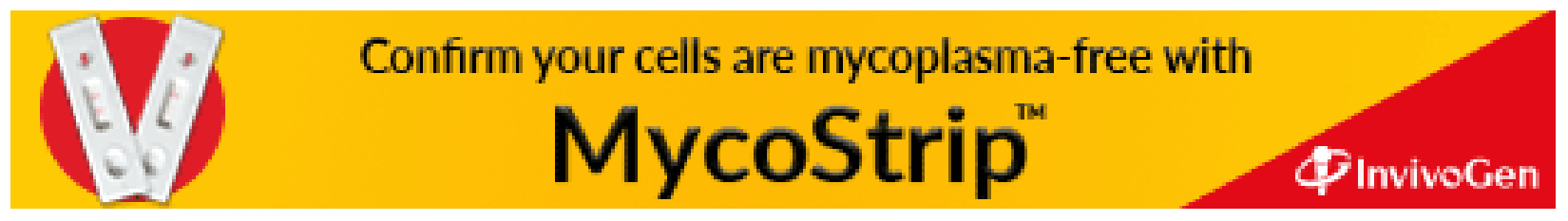

